\title{
Effects of explosions on embankment dams
}

\author{
by
}

George A. Afriyie

A thesis submitted to the Faculty of Graduate and Postdoctoral Affairs in partial fulfillment of the requirements for the degree of

Master of Applied Science

In

Civil Engineering

Carleton University

Ottawa, Ontario.

(C) 2014, George A. Afriyie 


\begin{abstract}
The efficient management and protection of critical infrastructure such as dams is relevant to safety of the population of every country. A breach of any dam could have serious ramifications on downstream communities including loss of electricity, flooding, injury and fatality. The associated economic losses can also be enormous depending on the size and emergency preparedness of the community. The level of damage caused by an explosive device on an embankment dam depends on the type and amount of explosive as well as the placement of the explosive relative to the dam cross-section.
\end{abstract}

This thesis is a numerical study into the effects of explosion on embankment dams using the high fidelity physics based finite element package, LS-DYNA. A numerical model was developed in LS-DYNA and validated using field testing. The numerical results indicated that the LS-DYNA model was able to predict the crater dimensions on the embankment dam when compared with the field testing. The investigation on the effects of charge mass showed that there was an increase in crater diameter and depth as the charge mass increased. The effect of reservoir water level on crater dimensions was also investigated; the crater dimensions predicted were highest when the reservoir level was maximum and lowest when the embankment was dry. The dry embankment showed an increment in crater depth whereas there was a significant decrease in crater depth for the embankment with the water reservoir. Effects of negative pore water pressure (suction) above the phreatic surface was also investigated and the crater dimensions predicted showed a decrease in crater dimensions when compared to when suction is not incorporated into the model. 


\section{Dedication}

I dedicate this thesis to my parents and siblings who have been there for me throughout my two years of study. Thank you all for the love, support and encouragement. 


\section{Acknowledgement}

The successful completion of this thesis is due to the combined efforts of particular individuals worth recognising for their diverse contributions.

I would like to express my deepest gratitude to my supervisors, Dr. Mohammad Rayhani and Dr. Abass Braimah for their guidance and advice throughout my two year study. I am also very appreciative of every individual who contributed however little to making these two years a memorable. 
Table of Contents

Abstract.............................................................................................................................................. i

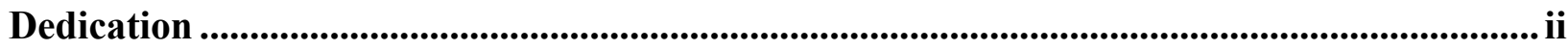

Acknowledgement ............................................................................................................................ii

List of Tables ................................................................................................................................. vi

List of Figures......................................................................................................................................... vii

List of Abbreviation and Symbols ..................................................................................................... $\mathrm{x}$

1 Chapter: Introduction ..................................................................................................... 1

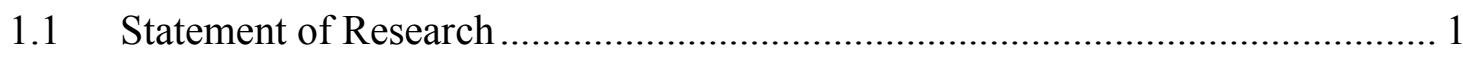

1.2 Research Basis..................................................................................... 2

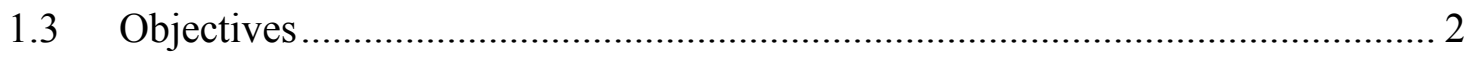

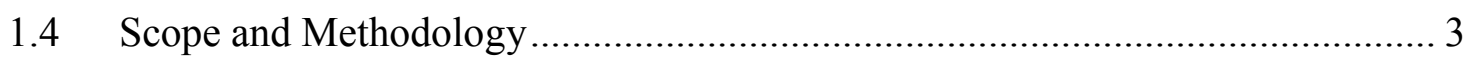

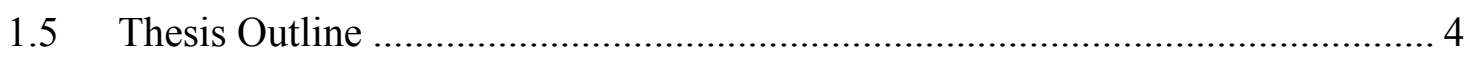

2 Chapter: Background ............................................................................................................. 5

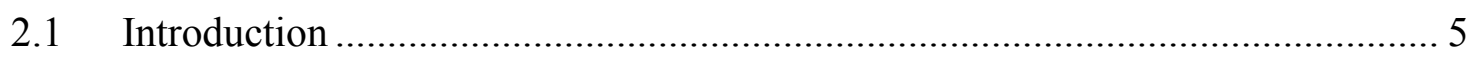

2.2 Review of Dam Failure by Explosive Devices .................................................. 6

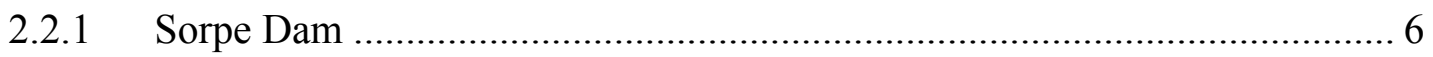

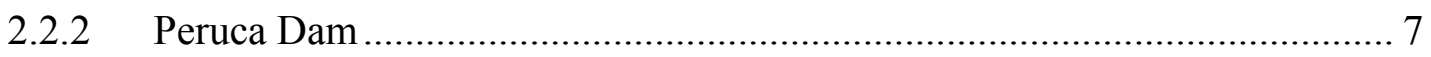

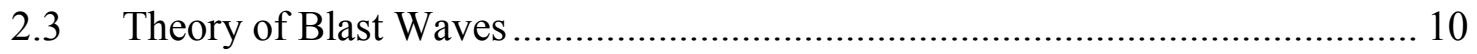

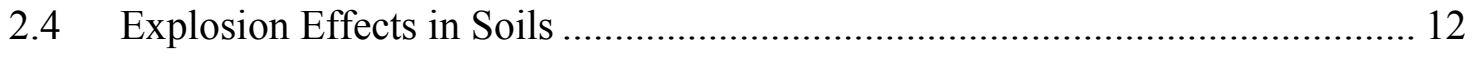

2.4.1 Propagation of Blast Shockwaves in Soil ................................................ 13

2.4.2 Crater Formation Due to Explosives.......................................................... 14

2.5 Attenuation of Shockwave in Soil............................................................. 19

2.6 Failure Modes of Dams .............................................................................. 22

2.5.1 Failure of Dam due to Crater Formation................................................... 25

2.5.2 Failure of Dam due to excess Pore water Pressure .................................... 26

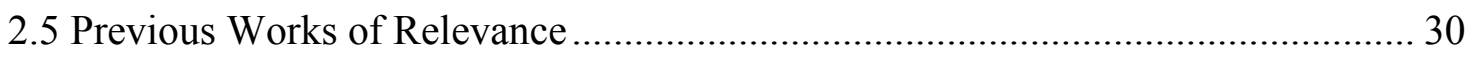

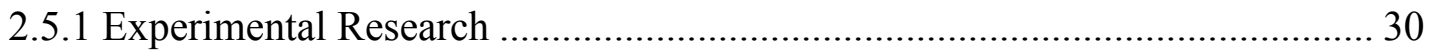

2.5.2 Numerical Simulation ………………………….................................. 37 


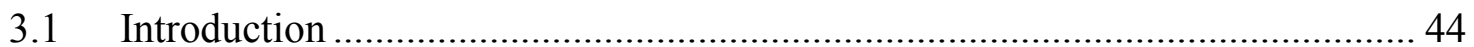

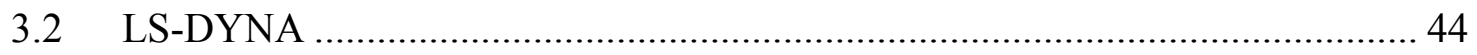

3.2 Numerical Modelling of Embankment Dam Model ..................................... 46

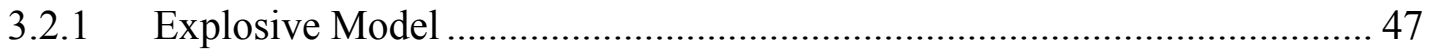

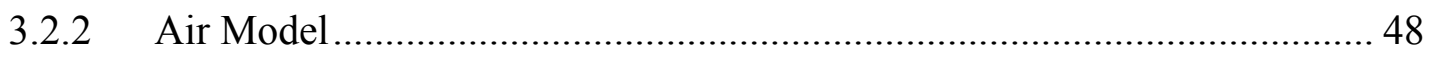

3.2.3 Embankment Dam Model ............................................................................ 48

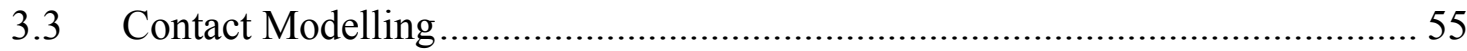

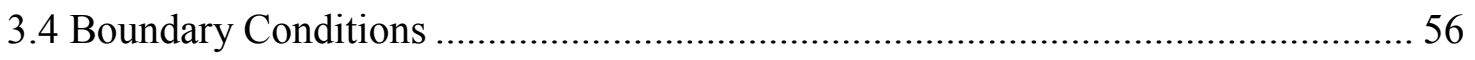

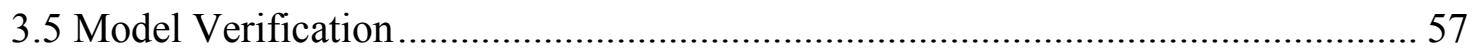

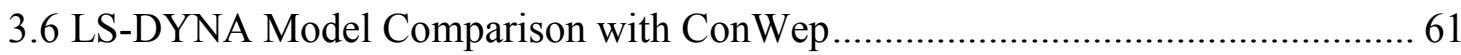

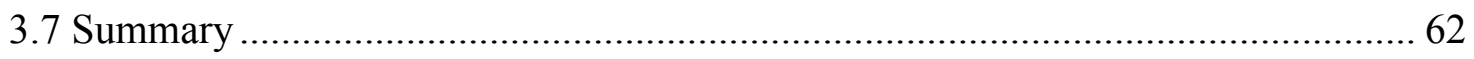

4.0 Parametric Study of Explosion on Embankment Dams............................................ 64

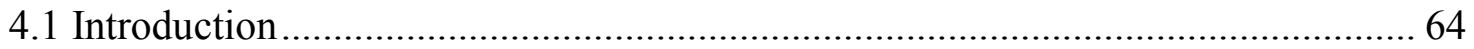

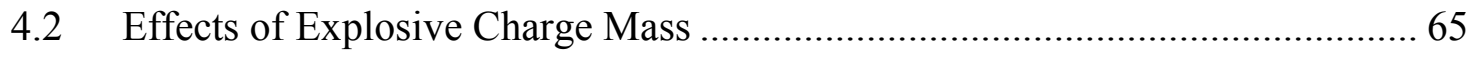

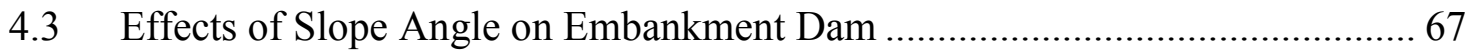

4.4 Effects of Reservoir Level on Crater Dimensions ......................................... 70

4.4.1 Reservoir at Maximum Level .............................................................. 70

4.4.2 Reservoir Level at $1 \mathrm{~m}$ above Ground Level ............................................. 72

4.5 Effect of Density on Crater Dimensions ..................................................... 73

4.6 Effect of Suction on Crater Dimensions ....................................................... 76

5. Chapter 5: Conclusion and Recommendation ................................................................... 79

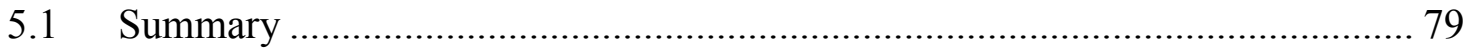

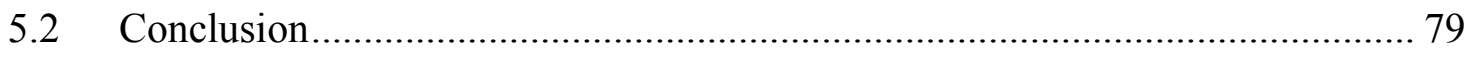

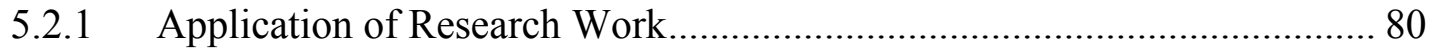

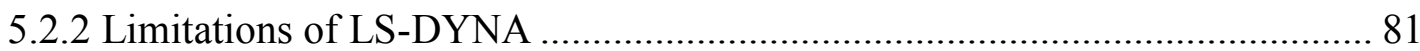

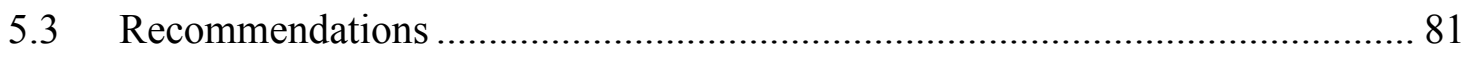

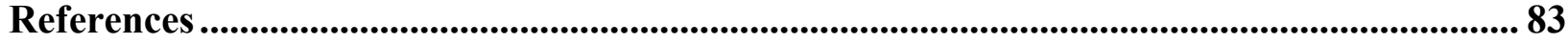

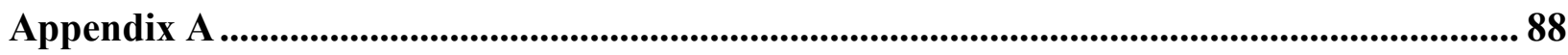

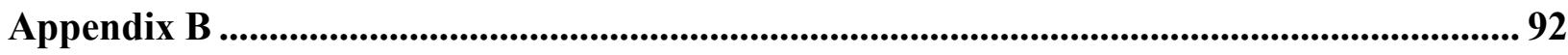




\section{List of Tables}

Table 2-1: Minimum Freeboard for Dams (Ontario Ministry of Natural Resources, 2011) ....... 26

Table 2-2: Research Summary of Blast Effects on Pore Water Pressure (US Department

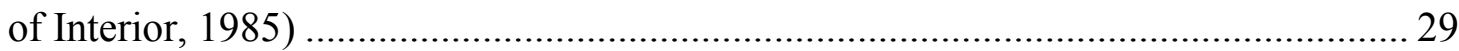

Table 2-3: Summary of Material Model for Simulation (Ambrosini et al., 2004)............................. 39

Table 2-4:Summary of Material Model Simulation (Jayasinghe et al., 2013) ................................. 40

Table 2-5: Summary of Material Model (Defence R \&D, 2009).......................................... 41

Table 3-1: Material Model Input for TNT ........................................................................ 47

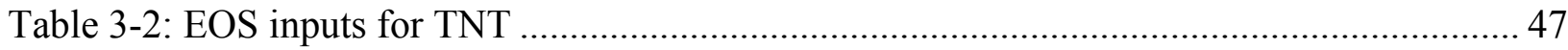

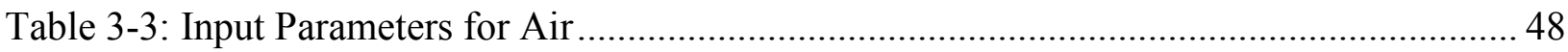

Table 3-4: Selected soil material models in LS DYNA (LS DYNA Manual, 2011)................. 49

Table 3-5: Mesh Sensitivity Analysis for $50 \mathrm{~kg}$ Charge ...................................................... 49

Table 3-6: Crater Dimension for Suitable Material Models ................................................... 53

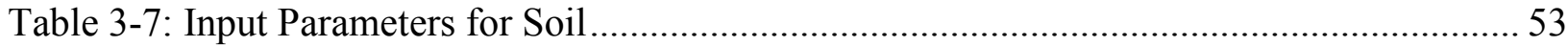

Table 4-1: Comparison of Crater Diameters for Dry and Reservoir backed Dam .................... 71

Table 4-2: Comparison of Effects of Suction on Crater Diameters for $1.65 \mathrm{~m}$ and $1 \mathrm{~m}$ Reservoir backed Dams 76 


\section{List of Figures}

Figure 2-1: Sorpe Dam (http://thedambusters.org.uk/sorpe.html) .............................

Figure 2-2: Peruca Dam (http://www1.american.edu/ted/ice/noah.htm)........................ 8

Figure 2-3a: Attack incidents by year (US Homeland Security, 2012) .........................

Figure 2-3b: Attack incidents by type (US Homeland Security, 2012) ........................

Figure 2-4: Pressure-Curve Profile for air Blast (Larcher, 2008) ..............................11

Figure 2-5: Crater formed at Mariot Hotel

(http://news.bbc.co.uk/2/hi/in_pictures/7627729.stm)..........................15

Figure 2-6: Profile of a crater (Ambrosini et al. 2004) .............................16

Figure 2-7: Crater sizes with given DOB (TM 5-855-1)............................ 17

Figure 2-8: DOB and resulting Crater Diamter in Clay, Sandy Clay and Sand (TM -5-

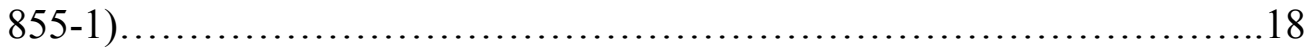

Figure 2-9: Peak Stress in different Soils based on Scaled Distance (Kumar et al.,

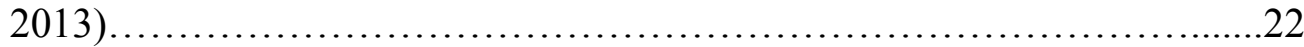

Figure 2-10: Piping through Embankment..........................................24

Figure 2-11: Overtopping of the Lower San Fernando Dam Crest in 1971 (Dahms,

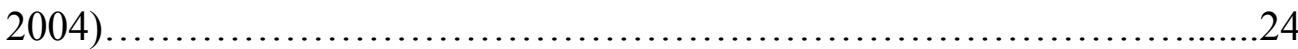

Figure 2-12: Cause of Dam Failures (Association of State Dam Safety

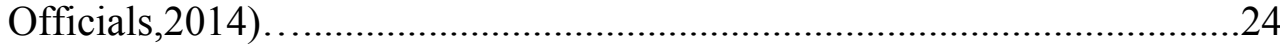

Figure 2-13: Pore Water Pressure against Distance (US Department of Interior, 1985)

Figure 2-14: Finished Embankment (Li et al., 2007) ....................................32

Figure 2-15: Cross-Section of Dry Embankment (Li et al., 2007)......................33 
Figure 2-16: Particle Size Distribution Curve (Braimah et al., 2012) ....................34

Figure 2-17: Measurement Technique for Crater Estimation (Li et al., 2007)............34

Figure 2-18: Crater Profile for $100 \mathrm{~kg}$ ANFO (Li et al., 2007)..........................35

Figure 2-19: Crater Diameter against Explosive Mass (Li et al., 2007) ...................36

Figure 2-20: Crater Depth against Explosive Mass (Li et al., 2007) ..........................37

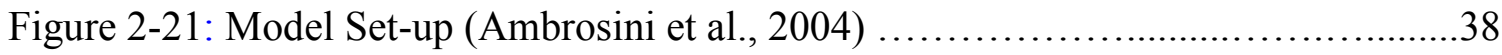

Figure 2-22: Numerical Model (Jayasinghe et al., 2013) ..............................40

Figure 2-23: 3D Model of Embankment Dam (De at al., 2013) ..........................42

Figure 2-24: Crater Depth against Explosive Size (De et al., 2013) .......................42

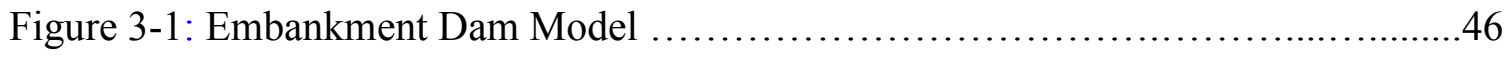

Figure 3-2: Mohr-Coulomb Failure Criterion (Pervizpour, 2004) ....................51

Figure 3-3: Failure Criterion Pseudo Tensor (LS-DYNA Material Manual 2011) ........51

Figure 3-4: Comparison of Mohr Coulomb and Pseudo Tensor with Experimental

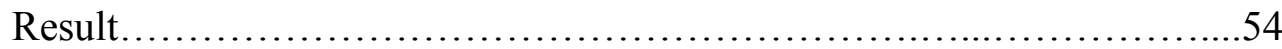

Figure 3-5: Comparison of Mohr Coulomb and Pseudo Tensor with Experimental Results..........................................................55

Figure 3-6: Comparison of Mohr Coulomb and Pseudo Tensor with Experimental

Results.........................................................55

Figure 3-7: Propagation of Shockwave through the embankment dam...................57

Figure 3-8: Cross-section of crater in numerical model for $50 \mathrm{~kg}$ charge mass ..............59

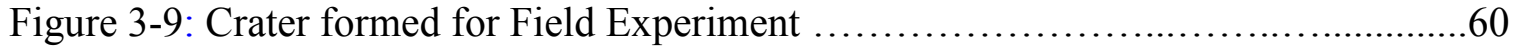

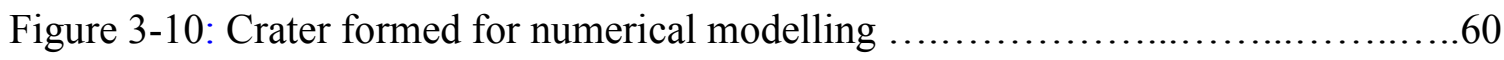

Figure 3-11: Verification of Crater Diameter Parallel to Dam Axis ....................60

Figure 3-12: Verification of Crater Diameter Perpendicular to Dam Axis ..................61 
Figure 3-13: Verification of Crater Depth......................................61

Figure 3-14: Comparison of ConWep and LS-DYNA Crater Diameters. ....................62

Figure 3-15: Comparison of ConWep and LS-DYNA Crater Depths . ..................63

Figure 4-1: Typical GeoStudio Simulation showing Phreatic Surface.......................64

Figure 4-2: Bulging at Downstream of Embankment ................................66

Figure 4-3: Effect of slope angle on crater depth....................................67

Figure 4-4: Comparison of Crater Parallel Diameter with Downstream Slope Angles.....68

Figure 4-5: Comparison of Crater Perpendicular Diameter with Downstream Slope Angles ...............................................................68

Figure 4-6: Comparison of True Crater Depth for Dry Embankment and Embankment

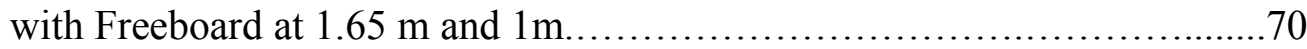

Figure 4-7: Effect of density on crater diameter parallel to dam axis.......................73

Figure 4-8: Effect of density on crater diameter perpendicular to dam axis ................73

Figure 4-9: Effects of Density on Crater Depth for Dry Embankment and Embankment with

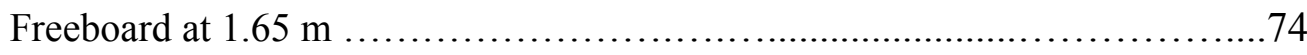

Figure 4-10: Effect of suction on crater depth........................................... 76 


\section{List of Abbreviation and Symbols}
$\mathrm{A}, \mathrm{B}, \mathrm{R}_{1}, \mathrm{R}_{2}, \omega$
Constants for JWL equation of state for explosive
ALE
ANFO
C
C
CDA
$\mathrm{C}_{\mathrm{o}}, \mathrm{C}_{1}, \mathrm{C}_{2}, \mathrm{C}_{3}, \mathrm{C}_{4}$,
$\mathrm{C}_{5}, \mathrm{C}_{6}$ and $\mu$
D
DOB
E
FEMA
JWL
LSTC
m,n
$\mathrm{P}$
$\mathrm{R}$
TNT
Arbitrary Langrangian Eulerian mesh
Ammonimum Nitrate of Oil
Ground transmission constant
Cohesion value for soil
Canadian Dam Association
Constant for the polynomial equation of state for air
Crater diameter
Depth of Burst
Energy
Federal Emergency Management Agency
Jones-Wilkins-Lee equation of state for explosives
Livermore Software Technology Corporation
Empirical site specific constant for particle velocity
Pressure
Distance between explosive and point of interest
Trinitrotoluene 
$\mathrm{V}_{\text {peak }}$

W

$\sigma$

$\sigma$

$\rho$

$\rho_{\mathrm{o}}$

$\sigma_{\mathrm{n}}$

$\phi$
Pore water pressure

Relative volume

Peak particle velocity

Quantity of explosive

Effective stress of soil

Total stress of soil

Density

Reference density

Normal stress for soil

Friction angle of soil 


\section{Chapter: Introduction}

\subsection{Statement of Research}

The efficient management and protection of critical infrastructure such as dams is relevant to the safety of the population of every country. In Canada, the Canadian Dam Association (CDA) has reported that there are over 10,000 dams in Canada of which 933 are classified as large dams. Large dams are defined as dams having a height of 5-15 m with a reservoir exceeding 3 million $\mathrm{m}^{3}$ (Aquastat, 2007). The large dams are mainly hydroelectric dams or tailings dams and impound millions of gallons of water or mine tailings. A breach of these dams could have serious ramifications on downstream communities including loss of electricity, flooding, injury and fatality. The associated economic losses can also be enormous depending on the size and emergency preparedness of the community.

With the global increase in terrorism and the likely damaging effects of a dam breach, the vulnerability of dams to explosion effects is of utmost importance. Although no terrorist attacks have been successful in breaching dam infrastructure, the literature shows many successful and unsuccessful attempts to attack dam infrastructure with explosives; for example Chingaza Dam in Columbia and Bhakra Dam in India. As acts of terror continue to increase globally, dams appear to be attractive targets due to the capacity to adversely impact downstream communities and to attract media attention. Dams are primarily concrete or earthen structures and depending on the mode of lateral load resistance can be massive. Concrete gravity dams are least likely to be affected by explosives (Braimah et 
al., 2012). Embankment dams on the other hand are generally earth-fill or rock-fill dams and are more susceptible to cratering. The size of the crater can lead to overtopping and erosion of the dam.

\subsection{Research Basis}

According to the Federal Emergency Management Agency (FEMA 2003), one in every two acts of terror involves the use of explosives.. The US Homeland Security has suggested that the direct economic impact of the failure of a large dam is approximately $\$ 4.3$ billion. This does not include the likely loss of lives as well as indirect impacts such as lost in revenue from reduction in tourism due to such flooding (US Homeland Security, 2011).

The effects of explosion on embankment dams are not very well researched. Most of the research on cratering effects of explosion were conducted on flat grounds (Braimah et al., 2012). Only scant information is available on the effects of the sloped embankment dams on the crater properties. Also the effects of the blast wave on the pore water pressure and effective stress within the dam have not been adequately studied. Hence this thesis aims to investigate the effects of explosions on embankment dams with due consideration to the effect of embankment slope, dam reservoir level, density of fill materials and soil suction.

\subsection{Objectives}

The objectives of the research work presented in this thesis are;

- Investigation of the effect of explosive charge mass on embankment dams. 
- Studythe impact of pore water pressure on crater dimensions.

\subsection{Scope and Methodology}

The investigation into the effects of explosions on embankment dams can be done either through field testing or through numerical simulations. Experimental field testing involving explosives can be very expensive and also limiting on the amount of explosives that can be used for the investigation. In addition, field testing is limited in the number of parameters that can be investigated without further increasing the cost of the testing. Numerical simulation, on the other hand, is an inexpensive way of investigating the effects of explosives on structures and affords the room to investigate more parameters at lower cost. In carrying out the objectives of this thesis, a general purpose high-fidelity physics based finite element package developed by Livermore Software Technology Corporation (LSTC), LS-DYNA, was used. LS-DYNA was used to model the embankment dam and the evolution of the blast wave and its interaction with the dam. The numerical analysis was modelled after field testing conducted by Li et al. (2007) to validate the ability of LS-DYNA to correctly predict the crater dimensions resulting from detonation of an explosive on an embankment dam. The validated work was also compared to results from ConWep - a collection of conventional weapons effects calculation based on equations from TM 5-855-1 (PDC, 2007). The validated model was then used for further parametric study in order to satisfy all outlined objectives in this thesis. 


\subsection{Thesis Outline}

The remaining portions of the thesis deals with the following topics:

Chatper 2: Background

The chapter reviews the literature and presents the theory of blast waves, the effects of explosions in soil, and factors that affect crater dimensions in soil. Finally work of relevance undertaken in the area of explosion effects in soil and embankments are reviewed with consideration to both field testing and numerical simulations.

Chapter 3: Numerical simulation of blast load effects on embankment dams This chapter deals with the validation of the numerical model with results from experimental field testing. The material models available for modelling the embankment dam, explosive and explosion process are reviewed and discussed and the best models chosen for the simulations. The results from the numerical model are also compared to results obtained with ConWep.

Chapter 4: Parametric study of explosive cratering on embankment dams The chapter presents the parametric analysis to investigate the effect of various material properties on explosion effects on embankment dams. Specifically density of fill materials, level of water in reservoir and soil suction are discussed.

Chapter 5: Conclusion and Recommendation

Conclusions from results of the different parametric analyses and recommendations for future work based on findings in this thesis are presented here. 


\section{Chapter: Background}

\subsection{Introduction}

Dams are civil engineering structures that are used to impound water or mine tailings. According to the Canadian Dam Association (CDA), there are over 10,000 dams in Canada of which 933 are classified as large dams. These dams are classified as critical infrastructure due to the adverse effect they could have on downstream communities upon failure. Large dams are defined as dams having a height of 5-15 m with a reservoir exceeding 3 million $\mathrm{m}^{3}$ (Aquastat Programme, 2007). In the event of a dam failure, the consequences on lives, property as well as the economy of a country are severe and damaging. Dam failures have been widely covered in the media and literature, and highlight the causes as well as the ramifications associated with dam failure (MacDonald and Langridge-Monopolis., 1984; De Alba et al., 1988; Kennard and Bromhead, 2000; Muhunthan and Schofield, 2000; Shepherd, 2003; Braimah and Contestabile, 2007; Graham, 2009). The US Homeland Security suggested that the direct economic impact on the failure of a large dam is about $\$ 4.3$ billion, not including the loss of lives as well as indirect impacts due to dam failure (US Homeland Security, 2011). For these reasons, dams can be viewed as attractive targets for terrorists as well as extremist groups seeking to cause damage to property and inflict large human casualties (Braimah and Contestabile, 2007). In addition to acts of terrorism, explosives are sometimes used as soil improvement techniques in close proximity to dam sites. Current literature does not provide adequate knowledge in predicting blast effects on embankment dam structures as well as pore water pressure within the dam due to proximate explosions. Hence there is a 
need to investigate and understand the effects of explosives on embankment dams in order to safeguard dams against such explosions and avert the ramifications accompanying dam failure.

\subsection{Review of Dam Failure by Explosive Devices}

There have been various attacks on dams with explosive devices (Braimah et al., 2012). Most of these attacks occurred during conflicts between nations. A review of literature indicates that most of the attacks have been against both embankment and concrete dams. While a localized failure will not necessarily lead to breach of a concrete dam, the localized failure of an embankment dam has a potential to develop into full dam breach through overtopping and scour (Braimah and Contestable., 2007; Braimah et al., 2012; De et al., 2013). The following section reviews embankment dam failure due to explosions.

\subsubsection{Sorpe Dam}

The Sorpe Dam is located near Sudern, a small town in the German district of Hochsauerland. Sorpe Dam is an earth-fill dam with a concrete core. The dam, constructed between the years of 1922 and 1935, is $700 \mathrm{~m}$ long and $60 \mathrm{~m}$ high (Kirschnne, 1949). The dam has the capacity to contain $3,380,000 \mathrm{~m}^{3}$ of water. Figure 2-1 shows an aerial photograph of the dam. As part of the Dambusters Raid by the Royal Air Force No. 617 Squadron, the Sorpe Dam was attacked with $3600 \mathrm{~kg}$ of Research Department Explosive (RDX) on its crest on May 17, 1943 resulting in a 12-m deep crater (Braimah and Contestabile, 2007). The dam was subsequently attacked again on 
October 16, 1944. The second attack used a 5500-kg Tallboy bomb leading to formation of a 12-m deep and 25-30-m diameter crater (Charles, 2004). Although the dam was not breached, extensive repair works were needed to repair the cratered dam. The Sorpe Dam

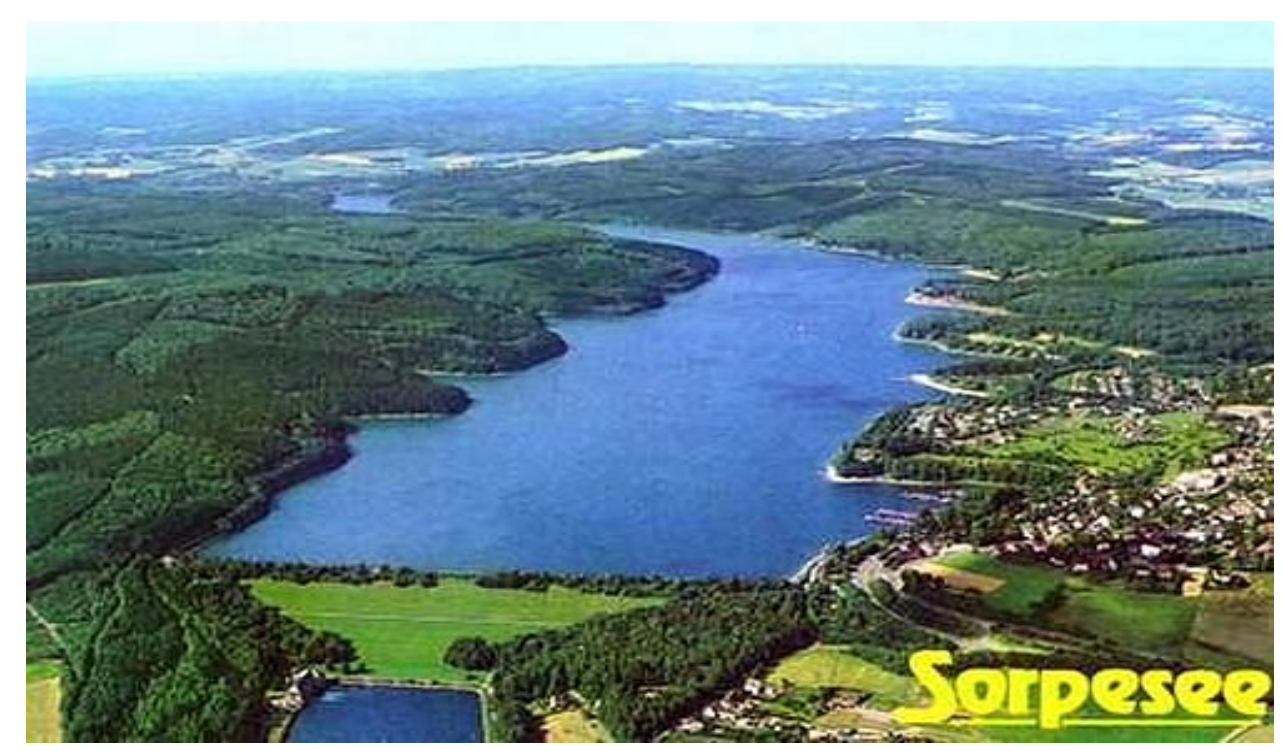

Figure 2-1: Sorpe Dam (http://thedambusters.org.uk/sorpe.html)

remains in operation to date.

\subsubsection{Peruca Dam}

The Peruca Dam is located in Dalmatia, Croatia over the Cetina River. The dam is a zoned rock-fill embankment with a clay central core (Figure 2-2). The dam is $425 \mathrm{~m}$ in length and $60 \mathrm{~m}$ in height (Nonveiller et al., 1999) and has a reservoir capacity of $565,000,000 \mathrm{~m}^{3}$. During the conflict in the Balkans, the Serbian forces planted 20 to 30 tonnes of Trinitrotoluene (TNT) on the dam in January 1993. In order to ensure overtopping of the dam when the explosives were detonated and hence cause severe damage to the villages downstream and the hydroelectric power station located downstream in the Cetina River Valley, the water level was raised by closing the 
spillgates and outlets (Nonveiler et al., 1999). In the case of the Peruca dam, the detonation did not breach the dam. Nonveiller et al. (1999) attributed the inability of the detonation to breach the dam to three entrances of the inspection gallery of the dam being open and hence the potential damage that could have been caused by the confined pressures of the explosives was reduced. Also, the Serbian forces detonated the explosive when the water level was $5 \mathrm{~m}$ below the intended level. The breach of the dam, according to Vajic (1994), would have led to about 12,000 deaths and about 60,000 of the downstream population displaced from their homes while leaving the entire population without electricity. The dam was repaired and brought back into operation in 1996, three years after the damage caused by the Serbian forces.

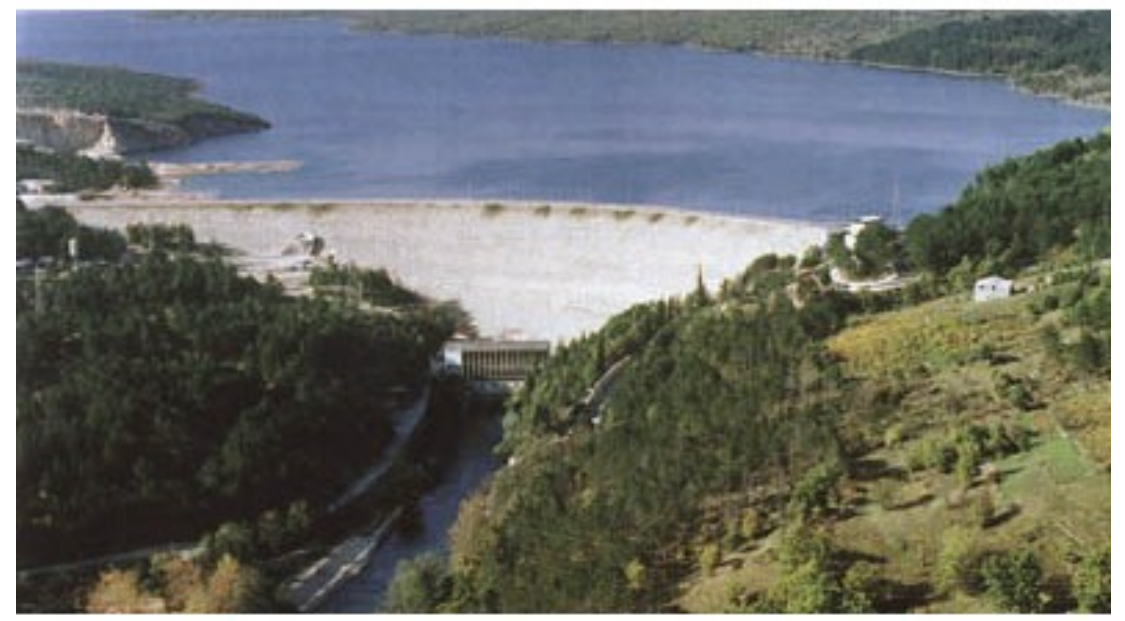

Figure 2-2: Peruca Dam (http://www1.american.edu/ted/ice/noah.htm)

Although these two aforementioned attacks occurred more than two decades ago, the threat to dams still exists to date. Terrorist groups have planned attacks on different dams in different country around the world in attempts to cause damage to downstream communities. Countries where such attacks have taken place include Indonesia, Nepal, India, Columbia, Iraq, Burma, United States of America amongst others. Figure 2-3a 
shows the number of attacks that have taken place from 2001 to 2011 while Figure 2-3b indicates the mode by which the attacks were carried out on dams worldwide. These recent attacks show that dams are still attractive targets for extremist groups and there is the need for a good understanding of soil interactions with blast loads in order to evaluate the effects of the various explosive devices on the stability of the embankments. Different reports in the media suggest plans were made by Al-Qaeda to attack dams in the United States of America (The Telegraph, 2002; The World Post, 2013).

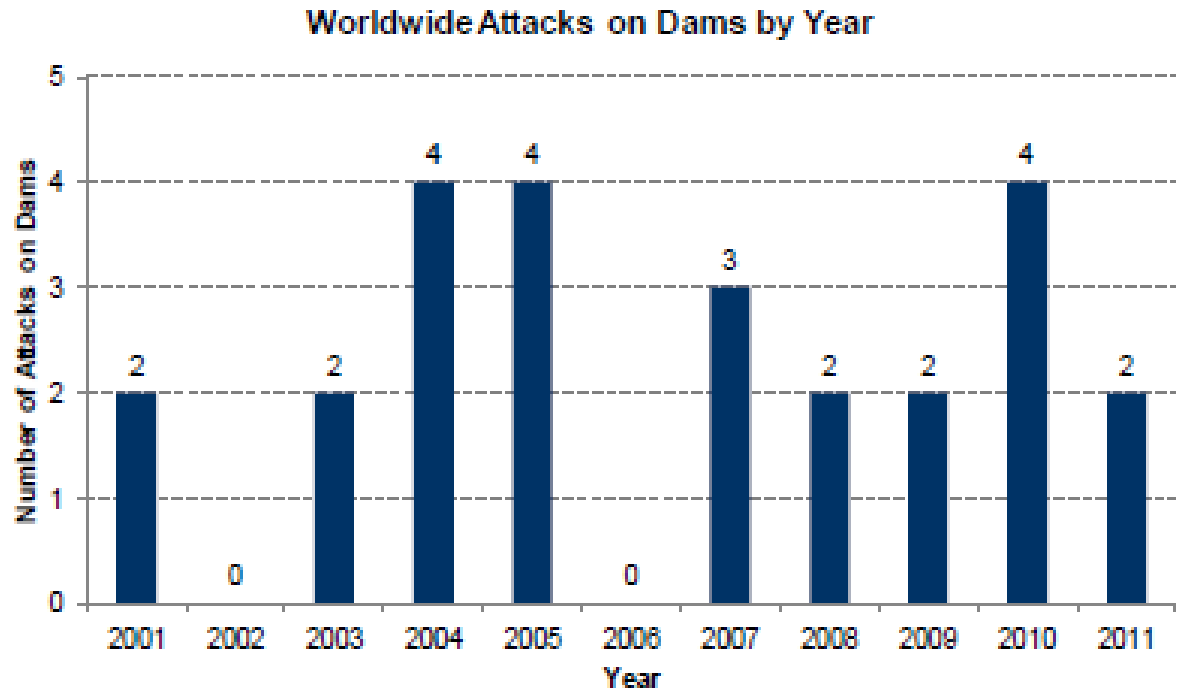

Figure 2-3a: Attack incidents by year (US Homeland Security, 2012)

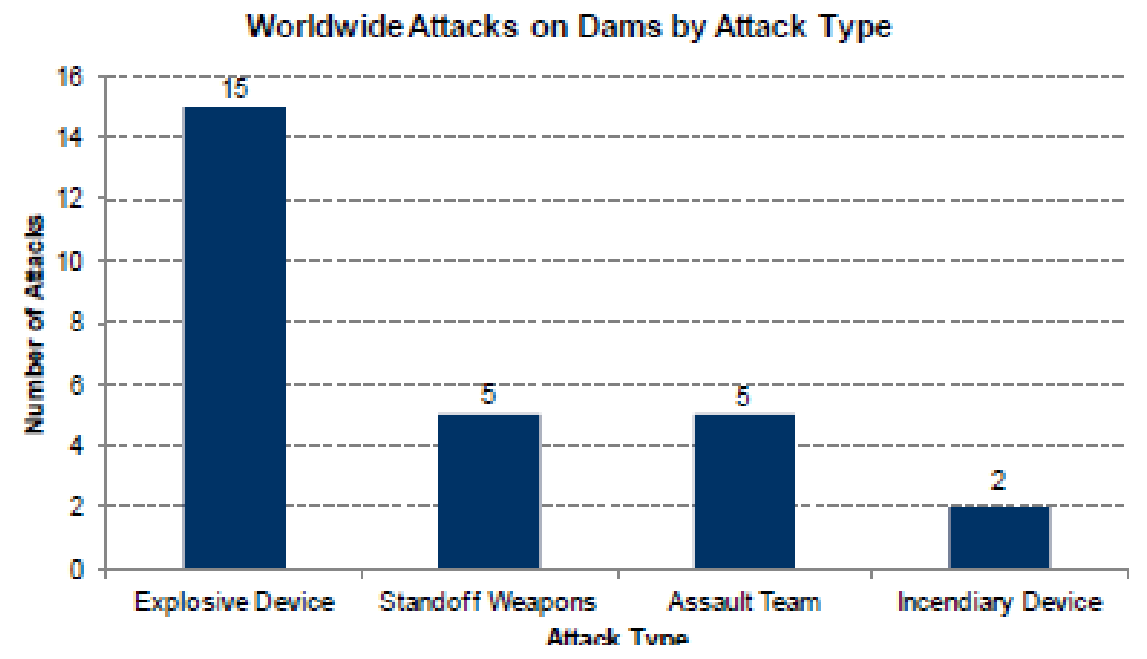

Figure 2-3b: Attack incidents by type (US Homeland Security, 2012) 


\subsection{Theory of Blast Waves}

When an explosive device is denoted in a medium (air, soil, water), an expanding volume of hot gases is formed, preceded by a high pressure shock front. The leading shock front carries the pressure associated with the explosive detonation. When the shock front reaches a point at atmospheric conditions, a sudden increase in pressure to the incident blast pressure occurs. The blast pressure, then, attenuates over time to the atmospheric pressure. The incident blast pressure is dependent on the distance from ground zero (point of detonation) and the size of the explosive charge. A typical blast pressure-time history is shown in Figure 2-4 for an air blast. The curve indicates a sharp increase in ambient pressure when the shock front arrives at a point remote from the centre of detonation followed by an exponential decay to ambient pressure, and then a negative phase of the profile where pressure is less than ambient pressures. $p_{\max }$ is the peak overpressure, which refers to the maximum pressure above ambient at a point remote from the centre of detonation. $\mathrm{p}_{\min }$ and $\mathrm{p}_{\mathrm{o}}$ are the minimum under-pressure and ambient pressures respectively. $t_{a}, t_{d}$ and $t_{n}$ refer to the arrival time of the shock front at the point of interest, the duration of blast in the positive phase, and the duration of the blast in the negative phase respectively. 


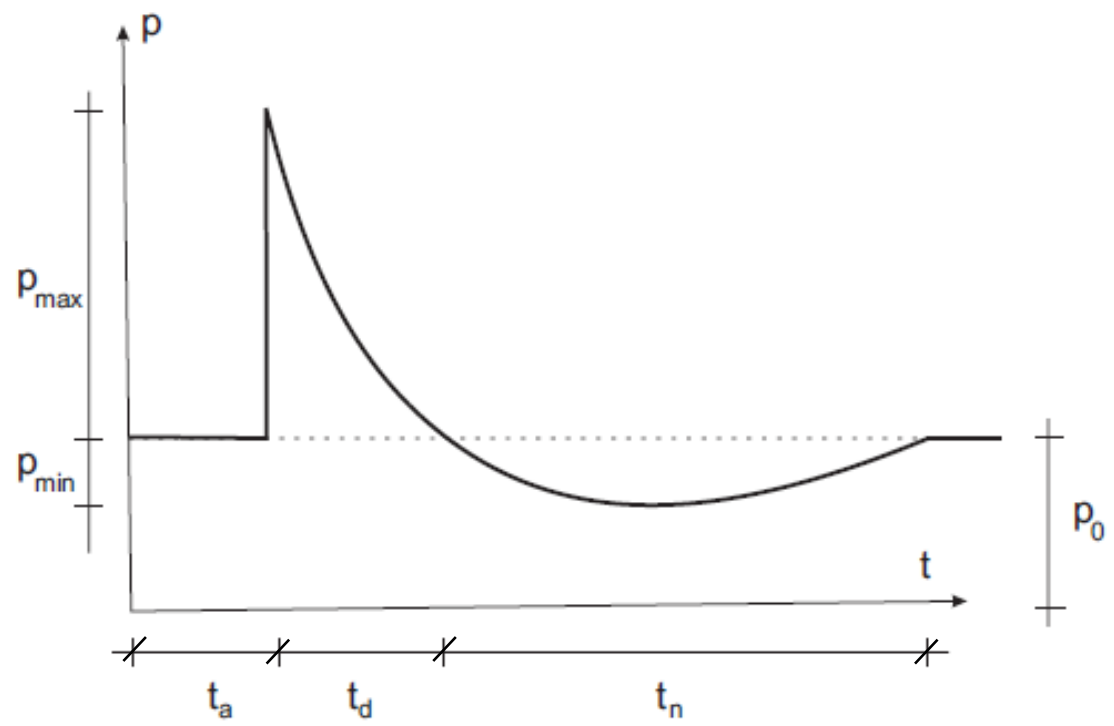

Figure 2-4: Pressure-Curve Profile for air Blast (Larcher, 2008)

Ambrosini et al. (2002) indicated that the most widely used method for calculating blast wave scaling is based on Hopkinson's law which shows that self-similar waves are produced at identical scaled distances when two different charges of a given explosive with the same geometry are detonated under the same atmospheric conditions. The use of this law which is expressed mathematically by Equation 2-1 allows for efficient representation of blast wave characteristics for a wide range of situations.

$$
Z=\frac{R}{W^{1 / 3}}
$$

In this equation, $\mathrm{R}$ is the distance measured from the point of detonation to point of interest expressed in metres and $\mathrm{W}$ is TNT-eqivalent mass of explosive expressed in kilograms. For explosives other than TNT there is a need for mass of the explosive to be converted into TNT equivalent mass.

Depending on the location of an explosive charge prior to detonation, the blast can be classified as spherical, hemispherical or buried. Spherical blast occurs when explosive is 
detonated above ground in the air whereas hemispherical blast occurs when the charge is in contact with the ground. When the explosive is buried in soil, we get buried explosions.

\subsection{Explosion Effects in Soils}

Soil is an assembly of individual particles with varying sizes and degree of saturation. The rapid release of energy from an explosive causes shockwave to be propagated through the soil medium (An et al., 2011). When an explosive device is detonated near the ground surface, a crater is created. The dimensions of the crater depend on the centre of detonation relative to the ground surface. The crater size increases with a decrease in the height of burst (HOB) when the explosive is detonated in air and increases with the depth of burial (DOB) up to an optimum depth beyond which the crater dimensions decrease. Also, crater size depends on the engineering properties of soil. The engineering properties of soil that may affect the crater dimensions include moisture content, density, permeability, shear strength and volume change behaviour which differ from soil to soil.

The detonation of explosives in soil, like any other medium, leads to the propagation of blast waves through the soil and results in ground shock in the soil. The shockwaves are dynamic in nature and tend to induce strain rates in the magnitude of $10^{-1}$ to $10^{3} \mathrm{~mm} / \mathrm{sec}$. The increased strain rate exerts short sequence of dynamic loading on the soil mass leading to soil over strength and increased stiffness as compared to the effects of static forces (Ambrossini et al., 2004). 


\subsubsection{Propagation of Blast Shockwaves in Soil}

Ground shock occurs due to the detonation of an explosive device on or buried in soil mass. The shockwave propagation in soil is accompanied by straining of the soil mass and can potentially cause damage to proximate buried or aboveground structures due to blast induced vibrations (Leong et al., 2006). Underground explosions, according to Roman (1986), result in two mechanical responses of the soil to the blast waves from the explosive device. These two responses are the soil losing its shear strength and the soil reacting hydro-dynamically (i.e. as a fluid), in the immediate vicinity of the underground explosion where stresses in the soil are extremely high. The shockwave propagation in soil may lead to the formation of crater or a camouflet depending on the Depth of Burst (DOB).

TM 5-855-1 (1986) describes ground shockwave as a complex function of the dynamic constitutive soil properties, detonation products and explosive geometry. Soil properties affecting ground shockwave include:

- Degree of Saturation

- Relative Density

- Air-void volume

- Dry unit weight

The degree of saturation has a significant effect on the propagation of ground shockwave in cohesive soils; especially soils with degree of saturation greater than or equal to $95 \%$. The bound-water to solid skeletons contributes to the stiffness and strength of cohesive 
soils. For wet clays, clay shales, and sandy clays with degree of saturation approaching 100\%, very high peak stresses and accelerations are observed (TM5-855-1, 1986).

For granular soils, the relative density affects the ground shock propagation. Soils with high relative density are not affected by water saturation as compared to the case in cohesive soils. In granular soils the stiffness is provided by the grain to grain contact and little contribution from water. Low relative density soils, on the other hand, are affected by the presence of water and a similar occurrence in cohesive soils is observed. For examples saturated sands with low relative density would lose their grain to grain contact resulting in high pore pressure and eventual liquefaction of the sands in the event of a ground shock occurrence.

The rate of attenuation of ground shock in soil is a function of the air void volume, especially in cohesive soils. Soils with high air void volume tend to attenuate ground shockwave faster than those with low air void volume. Generally for granular soils, the rate of attenuation of the ground shock is determined by the dry unit weight of the soil. A soil with high dry unit weight would reduce ground shock slowly and vice versa.

\subsubsection{Crater Formation Due to Explosives}

A crater is a hole formed in the ground after an explosions occurs. Luccioni et al (2009) defined a crater as a cavity formed when confined explosion takes place in a mass of soil. The cavity formation is a complex interaction taking place between gravity effects, soil strength and transient load. A crater maybe used to study blast phenomena. The crater properties give information about the energy yield of explosives and where detonation 
occurred (Ground Zero). Figure 2-5 shows a crater formed after a fuel tank exploded at the Marriott Hotel in Islamabad (BBC, 2008).

The hole which is visible after an explosion is the apparent crater. The true crater formed is often masked by fallback (dirt or debris that falls back into crater) after the explosion. The rupture zone refers to the region immediately surrounding the true crater in which the soil has been severely disturbed. Beyond the rupture zone is the plastic zone, where there is less disturbance to the soil material as compared to the rupture zone. Figure 2-6 gives a diagrammatic representation of a crater with a given DOB. The ejecta covers the upthrust caused by the rupture and plastic zones. Material thrown out of the soil of a sufficient size (missiles) can be harmful to human life or structures in the vicinity of the centre of detonation.

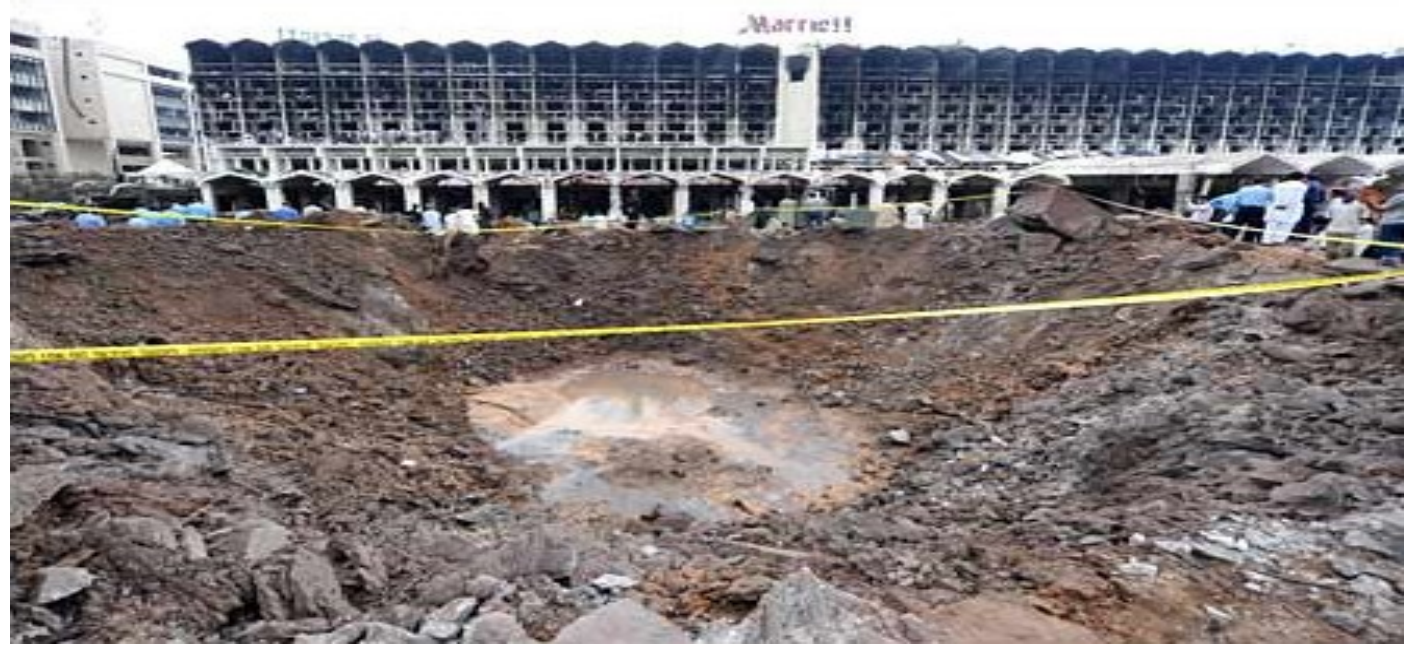

Figure 2-5: Crater formed at Marriott Hotel (http://news.bbc.co.uk/2/hi/in_pictures/7627729.stm) 


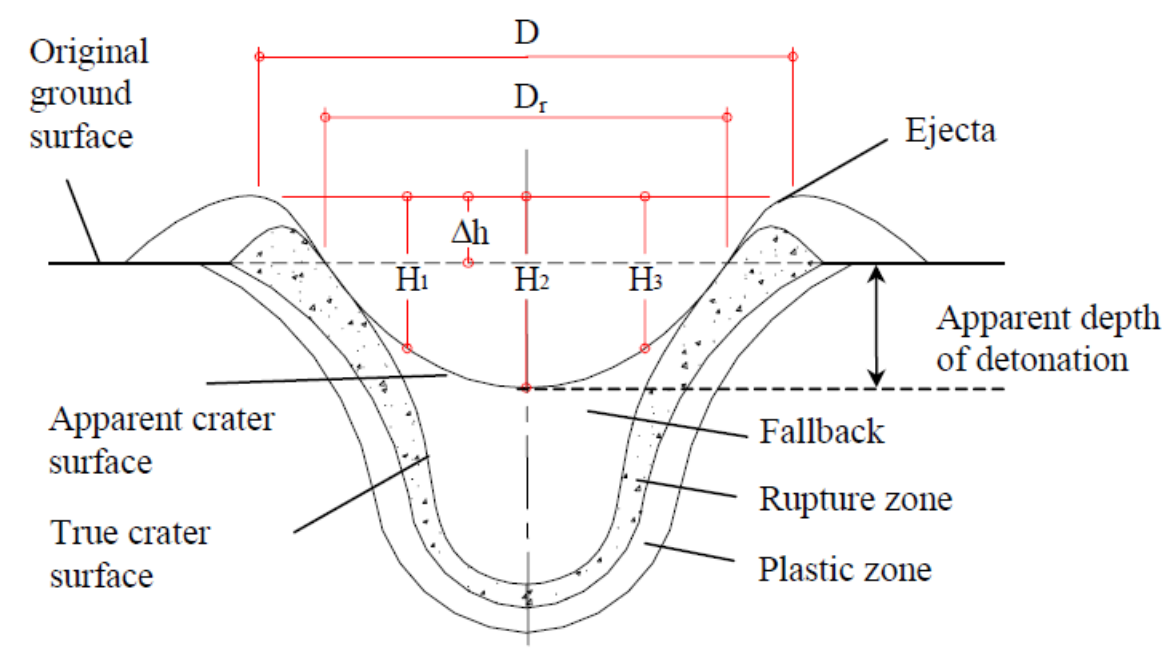

Figure 2-6: Profile of a crater (Ambrosini et al. 2004)

\subsubsection{Factors Affecting Crater Formation}

The nature and characteristics of a crater are dependent on factors such as: (a) DOB, (b) Soil Type and (c) Type of Explosives. The DOB determines the shape and size of a crater for a given type of explosive. The crater size tends to increase as the DOB increases until an optimum DOB is reached where the highest crater volume is observed. The highest apparent crater depth tends to occur at a depth less than the optimum DOB whereas the highest apparent diameter occurs at a slightly greater depth than the optimum DOB. Beyond the optimum DOB, the overburden begins to suppress the effect of the explosives and hence not much ejecta is thrown out leading to a decrease in the apparent crater diameter. At a DOB known as the containment depth, the crater disappears on the surface, leaving a visible mound. At DOB greater than containment depth, a subsurface cavity (camouflet) is formed with little or no surface disturbance. The corresponding depth of camouflet formation is the camouflet depth. Figure 2-7 shows various depths of 
burst with variation in crater size and shape for a given explosive indicating the crater dimensions that are expected depending on the position of the explosive device. Figure 2$7 \mathrm{~d}$ and 2-7f illustrate the optimum DOB, the DOB where the apparent crater diameter is maximum, and the camouflet DOB respectively.

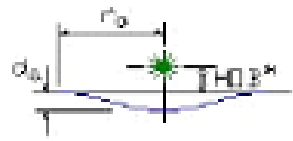

a. Low Airburst

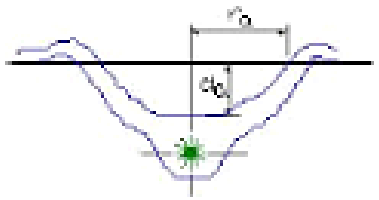

d. Optimum DOB

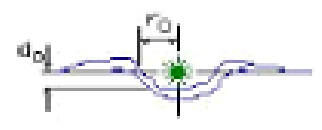

b. Surface Burst

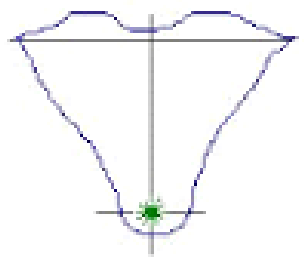

e. Deeply Buried

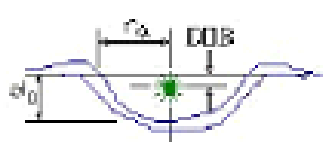

c. Shallow DOB

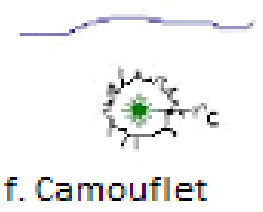

f. Camouflet

Figure 2-7: Crater sizes with given DOB (TM 5-855-1)

The determination of optimum DOB is beneficial for mining or in subsurface exploration where explosives are required as a means of excavation as this would enable the efficient use of the explosive to achieve optimum and desirable results.

The craters formed as a result of explosions in the soil differ for different soil types. Craters formed in sandy soil are smaller than those in clay. Explosions in saturated soils also produce larger craters than in dry soils. From Figure 2-8, it can be seen that the depth and diameter of apparent crater from an explosion is greatest in clay compared to sandy clay while the depth and diameter is the least in sand (TM 5-855 1986). 
The type of explosive used in cratering affects the crater properties. The energy density of explosives and the volume of gas produced in the explosion reaction vary from one explosive to another. To this end TNT is used as normalised reference explosive to which all other explosives are compared. The mass of a given explosive is converted to TNTequivalent mass by multiplying by a TNT-equivalence factor. TM 5-855-1 (1986) points out that most crater prediction curves are based on test data for bare explosives in TNTequivalent explosive weight and centrally detonated.

The shape of a charge also determines the manner in which the shock front propagates through the explosive and hence the size and shape of the crater. For example a cylindrical charge in a homogenous medium would produce a shock front that propagates cylindrically and that of a spherical charge in a homogenous medium propagates radially outward from the center of explosion (Wiss, 1981).

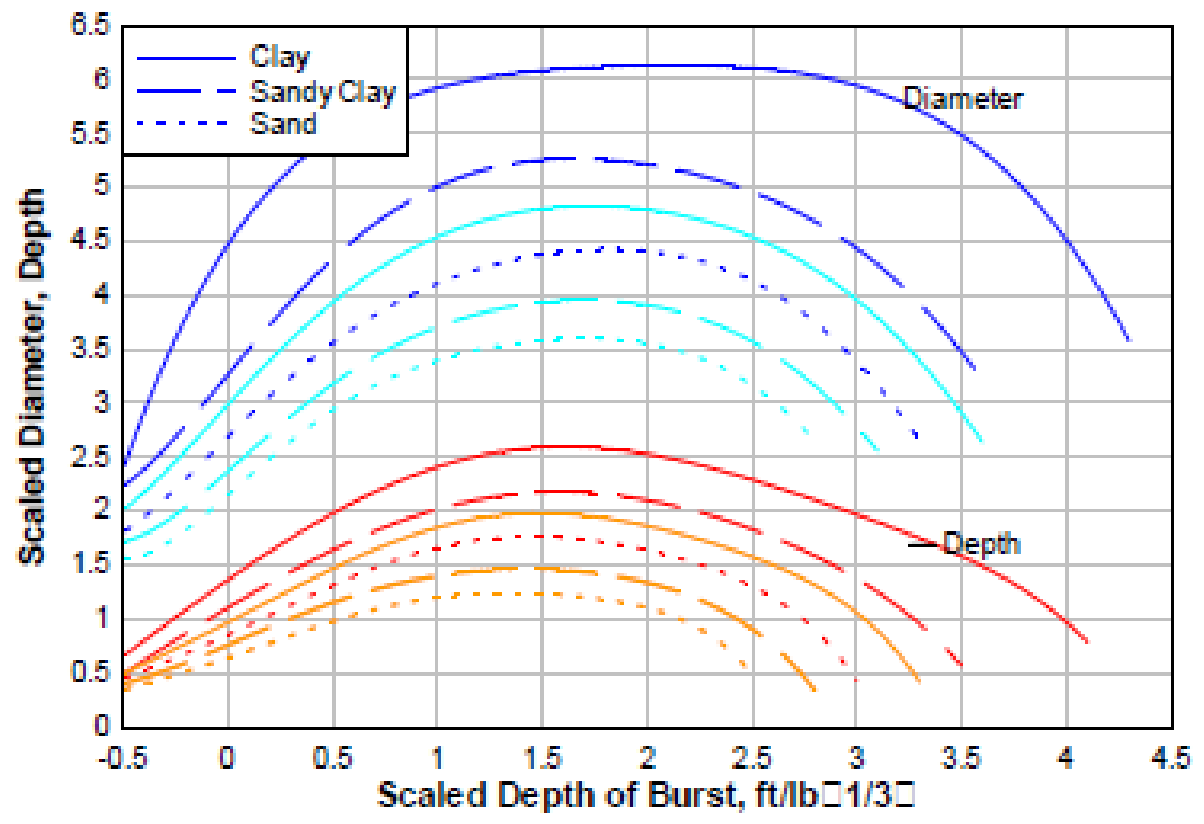

Figure 2-8: DOB and resulting Crater Diameter in Clay, Sandy Clay and Sand (TM -5-855-1) 


\subsection{Attenuation of Shockwave in Soil}

Attenuation of blast waves is the decay of the blast pressure after the peak pressure has been reached. In soil the attenuation maybe due to factors such as the distance from the centre of detonation, the air void volume and dry unit weight. The air void volume within soil greatly affects the attenuation of the blast pressure. As the air voids within the soil increase, the attenuation occurs more rapidly and vice versa. The effect of air void volume on pressure attenuation is greater in cohesive soils. This is because of the discontinuity in the soil mass, due to the presence of air voids, which increases the velocity of the shockfront in the soil medium.

In granular soils, on the hand, the factor which greatly affects attenuation is the dry unit weight. The propagation of the shockwaves reduces in granular soils with a lower dry unit weight and vice versa. The dry unit weight refers to the weight of the soil when all void spaces in the soil are filled with air, hence there is reduced surface to surface contact of the soil particles and therefore a high dry unit weight would easily allow the shockwave to travel through a given soil medium quickly as opposed to a lower dry unit weight

Literature gives various equations that maybe used in estimating the peak particle velocity at varying distances from the explosive charge. The general form of the widely used equation for estimating the peak particle velocity, $V_{\text {peak }}$ is given by Equation [2-2] ((US Department of Interior, 1985).

$$
V_{\text {peak }}=C\left(\frac{R}{W^{m}}\right)^{-n}
$$


Where $C$ is the ground transmission constant which is dependent on the charge confinement and the local geology of soil. $R$ refers to the distance between the centre of explosion and the point of interest (m). $W$ refers to the quantity of explosive measured in $\mathrm{kg}$ and $m$ and $n$ are empirical site specific constants. In a more specific sense different researchers have expressed this particle velocity differently, allocating the constants based on three different categories; scaling laws, charge confinement, and soil saturation.

\section{Scaling Laws}

The Scaling Law is based on Hopkinson's law which shows that similar waves are produced at identical scaled distances when two different charges of a given explosive with the same geometry are detonated under the same atmospheric conditions (Ambrosini et al., 2002). Based on the scaling laws, the square-root or cube-root scaling laws use $m$ values equal $1 / 2$ and $1 / 3$ respectively. The square-root scaling is suitable for line charges and near surface charges whereas the cube-root scaling suits for deeply buried charges. (US Department of Interior, 1985). Equations [2-3] and [2-4] present the peak velocity for the square-root and cube-root scaling laws respectively.

$$
\begin{aligned}
& V_{\text {peak }}=C\left(\frac{R}{W^{1 / 2}}\right)^{-n} \\
& V_{\text {peak }}=C\left(\frac{R}{W^{1 / 3}}\right)^{-n}
\end{aligned}
$$

\section{Charge Confinement}

Considering charge confinement, the peak particle velocity in soil can be expressed as normal or heavy confinement as predicted by Dupont (1980) and presented by Equations 
[2-5] and [2-6] respectively for square-root and cube-root scaling laws. The ground transmission constant, $C$, is given as 1.1 and 5.7 for normal and heavy confinements respectively whereas $n$ is expressed as 1.6;

$$
\begin{aligned}
& V_{\text {peak }}=1.1\left(\frac{R}{W^{1 / 2}}\right)^{-1.6} \\
& V_{\text {peak }}=5.7\left(\frac{R}{W^{1 / 2}}\right)^{-1.6}
\end{aligned}
$$

Deep Saturated Soil

Drake and Ingram (1981) proposed equations based on row (line) and point charges as presented by Equations [2-7] and [2-8];

$$
\begin{aligned}
& V_{\text {peak }}=C\left(\frac{R}{W^{1 / 2}}\right)^{-1.15} \\
& V_{\text {peak }}=C\left(\frac{R}{W^{1 / 3}}\right)^{-2.3}
\end{aligned}
$$

C ranges from 1.1 to 3.6. Long et al. (1981) also predicted the particle velocity in saturated sands by Equation [2-9];

$$
V_{\text {peak }}=0.6\left(\frac{R}{W^{1 / 2}}\right)^{-1.35}
$$

Figure 2-9 shows the peak stress attenuation in various soil types as a function of scaled distance. It can be observed that attenuation is higher in sands compared to clays. Also for dry conditions in a given soil, the peak stress from the blast load decreases significantly as the scaled distance increases but the increase is minimal in saturated conditions. 


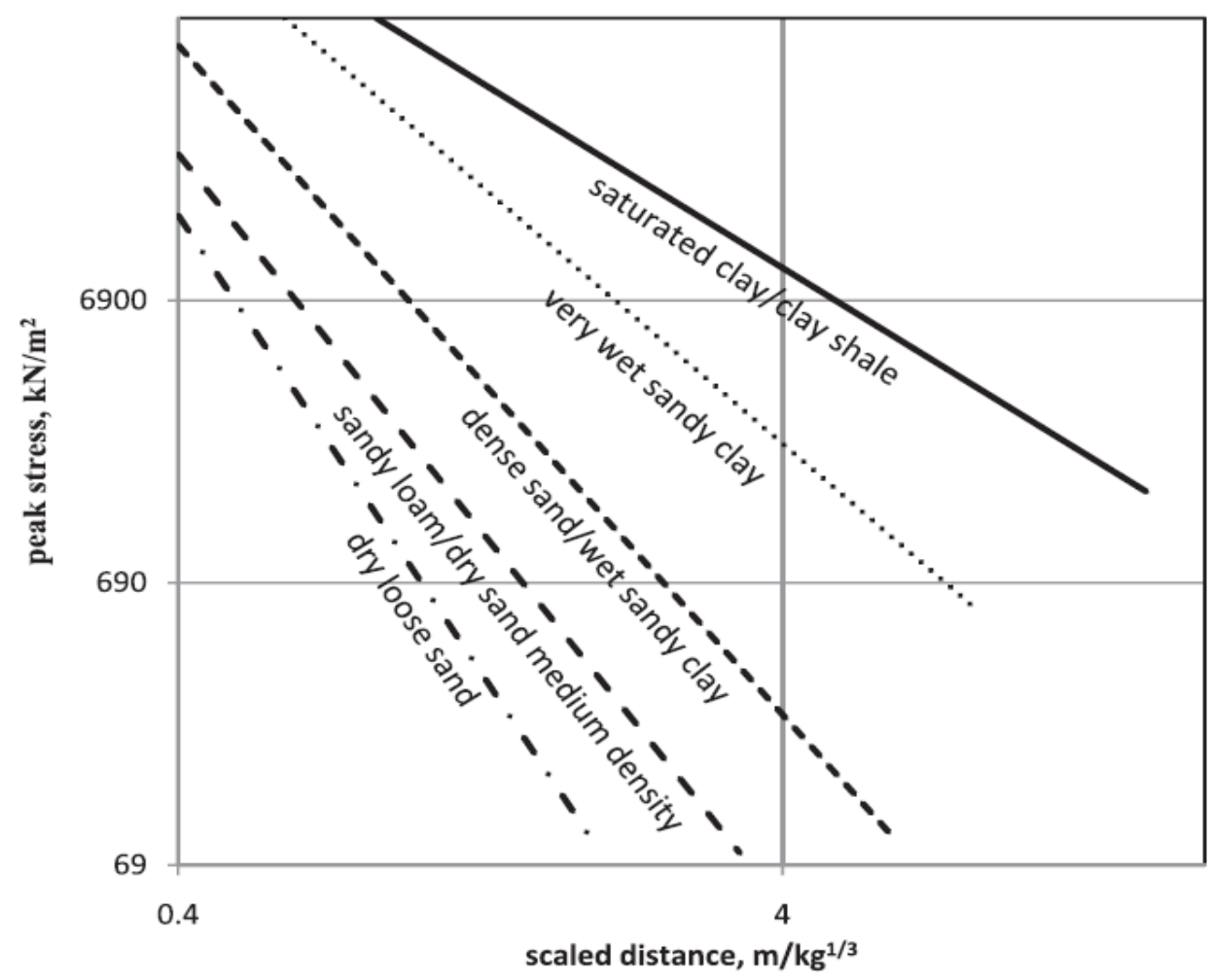

Figure 2-9: Peak Stress in different Soils based on Scaled Distance (Kumar et al.. 2013)

\subsection{Failure Modes of Dams}

The importance of safe design as well as construction of a dam cannot be overemphasized. According to the United States Society on Dams (USSD, 2011) the basic requirements for the satisfactory performance of constructed dams include;

- The ability of the embankment, foundation and abutments to withstand slumping (movement of loosely compacted soil material down the embankment), sliding and sloughing (downstream slope instability caused by wet conditions present at 
the portion below the exit point for seepage through the dam) during construction and all conditions of reservoir operation. These parts of the dam are also expected to be stable during and after unusual events such as earthquakes, floods and blast loads.

- The control and collection of seepage water through the embankment, foundation and abutments to prevent excessive uplift pressures, piping, sloughing and erosion of materials into cracks, joints and cavities.

- Providing adequate freeboard to prevent overtopping by wave action.

- Preventing upstream and downstream slope erosion by wave action, rainfall, reservoir level fluctuation and string winds by using adequate outer face protection.

- Constructing the dam using the appropriate quality control and assurance procedures.

An embankment dam may fail if any of the above criteria is not met during construction or operational cycle of the dam.

Generally an embankment dam may fail due to piping or overtopping. Piping is internal erosion of the embankment or foundation due to seepage. Piping is dependent on the plasticity of the soil, the soil gradation as well as the degree of compaction of fill materials. Figure 2-10 shows piping failure of an embankment dam. Internal erosion if allowed to persist would cause eventual failure of the dam.

Overtopping is a precursor to dam failure due to erosion and scour of the embankment dam by the flowing water. Overtopping can be caused by breaching of the freeboard of 
the dam. Figure 2-11 shows overtopping failure of the Lower San Fernando dam after the 1971 San Fernando earthquake. Overtopping is the major cause of dam failures. Dam failure data collated from the US between 1975 and 2001 shows that almost $70 \%$ of all dam failures are attributed to overtopping (Figure 2-12).

Thus, detonation of explosive charge on an embankment dam could lead to dam failure if the crater is large enough to precipitate overtopping of the crest. Additionally, the shock wave propagation through the body of the dam may lead to increased excess pore water pressure and reduction in effective stress.

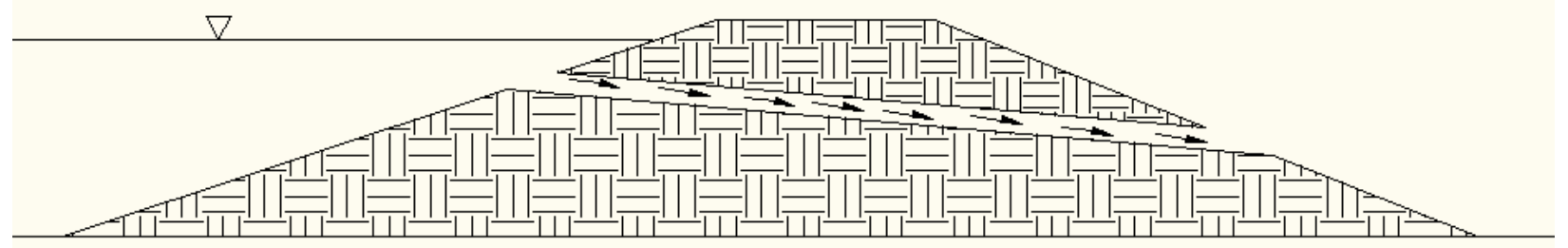

Figure 2- 10: Piping through Embankment of Dam
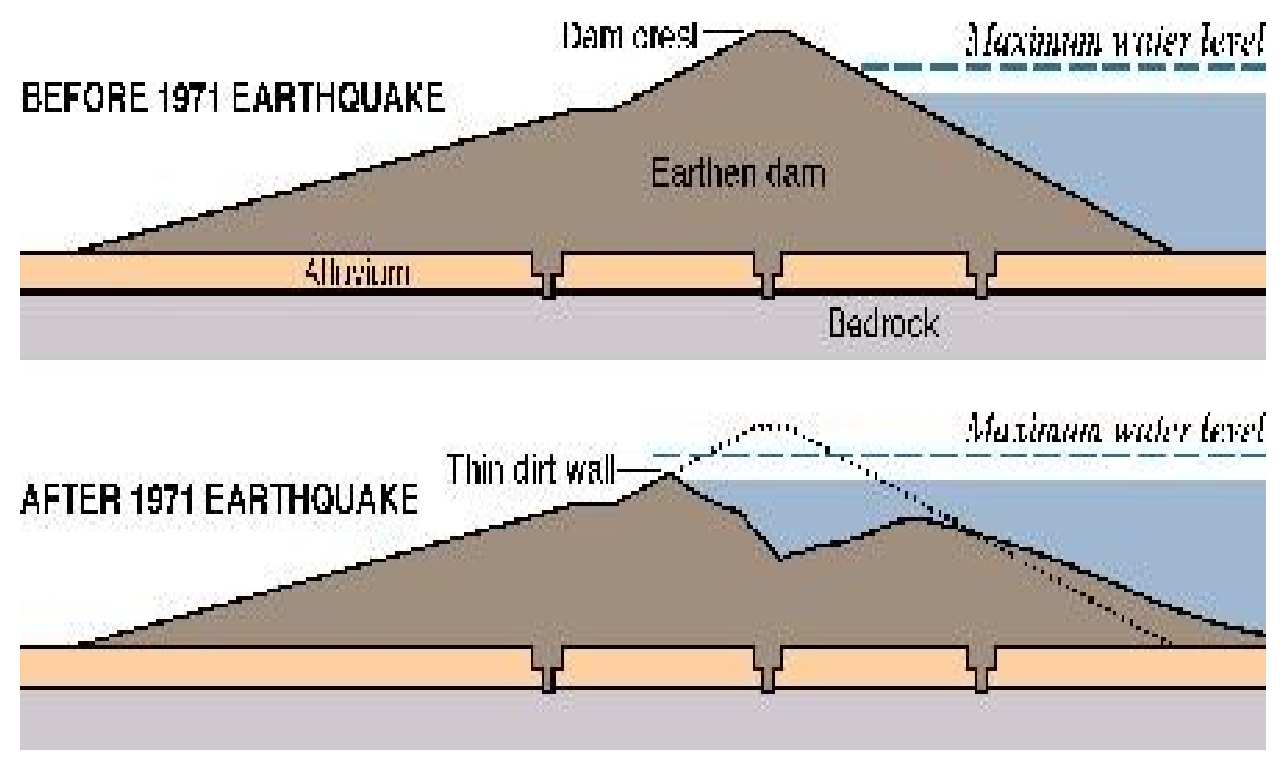

Figure 2-11: Overtopping of the Lower San Fernando Dam Crest in 1971 (Dahms, 2004) 


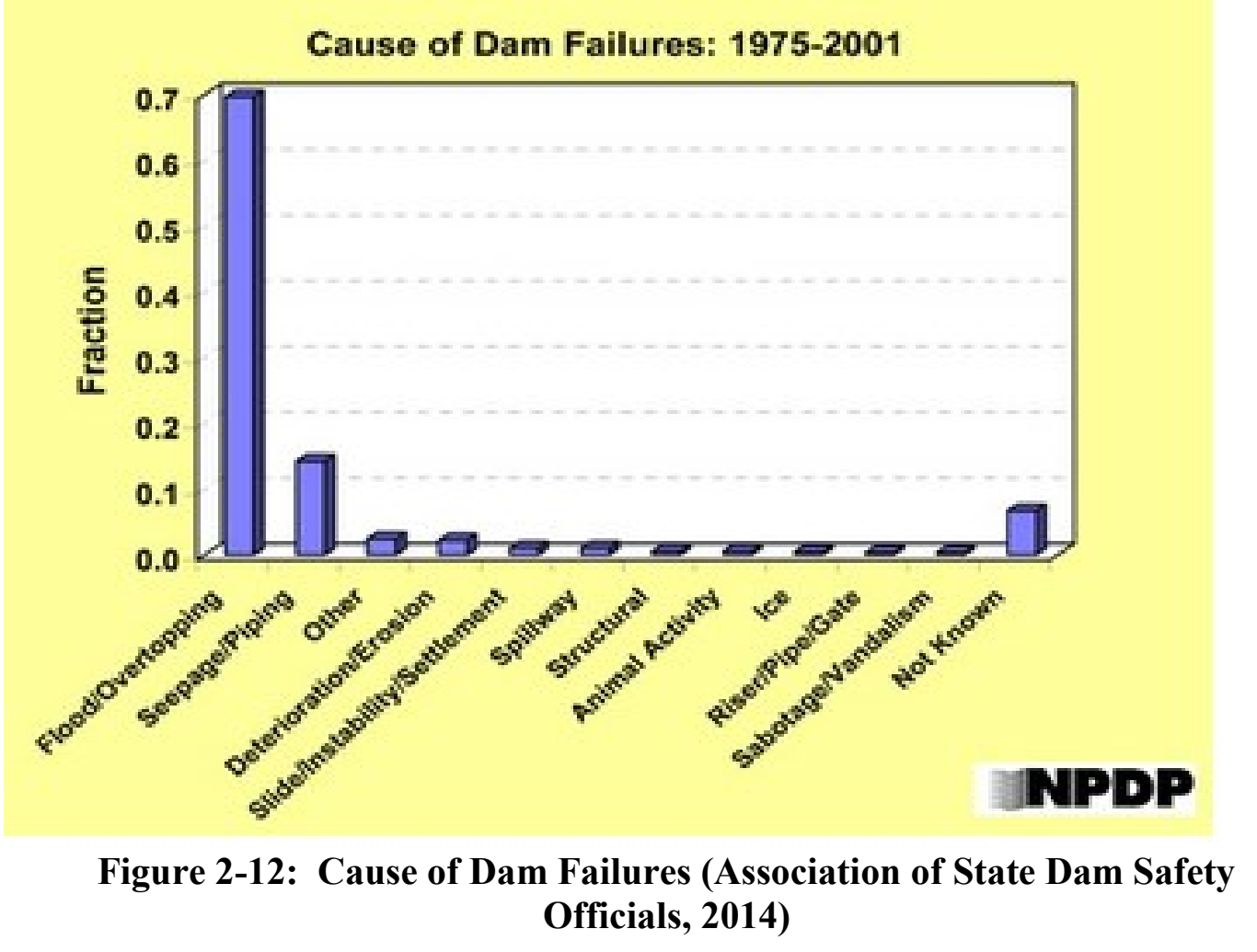

\subsubsection{Failure of Dam due to Crater Formation}

Most of the research work on explosive cratering has been conducted on flat undisturbed ground. However, effects of explosive cratering on the crest of an embankment will also depend on the available freeboard - the vertical distance between the crest of the dam and the maximum water level of the dam. If the dimensions of a crater are similar to the available freeboard, the dam crest can be overtopped and eroded. The freeboard is thus an essential design parameter for an embankment dam; especially when the explosion effect 
is of consideration. The design freeboard for an embankment dam is dependent on wind effects, landslide effects and earthquake effects (Ontario Ministry of Natural Resources, 2011). Table 2-1 presents the proposed freeboard heights for dams in Canada based on their heights and the climatic and environmental conditions (annual rainfall, wind speeds, earthquake) of the site.

With the current state of global terrorism and environmental activism, another factor that should be considered in designing the freeboard is explosion effects. Thus, the freeboard must be adequate to prevent overtopping under the effects of detonation of design basis explosive charge mass.

Table 2-1: Minimum Freeboard for Dams (Ontario Ministry of Natural Resources, 2011)

\begin{tabular}{|c|c|}
\hline Reservoir Fetch (Length) & Freeboard \\
\hline Under $200 \mathrm{~m}$ & $300 \mathrm{~mm}$ \\
\hline Up to $400 \mathrm{~m}$ & $450 \mathrm{~mm}$ \\
\hline Up to $800 \mathrm{~m}$ & $600 \mathrm{~mm}$ \\
\hline Over $800 \mathrm{~m}$ & Comprehensive assessment required. \\
\hline
\end{tabular}

\subsubsection{Failure of Dam due to excess Pore water Pressure}

Pore water pressure in soil arises due to the presence of water in the pore of soil or rocks. Pore water pressure has an effect on the mechanical properties of soil. Mechanical properties of soil such as shear strength, permeability and volume change are directly or indirectly affected by pore water pressure. Pore water pressure maybe positive or negative (Fredlund, 1987; Vanapalli et al., 2003; Fredlund and Rahardjo, 1993).

Researchers (Vanapalli, 2010; Zhang et al., 2010; Fredlund 1987) indicate that negative pore water pressures also known as matric suction or suction contributes to the shear 
strength of soil. Although this unsaturated zone contributes to shear strength, the strength increase is often neglected in design of embankment dams. The shear strength in embankment dams is defined by the single stress state variable proposed by Terzaghi:

$$
\sigma^{\prime}=\boldsymbol{\sigma}-\boldsymbol{u}
$$

where $\sigma^{\prime}$ is the effective stress, $\sigma$ is the total stress and $u$ is the pore water pressure.

In large embankment dams, substantially higher pore water pressures may be observed within the core of the dams (St-Arnaud, 1995). This implies that dams need constant observation throughout its operational period to make sure fill materials as well as foundation material do not lose their strength. When steady-state seepage is achieved, depending on the reservoir level, the phreatic line is defined within the embankment dam.

Initial pore water pressure levels are defined within the embankment dam when steady state seepage within the embankment dam is reached. The pore water pressure may fluctuate depending on the reservoir level and hence the phreatic surface. However excess pore water pressure $(\Delta \mathrm{u})$ is generated when there is a change in stress applied to the dam such that there is no time for dissipation of this excess pore water pressure. This results in further decrease in shear strength. The continual increase of excess pore water pressure could lead to shear stress exceeding the designed shear strength and result in piping. Piping occurs when effective stress is less than or equal to zero and soil behaves as a liquid.

Explosion on a soil medium generates high shock stresses within the soil. The shock stresses introduce strain rates in the magnitude of $10^{-1}$ to $10^{3}$ leading to soil over-strength and increased stiffness compared to soil under normal static forces (Ambrosini et al., 
2004). The short duration shock stresses result in instantaneous increase in excess pore water pressure which persists over a comparatively longer period of time (Braimah and Rayhani, 2012). According to Wang et al. (2011), Terzaghi attributed the failure of the SWIR III Dam in Russia, which occurred in 1935, to blasting operations in close proximity, liquefaction of the embankment, and eventual failure of the dam.

To understand pore water pressure effects induced by explosion effects, three significant stages of interest are relevant; the transient response of the soil due to the propagation of the shockwave, the residual response of the soil after the passage of the shockwave and the dissipation of the pore water pressure (US Department of Interior, 1985). Residual pore water pressure generation is important for the safety of a dam. In saturated soils, there is an increase in excess pore water pressure when the fluid responds elastically and the soil response to the shockwave is plastic. In the case when both soil and water behave elastically, no excess pore water pressure increase is observed (Dobry et al. 1982).

A review of the unclassified literature has shown a dearth of information on explosion effects on pore water pressure in embankment dams. Table 2-2 shows a summary of blast related research in soil with concentration on the effects of pore water pressure. The research which ranges from different countries show that most of the research was conducted on sands. Figure 2-13, on the other hand, shows results from a test conducted on an embankment dam for a $2 \mathrm{~kg}$ charge mass. The results show readings of residual pore water pressure at different depths within the dam. More significantly the plot shows that residual pore water pressures decreases with distance from point zero. 
Table 2-2: Research Summary of Blast Effects on Pore Water Pressure (US Department of Interior, 1985)

\begin{tabular}{|c|l|}
\hline Research Origin & \multicolumn{1}{c|}{ Observations } \\
\hline \multirow{4}{*}{ Russia } & $\begin{array}{l}\text { Liquefaction does not occur in saturated sands with dry densities higher } \\
\text { than } 1.60 \mathrm{~g} / \mathrm{cm}^{3} .\end{array}$ \\
\cline { 2 - 3 } & $\begin{array}{l}\text { Liquefaction does not occur in soil subjected to peak particle velocities } \\
\text { lesser than } 7 \mathrm{~cm} / \mathrm{s} .\end{array}$ \\
\cline { 2 - 3 } & $\begin{array}{l}\text { The possible depth of liquefaction for explosives detonated below } \\
\text { groundwater table was measured as } 1.5 \text { times the depth of detonation. }\end{array}$ \\
\hline \multirow{4}{*}{ India } & $\begin{array}{l}\text { Residual pore water pressure increases out to a radial distance of } \\
\text { approximately } 15 \mathrm{~m} \text { in loose saturated sand for a } 10 \text { kg charge at a } \\
\text { depth of } 16 \mathrm{~m} \text { with a ground acceleration of } 0.1 \mathrm{~g} .\end{array}$ \\
\cline { 2 - 3 } & $\begin{array}{l}\text { Residual pore water increases in loose saturated sand to a radial } \\
\text { distance of } 20 \mathrm{~m} \text { for a } 2 \mathrm{~kg} \text { charge with a depth of burst of } 6 \text { m. }\end{array}$ \\
\hline \multirow{5}{*}{ Japan } & $\begin{array}{l}\text { A } 1 \mathrm{~kg} \text { charge at a } 6 \mathrm{~m} \text { depth of burst yielded residual pore water } \\
\text { pressure increase of } 10 \text { per cent of the initial effective stress under a } \\
\text { ground acceleration of } 2 \mathrm{~g} .\end{array}$ \\
\hline \multirow{5}{*}{ North America } & $\begin{array}{l}\text { Residual pore water pressure occurred for peak particle velocity } \\
\text { exceeding } 5 \mathrm{~cm} / \mathrm{s} .\end{array}$ \\
\cline { 2 - 3 } & $\begin{array}{l}\text { Peak partcile velocity should be limited to } 2.5 \mathrm{~cm} / \mathrm{s} \text { below a frequency } \\
\text { of } 40 \mathrm{~Hz} \text { and } 5 \mathrm{~cm} / \mathrm{s} \text { above } 40 \mathrm{~Hz} \text { for planned blasting near dams. }\end{array}$ \\
\hline
\end{tabular}

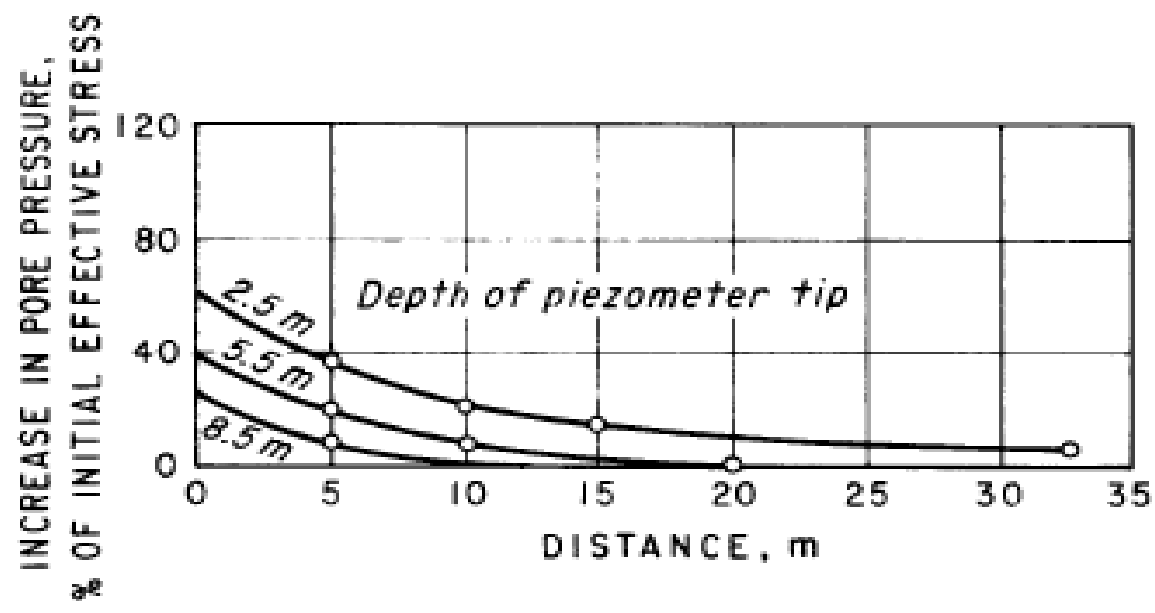

Figure 2-13 Pore Water Pressure against Distance (US Department of Interior, 1985) 


\subsection{Previous Works of Relevance}

Crater investigations can be done either by experimental tests or computer programmes. Many researchers have conducted experimental research to investigate the effect of explosion on soil properties (TM 5-855-1; Charlie et al., 2001; Ambrosini et al., 2002; Ambrosini et al., 2004; Luccioni et al., 2008; Luccioni et al., 2009; Li et al., 2007).

With advancement in computer technology, many researchers are choosing to use computer modelling to simulate explosions on soil mass. Computer modelling provides a less expensive alternative to the expensive field testing as well as eliminates the limitations on the amount of explosives used in testing. Computer programs capable of modelling the explosion process and the propagation of shock wave through the soil mass include Autodyn (Autodyn user manual, 2009), Abaqus (Abaqus user manual, 2012), LSDYNA (LS-DYNA user manual, 2007) and FLAC (FLAC user guide, 2002).

\subsubsection{Experimental Research}

Extensive experimental research programmes have been conducted to investigate crater formation on the flat ground as well as embankments. These experiments have mainly investigated crater dimension for differing explosive charge masses and location on embankment. Ambrosini et al. (2002) conducted an experiment to investigate the diameter and depth of craters formed by varying the height of burst and depth of burial of the explosive. The experiments were grouped into three categories; near-ground blast (spherical charge), hemispherical (charge on ground surface) and underground (buried)

explosions. The mass of the explosive charges used ranged from $1 \mathrm{~kg}$ to $10 \mathrm{~kg}$. The 
experiment was conducted on flat ground and the effect of the slopes on embankments was not investigated. The soil at the test site was mainly inorganic clays. The results from the three setups indicated that;

- Air blast have the least effects on crater diameter and depth since the explosive is not coupled with the ground and thus most of the explosive energy is transmitted through the air medium whereas the greatest crater dimensions were observed for buried charge masses. As the depth of burial decreases and as the height of burst increases the crater size reduces.

- The experimental tests were modelled with the Kinney and Graham (1985) equation for predicting crater diameter (Equation [2-11]) and showed very good correlation.

$$
D=0.8 W^{1 / 3}
$$

- Ambrosini et al. (2002) also proposed an equation for predicting the diameter of the crater for above ground explosions (spherical) as shown in Equation [2-12]. The equation can also be employed to predict the weight of explosive from diameter of the crater.

$$
\log \left(\frac{D / 2}{|d|}\right)=1.241 \log \left(\frac{W^{1 / 3}}{|d|}\right)-0.818
$$

Li et al. (2007) conducted an experiment on the effect of explosives on an embankment dam. The main aim of this investigation was to study the variation of crater dimensions on an embankment and compare with crater dimensions on the flat ground. The 
embankment was carved from the native soil at the test grounds. The sides of the embankment were dug out with a backhoe. The native soil at the test site was mainly made up of sand and gravel. Figures 2-14 and 2-15 show the finished embankment and the cross section of the finished embankment showing the position of the explosive charge respectively. Figure 2-16 shows the particle size distribution curve confirming the soil type at different depths at the test site respectively. The moisture content of the soil varied between $4 \%$ and $8.2 \%$ while the bulk density varied between $1200 \mathrm{~kg} / \mathrm{m}^{3}$ and 1440 $\mathrm{kg} / \mathrm{m}^{3}$. The bulk density of soil in the crater after the explosion was reported to be slightly higher at $1440 \mathrm{~kg} / \mathrm{m}^{3}$ (Braimah et al. 2012).

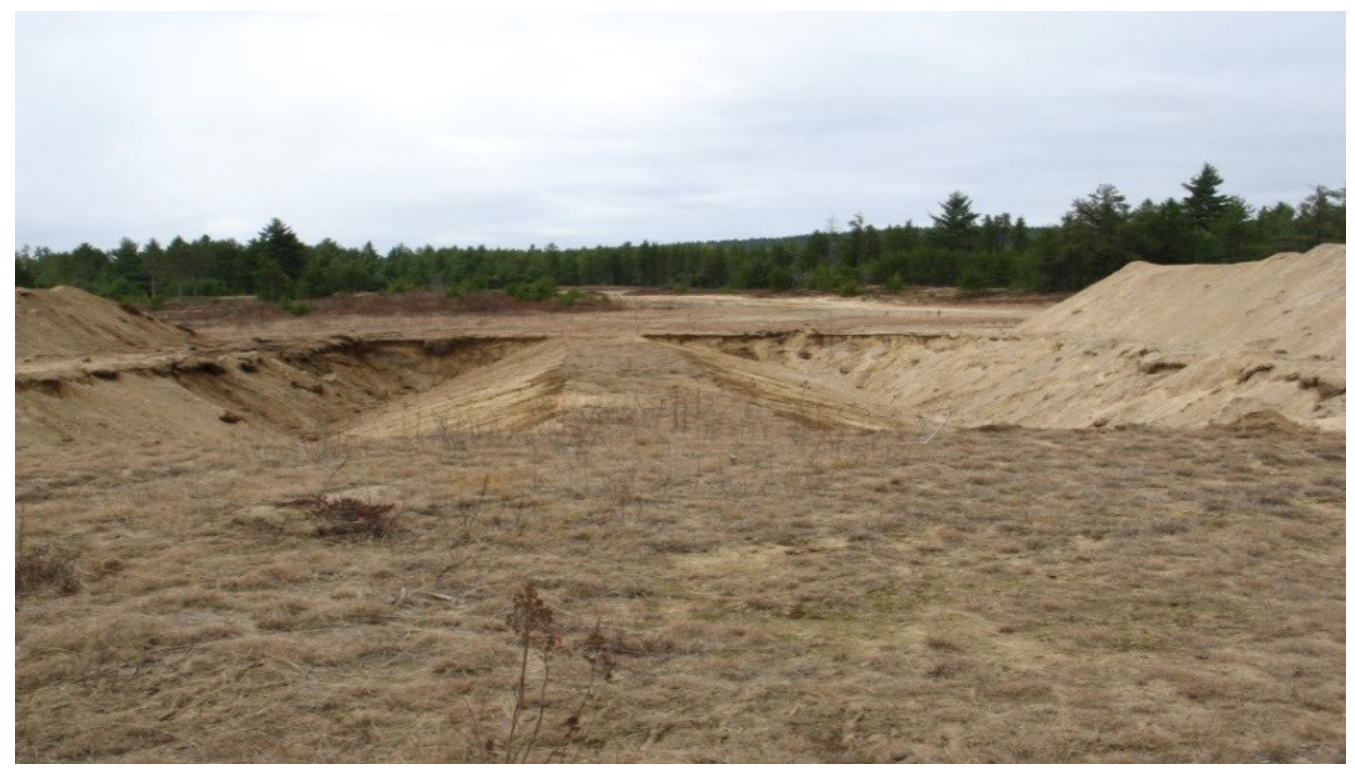

Figure 2-14: Finished Embankment (Li et al., 2007) 


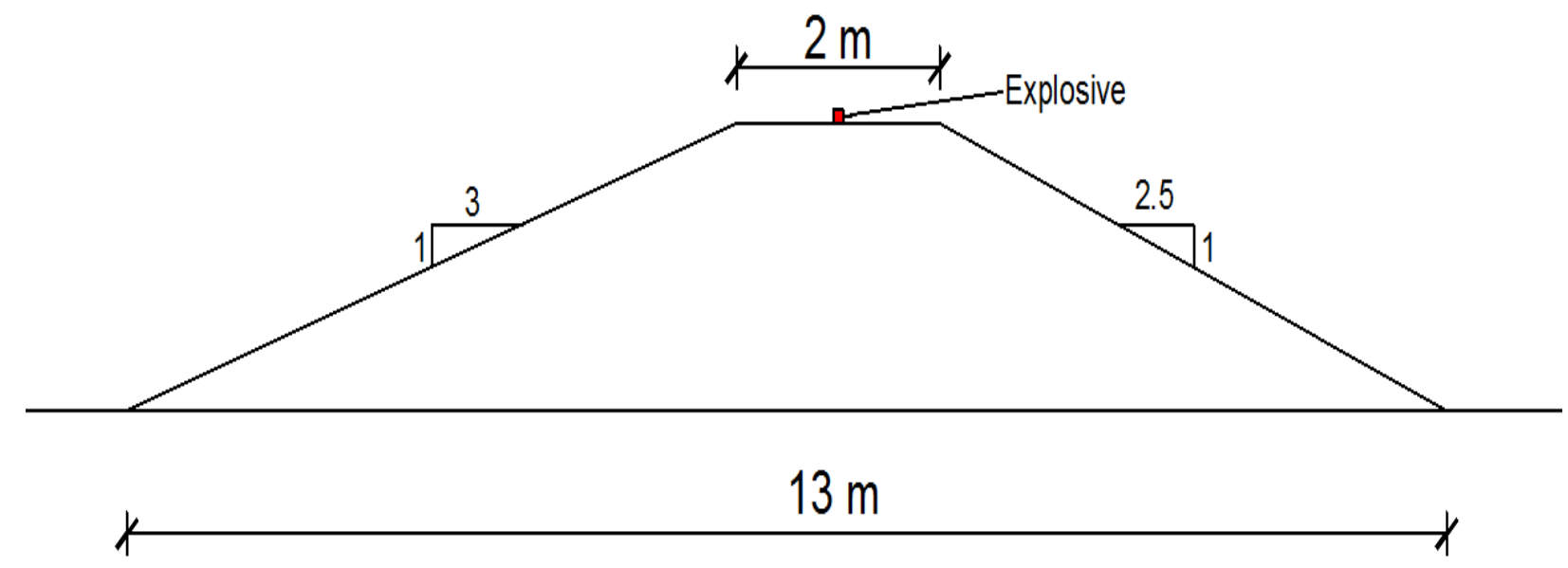

Figure 2-15: Cross-Section of Dry Embankment (Li et al., 2007)

Ammonium Nitrate of Oil (ANFO) of $25 \mathrm{~kg}, 50 \mathrm{~kg}$ and $100 \mathrm{~kg}$ charge masses were used for the test programme. The crater dimensions were measured across four diameters at $45^{\circ}$ and at four locations equidistant from the centre of the crater, two on either side as per Figure 2-17. Axis 1-1 was aligned to the axis of the embankment dam and 3-3 perpendicular to its axis.

Li et al. (2007) compared the experimental results to that from ConWep. Figure 2-18 shows results of crater formed for the $100 \mathrm{~kg}$ charge for the both flat ground and embankment as compared to ConWeP results for a dry sand and concrete. The Figure emphasizes the assertion that embankment dams which are made of soil are more vulnerable to explosive attacks due to the higher crater dimesions as compared to concrete. 


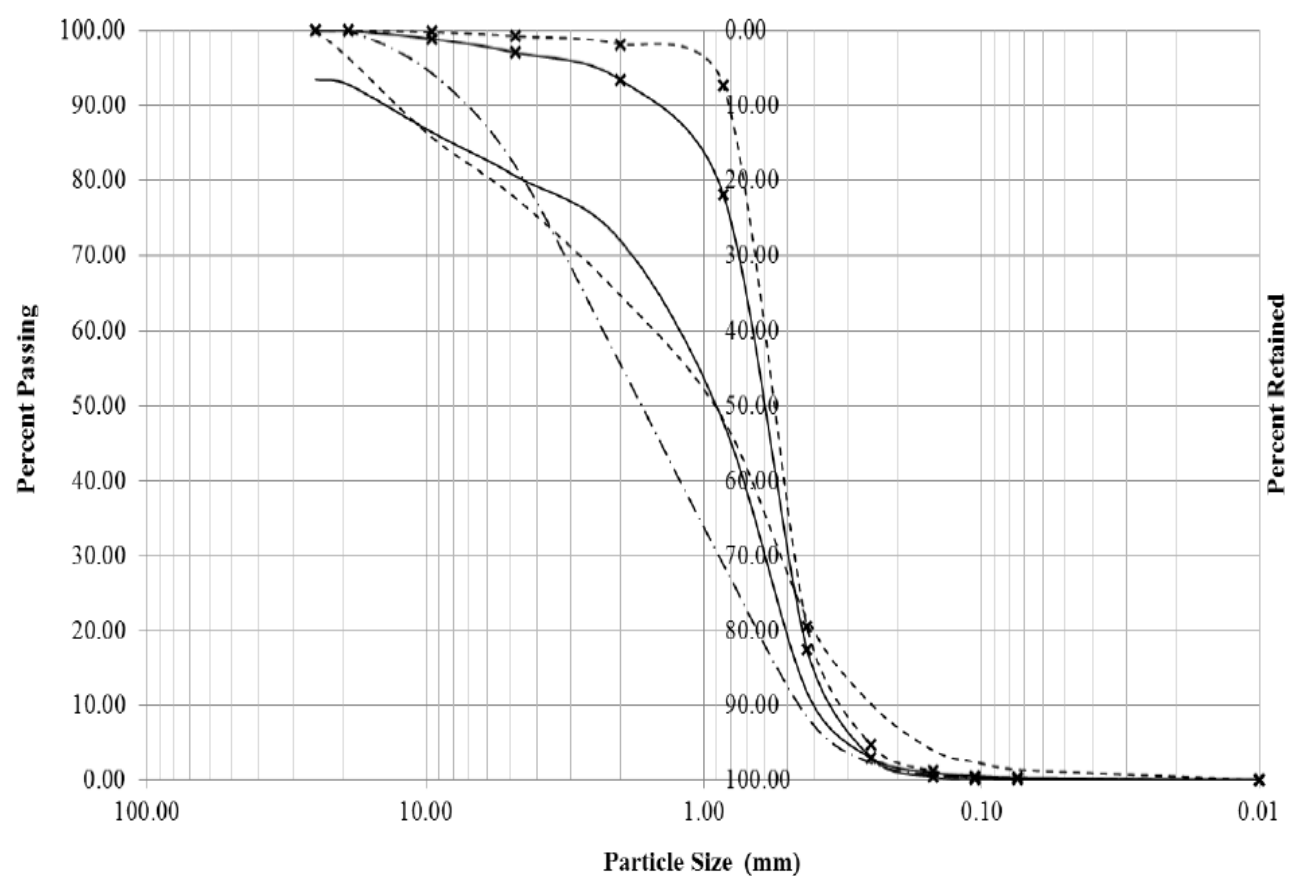

Figure 2-16: Particle Size Distribution Curve (Braimah et al., 2012)
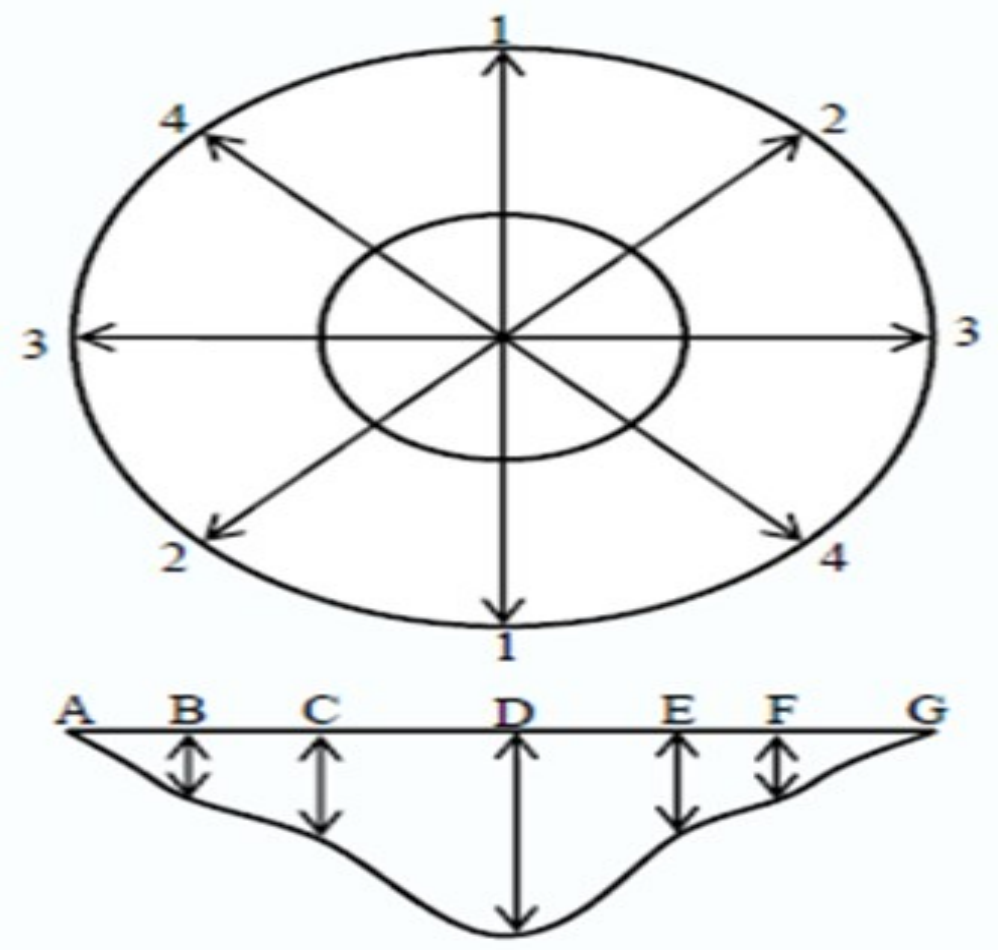

Figure 2-17: Measurement Technique for Crater Estimation (Li et al., 2007) 


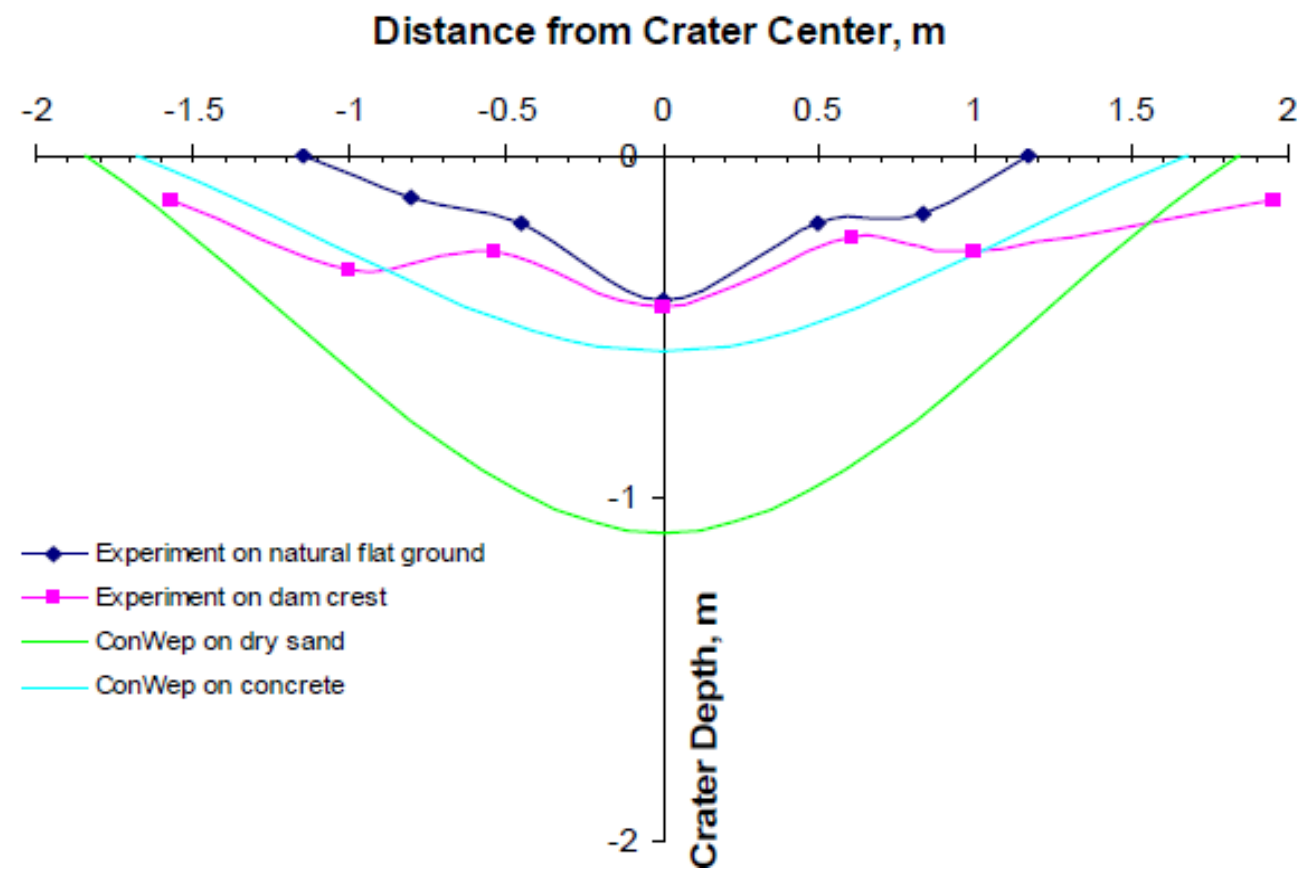

Figure 2-18: Crater Profile for $100 \mathrm{~kg}$ ANFO (Li et al., 2007)

The following observations were made by Braimah et al., (2012) by studying Figures 219 and 2-20 which are made of the experimental results as well as results from CoNWeP;

- The apparent crater dimensions (apparent diameter and apparent depth) increase with increase in charge mass.

- The crater dimensions in the case of the embankment was comparable to that of the flat ground for the $25 \mathrm{~kg}$ ANFO but for the $50 \mathrm{~kg}$ and $100 \mathrm{~kg}$ charge masses the embankment crater dimensions were found to be larger than that for the flat ground. The diameter of the embankment increased in the lateral direction.

- The slopes of the embankment contributed to large volume of ejecta thrown out towards the upstream and downstream faces of the embankment.

- The shape of the crater in the case of the embankment was elliptical with the long axis across the dam crest and the short axis along the axis of the embankment. In the 
perpendicular direction to the embankment, the apparent diameter was $50 \%$ larger than the average apparent diameter for the flat ground explosion.

- CoNWeP over estimates the crater dimensions for a given charge mass.

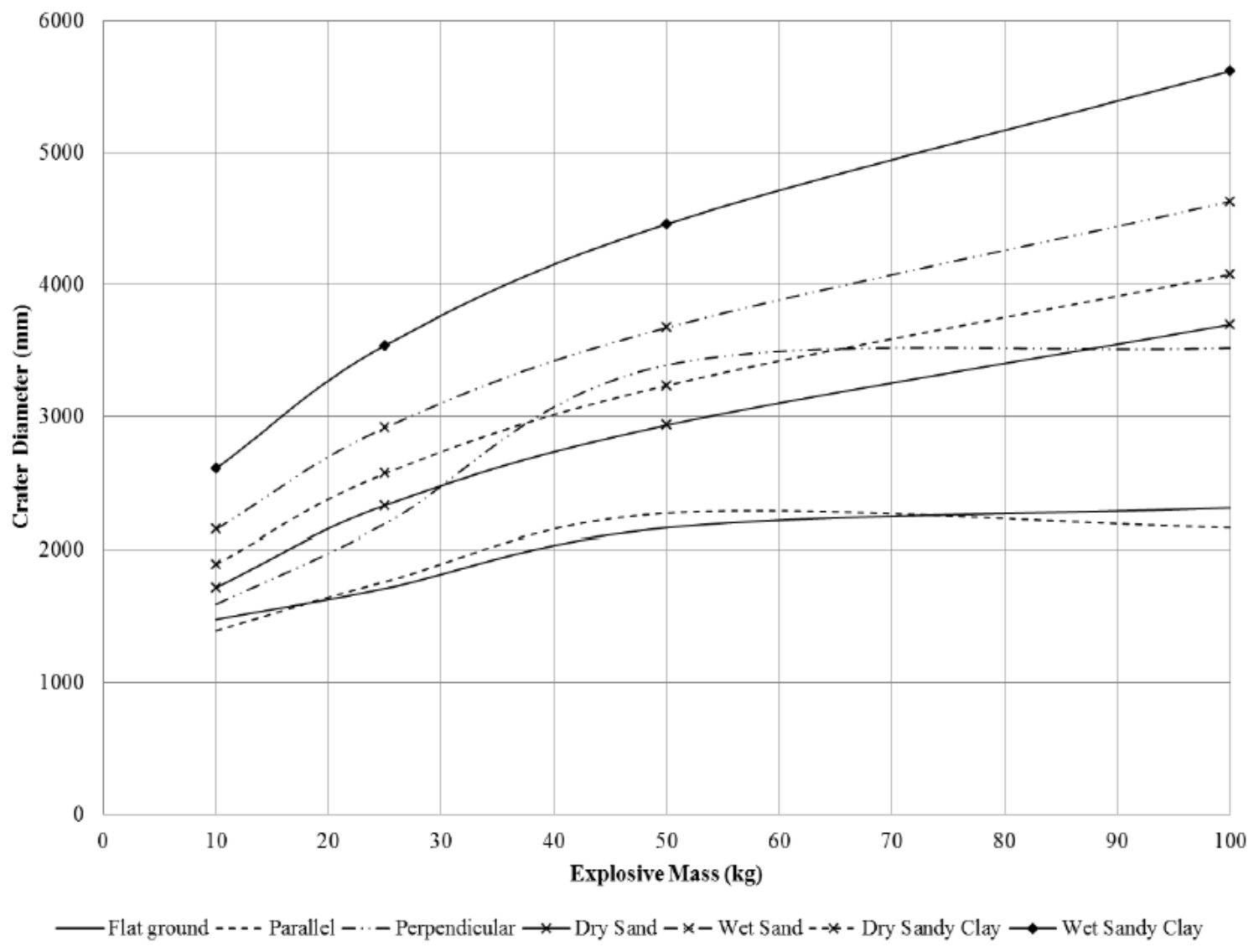

Figure 2-19: Crater Diameter against Explosive Mass (Li et al., 2007) 


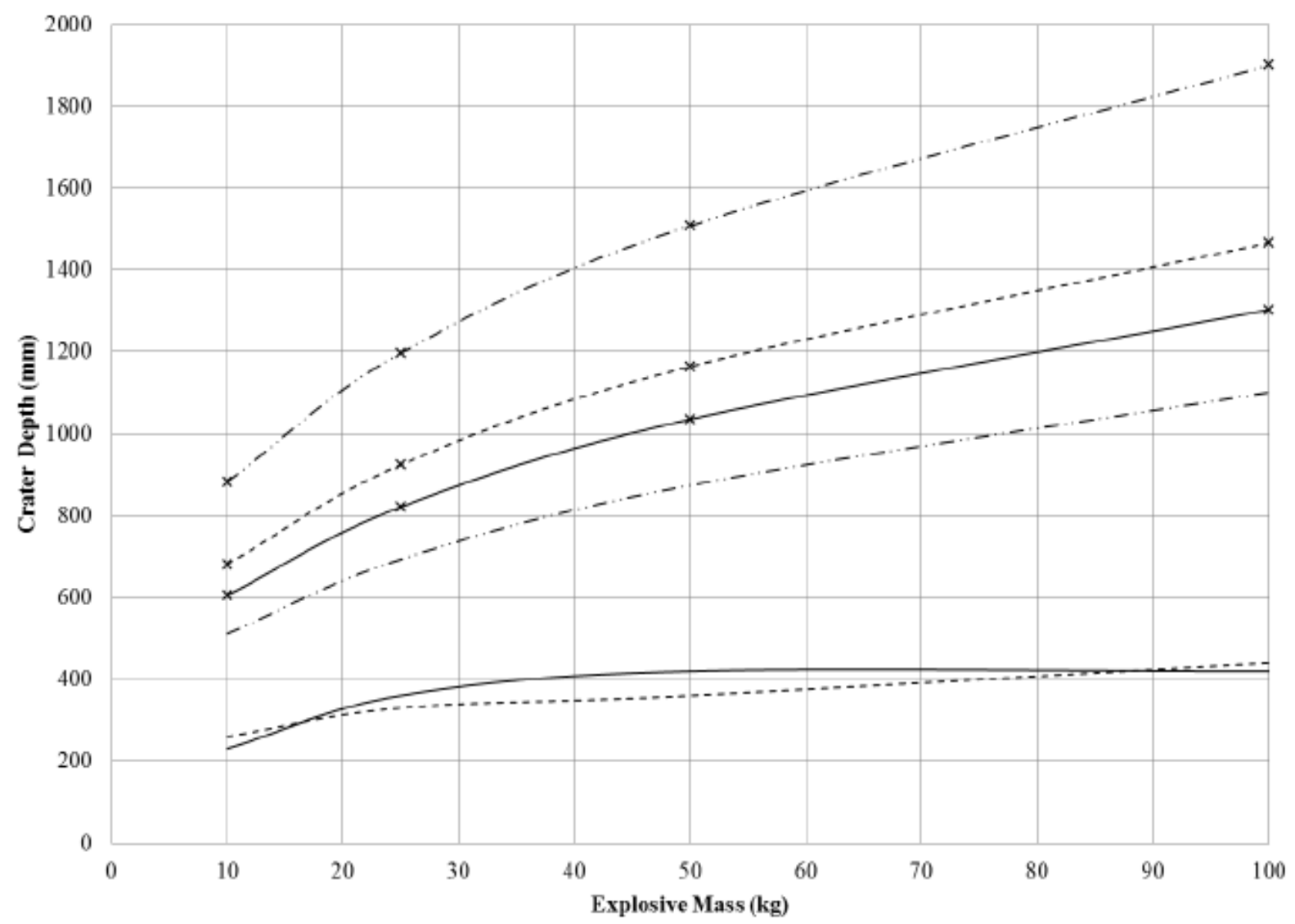

Figure 2-20: Crater Depth against Explosive Mass (Li et al., 2007)

\subsubsection{Numerical Simulation}

As compared to field testing, numerical modeling is less expensive and gives the flexibility for varying scenarios to be tested. However before a numerical model can be used in any parametric analysis, it has to be validated against an experimental test. Just as in the case of the experimental programme, the unclassified literature does not contain a wide range of knowledge on numerical simulation of explosion effects on embankment dams. The numerical models governing the explosion phenomena are based on various differential equations relating to conservation of mass, energy and volume changes. These parameters are related through an Equation of State. An Equation of State (EOS) 
simply defines pressure as a function of specific volume and internal energy and is widely used in modelling fluids and gases. Material models or constitutive model are key in achieving solutions for numerical modelling, and the equations supporting these material models are based on experimental work relating stress to deformations (strains). These complex equations and their interdependence during every cycle of analysis make it tedious for computation to be done by hand hence need computer program.

Ambrosini et al. (2004) simulated explosion effects on flat ground using TNT explosive ranging from $50 \mathrm{~kg}$ to $500 \mathrm{~kg}$. The simulation was done using AUTODYN. Figure 2-21 shows the model set up used for the simulation showing the meshes. The summary of the model properties associated with the various components of the model are shown in Table 2-3.
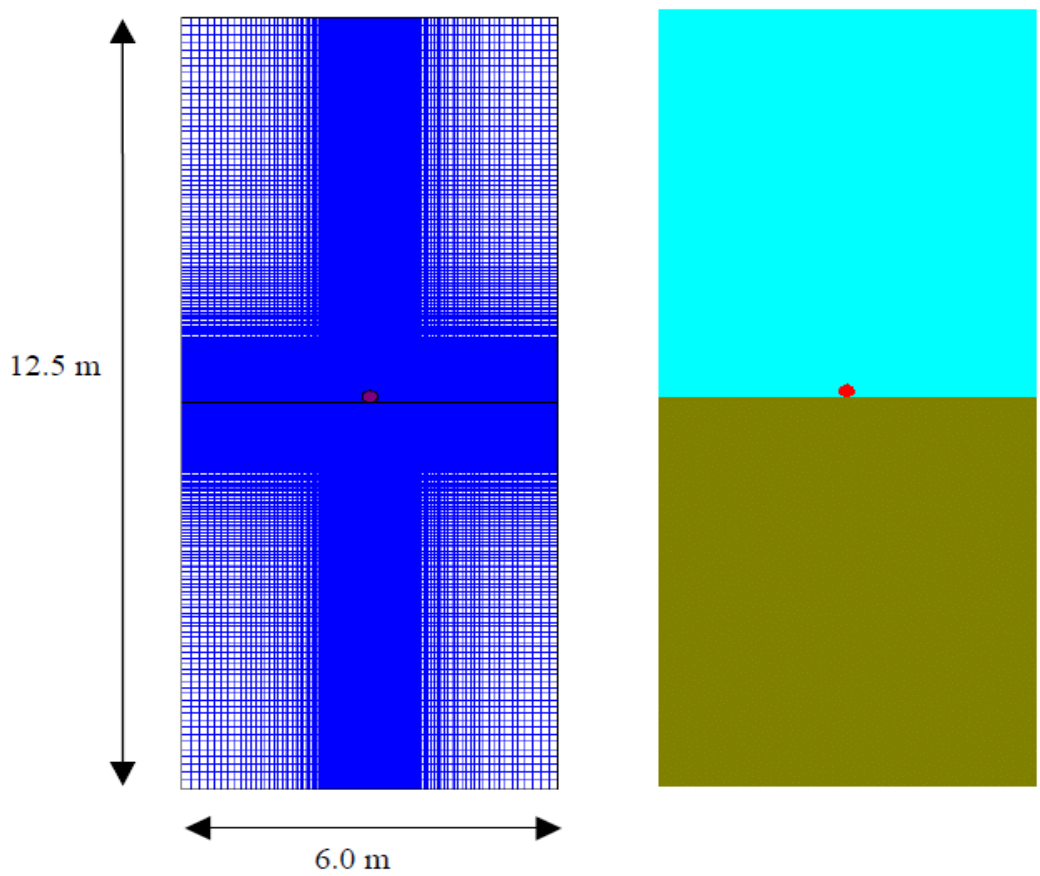

MATERIAL

LOCAT ION

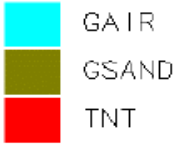

Figure 2-21: Model Set-up (Ambrosini et al., 2004) 
Table 2-3: Summary of Material Model for Simulation (Ambrosini et al., 2004)

\begin{tabular}{|c|c|c|}
\hline Model Component & Consitiutive Model & EOS \\
\hline Air & Ideal gas material & Ideal gas \\
\hline Explosive & High Explosives & JWL \\
\hline Soil & Mohr Coulomb & Mie-Gruneisen \\
\hline
\end{tabular}

The aim of this research was to investigate the effects of soil properties on crater formation on a flat ground. The summary of the findings made by simulations undertaken by Ambrosini et al (2004) indicated;

- The elastic properties of the soil taking into consideration the shear modulus and density do not affect the diameter of the crater. A variation of 5\% was observed in the crater dimensions for these property variations. The density was varied from $1250 \mathrm{~kg} / \mathrm{m}^{3}$ and $1950 \mathrm{~kg} / \mathrm{m}^{3}$ whereas the shear modulus was varied from $30 \mathrm{MPa}$ to $1000 \mathrm{MPa}$ which refers to materials ranging from soft soil and sound rock.

- Altering the failure limit of the soil as well as the yield functions between reasonable limits did not change the crater diameter.

Jayasinghe et al. (2013) modelled the response of a pile in saturated soil to blast. The numerical simulation was done using LS-DYNA. The aim was to check the displacement that occurs in the pile to the passage of blast shockwaves through the soil. Figure 2-22 shows the model set for the numerical simulation. The summary of the constitutive models used for the modelling are shown in Table 2-4; 
Table 2-4: Summary of Material Model Simulation (Jayasinghe et al., 2013)

\begin{tabular}{|c|c|c|}
\hline Model Component & \multicolumn{1}{|c|}{ Consitiutive Model } & EOS \\
\hline Air & *MAT_NULL & Polynomial \\
\hline Explosive & *MAT_HIGH_EXPLOSIVE_BURN & JWL \\
\hline Soil & *MAT_FHWA_SOIL & $\mathrm{n} / \mathrm{a}$ \\
\hline
\end{tabular}

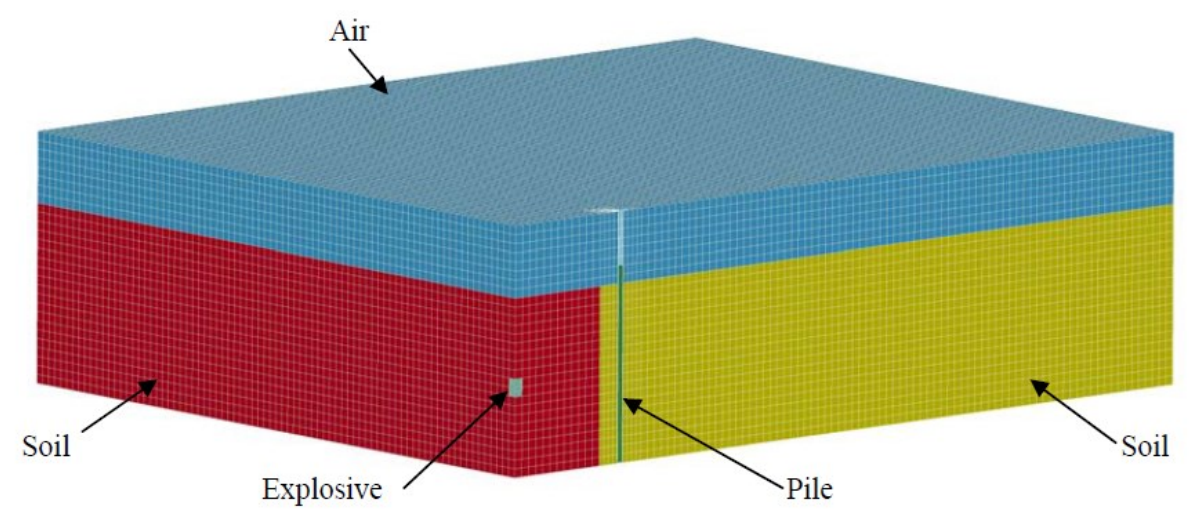

Figure 2-22: Numerical Model (Jayasinghe et al., 2013)

A comparative investigation into the material models available for granular soil material in LS-DYNA was conducted by Defence R \& D Canada (2009). The analysis was conducted by comparing *MAT_FOAM_AND_SOIL as well as *MAT_PSEUDO_TENSOR. The simulation was performed to investigate the ability of these material models to effectively predict crater dimensions. The summary of the constitutive models used for the simulation for these two material models are shown in Tables 2-5. The report concluded that LS-DYNA predicted the crater depths within acceptable ranges however there were significant differences in the experimental crater diameters and that predicted by the two material models. 
Table 2-5: Summary of Material Model (Defence R \&D, 2009)

\begin{tabular}{|c|l|c|}
\hline Model Component & Constitutive Model & EOS \\
\hline Air & *MAT_NULL & *EOS_POLYNIMIAL \\
\hline Explosive & *MAT_HIGH_EXPLOSIVE & *EOS_JWL \\
\hline Soil 1 & *MAT_SOIL_AND_FOAM & n/a \\
\hline Soil 2 & *MAT_PSEUDO_TENSOR & *EOS_TBAULATED_COMPACTION \\
\hline
\end{tabular}

Considering embankment dams, a numerical simulation was undertaken by De et al. (2013). De et al., (2013) produced a 3D numerical model using Ansys Autodyn to simulate explosion on an embankment dam with a height of $5.39 \mathrm{~m}$, a base of $31 \mathrm{~m}$ and a length of $32 \mathrm{~m}$. To validate the model used in the simulation, experimental results from a centrifuge experiment conducted by Sausville (2005) was used. A series of tests was conducted under this investigation and De et al., (2013) modelled these tests and compared the numerical and experimental data. The first series were conducted varying TNT explosives between 31.6 and $240.5 \mathrm{~kg}$ with no reservoir at the upstream side of the embankment. The second series conducted had the TNT explosives being varied 129.3 and $1326.9 \mathrm{~kg}$ with a reservoir on the side as shown in Figure 2-23. The model in Autodyn was concluded to have values comparable to that of the experimental data. The result of the numerical set up is shown in Figure 2-24 and indicated the model showed a good agreement for the depth of crater formed by the experimental setup.

Although this test is the closest numerical model of soil interaction in the case of an embankment dam, it still has limitations with regards to field conditions. De et al (2013) did not consider the effects of soil conditions such as the soil type, shear strength as well as moisture content. 


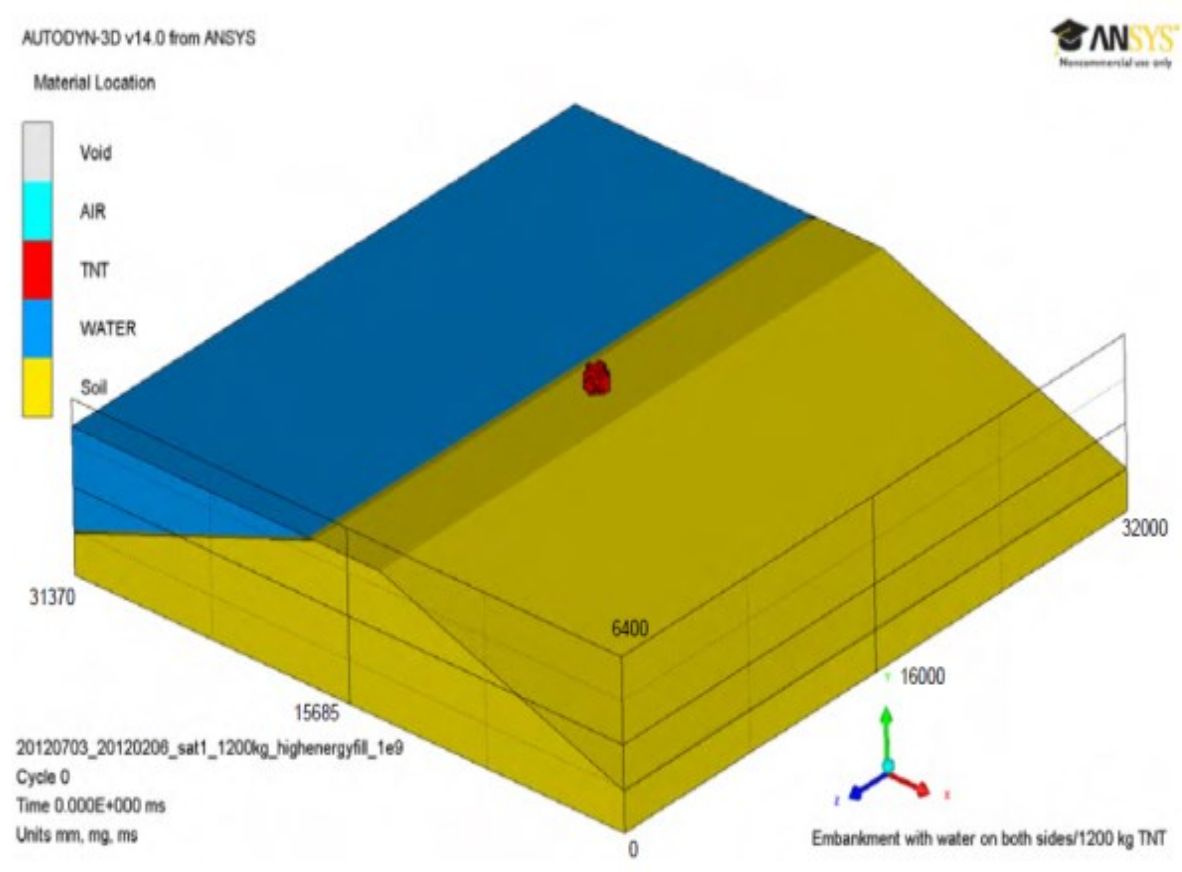

Figure 2-23: 3D Model of Embankment Dam (De at al., 2013)

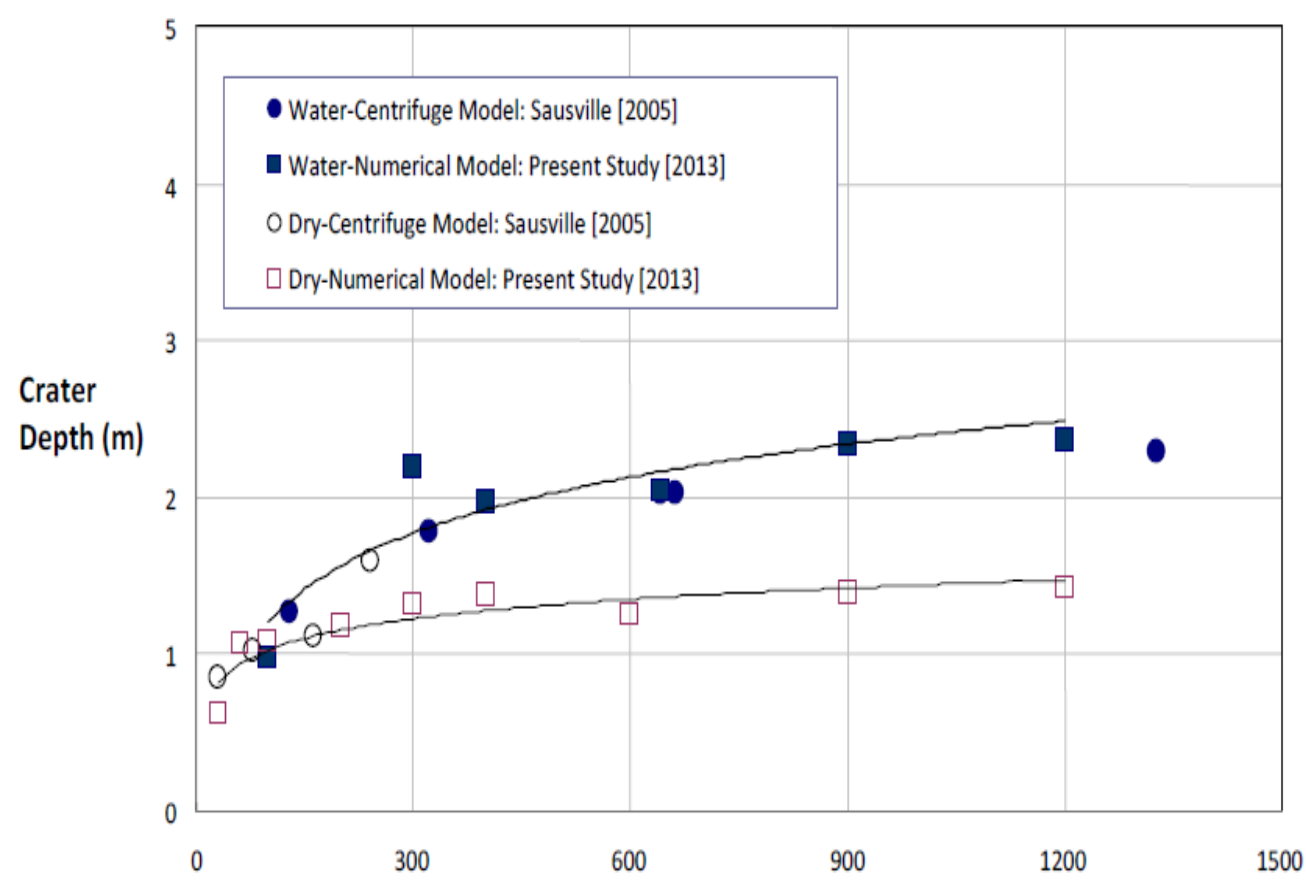

Figure 2-24: Crater Depth against Explosive Size (De et al., 2013) 


\subsection{Summary}

The information available in the unclassified literature showed that the crater dimensions are influenced by amount and type of explosives. The crater formation in soil is affected by properties such as dry unit weight, degree of saturation, relative density and air void volume. Most of the information available on explosions in soil has considered the explosion on flat ground, and information on the explosion effects on embankments is limited. Crater diameters formed on embankment dams in the perpendicular direction without adjacent confining soil are $50 \%$ larger than that on a flat ground. Numerical and analytical tools such as AUTODYN and LS-DYNA have been used in predicting crater dimensions in soil. In unclassified literature, previous numerical modelling done on an embankment dam was done using AUTODYN. For LS-DYNA, a review of numerical simulations undertaken with LS-DYNA showed that not all material models required an EOS in order to predict a blast simulation. Research that have been conducted both numerically and using field testing on blast effects on embankment dams have not

considered the effect of slopes on crater dimensions, the effects of pore water pressure and the effects of the explosive location.

The lack of information in literature informed the objectives of this thesis which is once again listed below;

- The investigation of the effects of blast loads on embankment dams

- The investigation of crater size and its effect on dam failure

- The study of the impact of pore water pressure on the performance of dams under explosion 


\section{Chapter: Numerical Simulation of Blast Load Effects on Embankment Dam}

\subsection{Introduction}

In investigating the effects of explosion on embankment dams, LS-DYNA was used for the numerical study. LS-DYNA was selected among other computer software due to its rich source of materials to model the soil and also the ease with which pore water pressure can be modelled. A 3D numerical model was developed to model the effects of blast loads on embankment dams. The numerical modelling and analysis was done by using LS-DYNA. The numerical model comprises of air, explosive and soil (embankment material.). The numerical model was validated against field testing carried out by Li et al. (2007) on a dry embankment. Further verification was carried out by comparing the LSDYNA model with ConWEp which is a collection of conventional weapons effects calculation based on equations from TM 5-855-1. This equations are the plots shown in Figure 2-8.

\subsection{LS-DYNA}

LS-DYNA developed by Livermore Software Technology Corporation (LSTC). LSDYNA is extensively used in various fields of engineering such as mechanical, aerospace as well as civil engineering and has undergone several modifications from when the code was limited to analysing stresses of impact loaded structures (Hallquist, 2006).

LS-DYNA has more than 250 material models and has a table for various materials under various service conditions. The LS-DYNA material model manual (LSTC, 2011) 
indicates there are possibly 8 material models that maybe used in modelling the embankment dams and a single material model each for modelling the explosive and air. The evolution of LS-DYNA has led to the development of various material models covering materials such as soil, plastics, concrete, and metals. LS-DYNA has 2D and 3D capabilities in solving numerical problems and the finite element types available are solid elements, shells, beams and smoothed-particle hydrodynamics (SPH).

The numerical simulation in this thesis was conducted using the solid elements. Solid elements in LS-DYNA are elements that model solid bodies and structures without any priori geometric simplification (LS-DYNA Forum, 2011). Solid elements can be formulated as constant stress solid elements (Lagrangian), Eulerian and Arbitrary Lagrangian-Eulerian (ALE). In 3D simulation, the solid elements are modelled as 8noded solid hexahedron elements having twenty-four degree of freedoms. As compared to the shell and beam elements, applied boundary conditions are treated more realistically with the solid elements. The use of the solid elements also makes the model look like the physical system being modelled. The disadvantages, however, associated with using solid elements include; more effort in mesh preparation, and higher CPU time required for convergence of the results (LS DYNA Forum 2011). There are various types of element formulation available for this finite element type. Amongst these, the constant stress solid element is the most appropriate option for solid element due to its ability to model severe deformations and requires lesser CPU time for convergence (LS-DYNA Forum 2011). 
In modelling blast loads, LS-DYNA has various ways of applying the blast pressures. There are load keywords that apply the blast loads to the segments of the numerical model and also the *MAT_HIGH_EXPLOSIVE_BURN which simulates a realistic way of applying the blast loads. The *MAT_HIGH_EXPLOSIVE_BURN allows for a point of detonation to be selected and also for a time of detonation to be specified.

\subsection{Numerical Modelling of Embankment Dam Model}

LS-DYNA was used to investigate the effects of explosion on embankment dams in this thesis. The LS-DYNA model was validated with results from Li et al. (2007) experimental research works. Li et al. (2007) shaped an embankment dam out of native sandy soils of the test site, while the crest (top) of the embankment was left undisturbed. The model dam, which represents a one-fifth scale of a 10-m (2m) high embankment dam with 3:1 upstream slope and 2.5: 1 downstream slope, was $33 \mathrm{~m}$ long and $2 \mathrm{~m}$ wide at the crest and $13 \mathrm{~m}$ wide at the base as shown in Figure 2-16. Figure 3-1 shows a 3D model of the dam from Li et al. (2007) with the explosive in LS-DYNA. The 3D model of the embankment in LS-DYNA used solid Lagrangian elements.

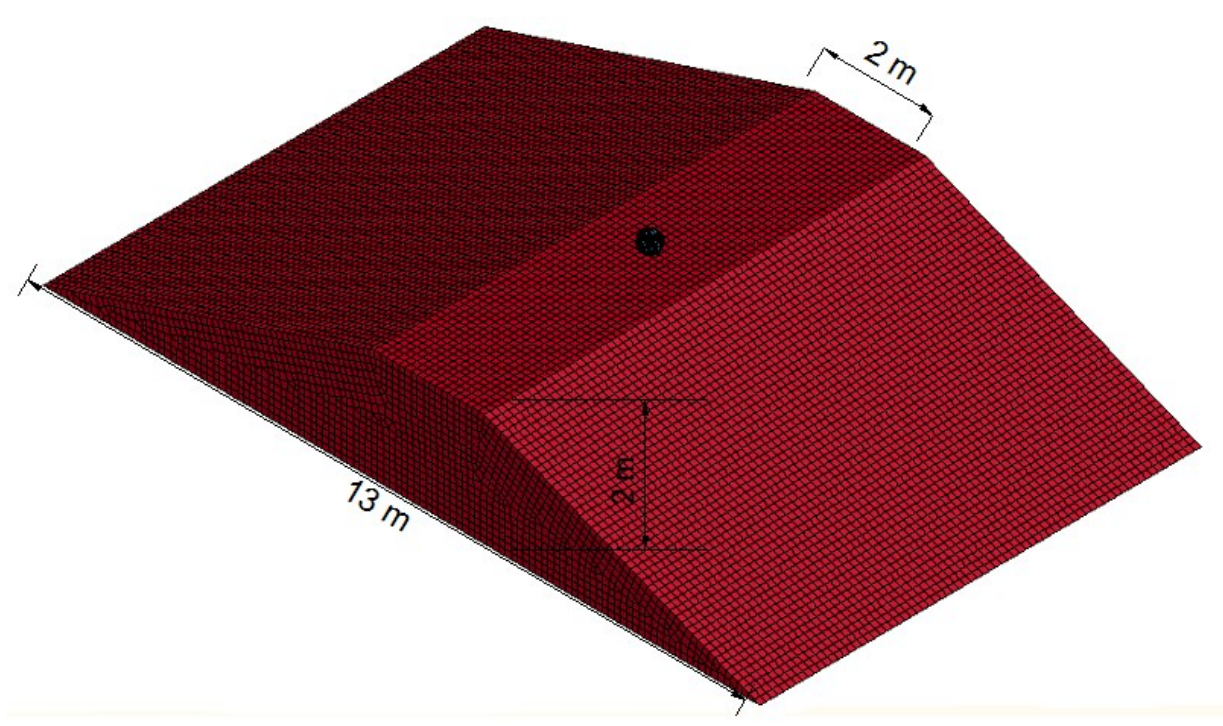

Figure 3-1: Embankment Dam Model 


\subsubsection{Explosive Model}

The explosive was modelled as solid elements with ALE formulation. In modelling the explosive, the keyword that is used was the *HIGH_EXPLOSIVE_BURN with the JoneWilkins-Lee Equation of State (EOS). The explosive charge masses used in the experiments were $25 \mathrm{~kg}, 50 \mathrm{~kg}$ and $100 \mathrm{~kg}$ of Ammonium Nitrate Fuel Oil (ANFO). However, for the numerical simulation, TNT was used by applying the TNT-equivalence of ANFO of 0.83 to give TNT mass for the numerical simulation. The material properties of the explosive used in the model as required by the *HIGH_EXPLOSIVE_BURN keyword card are presented in Table 3-1;

Table 3-1: Material Model Input for TNT

\begin{tabular}{|c|c|c|}
\hline $\begin{array}{c}\text { Density } \\
\mathrm{kg} / \mathrm{m}^{3}\end{array}$ & $\begin{array}{c}\text { Detonation Velocity } \\
\mathrm{m} / \mathrm{s}\end{array}$ & $\begin{array}{c}\text { Chapman-Jouget pressure } \\
\mathrm{Pa}\end{array}$ \\
\hline 1630 & 6930 & $2.1 \mathrm{e}+010$ \\
\hline
\end{tabular}

The JWL EOS relates the pressure to the relative volume and initial energy per volume of the detonation products as shown in Equation [3-1]. The parameters for the JWL EOS are defined in LS DYNA and their inputs for TNT are shown in Table 3-2;

$$
p=A\left(1-\frac{\omega}{R_{1} V}\right) e^{-R_{1} V}+B\left(1-\frac{\omega}{R_{2} V}\right) e^{-R_{1} V}+\frac{\omega E}{V}
$$

Where $\mathrm{p}$ is the pressure, $\mathrm{V}$ is the relative volume with $\mathrm{A}, \mathrm{B}, \mathrm{R}_{1}, \mathrm{R}_{2}$ and $\omega$ are constants pertaining to a given explosive.

Table 3-2: EOS inputs for TNT

\begin{tabular}{|c|c|c|c|c|c|c|}
\hline $\mathrm{A}$ & $\mathrm{B}$ & $\mathrm{R}_{1}$ & $\mathrm{R}_{2}$ & $\Omega$ & $\mathrm{E}_{\mathrm{o}}$ & $\mathrm{V}_{\mathrm{o}}$ \\
\hline $3.712 \mathrm{e}+011$ & $3.231 \mathrm{e}+009$ & 4.15 & 0.95 & 0.35 & $6 \mathrm{e}+009$ & 1 \\
\hline
\end{tabular}




\subsubsection{Air Model}

Air was modelled with ALE formulation to engulf the model embankment dam and the space above the dam to allow for blast wave propagation. The keyword used to achieve this was *MAT_NULL_MATERIAL with *EOS_LINEAR_POLYNOMIAL equation of state. The *EOS_LINEAR_POLYNIMIAL is expressed mathematically in Equation [3$2]$.

$$
P=C_{o}+C_{1} \mu+C_{2} \mu^{2}+C_{3} \mu^{3}+\left(C_{4}+C_{5} \mu+C_{6} \mu^{2}\right) E
$$

Where $P$ is the pressure, $E$ is the energy, $C_{o}, C_{1}, C_{2}, C_{3}, C_{4}, C_{5}, C_{6}$ and $\mu$ are constants. The constant $\mu$ is expressed as $\frac{\rho}{\rho_{0}}-1$, where $\rho$ is the current density of the air material and $\rho_{o}$ is the reference density of the air material which is listed as part of input materials for the air material model. The input parameters for air are shown in Table 3-3;

Table 3-3: Input Parameters for Air

\begin{tabular}{|c|c|c|c|c|c|c|c|c|c|}
\hline $\begin{array}{l}\text { Density } \\
\mathrm{Kg} / \mathrm{m}^{3}\end{array}$ & $\mathrm{C}_{0}$ & $\mathrm{C}_{1}$ & $\mathrm{C}_{2}$ & $\mathrm{C}_{3}$ & $\mathrm{C}_{4}$ & $\mathrm{C}_{5}$ & $\mathrm{C}_{6}$ & $\mathrm{E}_{0}$ & $\mathrm{~V}_{0}$ \\
\hline 1.29 & 0 & 0 & 0 & 0 & 0.4 & 0.4 & 0 & $2.5 \mathrm{E}+5$ & 1 \\
\hline
\end{tabular}

\subsubsection{Embankment Dam Model}

The material for the embankment was modelled with six different material models and the results compared with the experimental results to select the most suitable material model. Table 3-4 shows the material models investigated and their capabilities from the material models manual (LSTC, 2011). 
Table 3-4: Selected soil material models in LS DYNA (LS DYNA Manual, 2011)

\begin{tabular}{|l|l|}
\hline LS DYNA Material Model & \multicolumn{1}{c|}{ Capabilities } \\
\hline *MAT_SOIL_AND_FOAM & $\begin{array}{l}\text { Used when soil is confined within a structure or there } \\
\text { are geometric boundaries present. }\end{array}$ \\
\hline *MAT_PSEUDO_TENSOR & $\begin{array}{l}\text { Used for soils however the user manual points out it } \\
\text { have been previously been used for buried reinforced } \\
\text { concrete structures subjected to impulsive loadings. }\end{array}$ \\
\hline *MAT_FHWA_SOIL & It is an isotropic material used generally for soil. \\
\hline *MAT_MOHR_COULOMB & It is used generally for soil. \\
\hline *MAT_SOIL_BRICK & It is used for over-consolidated clay. \\
\hline *MAT_DRUCKER_PRAGER & It is used generally for soil. \\
\hline
\end{tabular}

In selecting a suitable mesh size for the embankment dam, the method of trial and error was used to refine the mesh in order to achieve results within reasonable limits of the experimental test results. Other criteria for selecting the appropriate mesh size included runtime as well as the storage space. The analysis was done using the Mohr Coulomb material model. Three mesh sizes were investigated for the $50 \mathrm{~kg}$ ANFO charge mass as was used in the field testing. The mesh sizes were $120 \mathrm{~mm}, 110 \mathrm{~mm}$ and $90 \mathrm{~mm}$. Table 35 shows the crater dimensions, run time as well as disk storage requirements for the selected mesh sizes;

Table 3-5: Mesh Sensitivity Analysis for $50 \mathrm{~kg}$ Charge

\begin{tabular}{|c|c|c|c|c|c|c|c|c|}
\hline \multirow{2}{*}{$\begin{array}{l}\text { Mesh } \\
\text { Sizes } \\
(\mathrm{mm}) \\
\end{array}$} & \multicolumn{3}{|c|}{$\begin{array}{l}\text { Numerical Crater } \\
\text { Dimension }(\mathrm{mm})\end{array}$} & \multicolumn{3}{|c|}{$\begin{array}{c}\text { Experimental Crater } \\
\text { Dimension }(\mathrm{mm})\end{array}$} & \multirow{2}{*}{$\begin{array}{c}\text { Run } \\
\text { time } \\
\text { (hrs) } \\
\end{array}$} & \multirow{2}{*}{$\begin{array}{c}\text { Hard disk } \\
\text { Storage } \\
\text { (kb) }\end{array}$} \\
\hline & 1_1 & 3_3 & Depth & 1_1 & 3_3 & Depth & & \\
\hline 120 & 1939 & 2616 & 200 & \multirow{3}{*}{2260} & \multirow{3}{*}{3390} & \multirow{3}{*}{370} & 32 & $8.05 \mathrm{e}+6$ \\
\hline 110 & 2370 & 2940 & 360 & & & & 50 & $9.44 e+6$ \\
\hline 90 & 2303 & 3050 & 370 & & & & 100 & $31.00 \mathrm{e}+6$ \\
\hline
\end{tabular}


From Table 3-5 the element size that predicted the crater dimensions most accurately, from the three that were tested, was the $90 \mathrm{~mm}$ size while the $120 \mathrm{~mm}$ size least predicted the crater dimensions. Hence the $90 \mathrm{~mm}$ and $110 \mathrm{~mm}$ were the two mesh sizes suitable for predicting the crater dimensions. The values for the $90 \mathrm{~mm}$ mesh size was more accurate comparing to the experimental crater dimensions, however the run time as well as the CPU storage were two-times and three-times, respectively, of that required for the $110 \mathrm{~mm}$. Thus, the efficient mesh size considering the run time and CPU storage for the embankment dam was $110 \mathrm{~mm}$ and this was used for the other charge masses of $25 \mathrm{~kg}$ and $100 \mathrm{~kg}$ of ANFO. The selected mesh size was then used to investigate the possible material models from Table 3-4, the $50 \mathrm{~kg}$ ANFO was used for the investigation.

The embankment was modelled as Lagrangian solid elements. Table 3-6 show a summary of the analysis results of four of the six material models investigated for $50 \mathrm{~kg}$ ANFO explosion. Only two of the material models: *MAT_PSEUDO_TENSOR and *MAT_COULOMB, were able to simulate explosive craters on the embankment. These two materials were further investigated for the $25 \mathrm{~kg}$ and $100 \mathrm{~kg}$ charge masses.

*MAT_MOHR_COULOMB has a Mohr Coulomb yield surface which is given by Equation [3-3];

$$
\tau_{\max }=c+\sigma_{n} \tan \phi
$$

where $\tau_{\max }$ is the maximum shear on a given failure plane, $\sigma_{\mathrm{n}}$ is normal stress on the plane, $\mathrm{C}$ is the cohesion and $\phi$ is the friction angle. The failure criterion is represented in Figure 3-2, which can also be expressed in terms of effective parameters. The Mohr failure envelope is a curved line approximated to a linear relationship (Pervizpour, 2004). 
In granular soils the cohesion value is often zero. *MAT_MOHR_COULOMB is an elasto-plastic material requiring material properties presented in the keyword listed in Table 3-7 for analysis. This material model requires basic inputs as shown in Table 3-7 to execute a simulation. The model was developed to mainly model sand and gravel (LS DYNA Material Manual, 2011). One key advantage of this material model is the ability to simulate anisotropy in the $\mathrm{x}, \mathrm{y}$ and $\mathrm{z}$ directions.

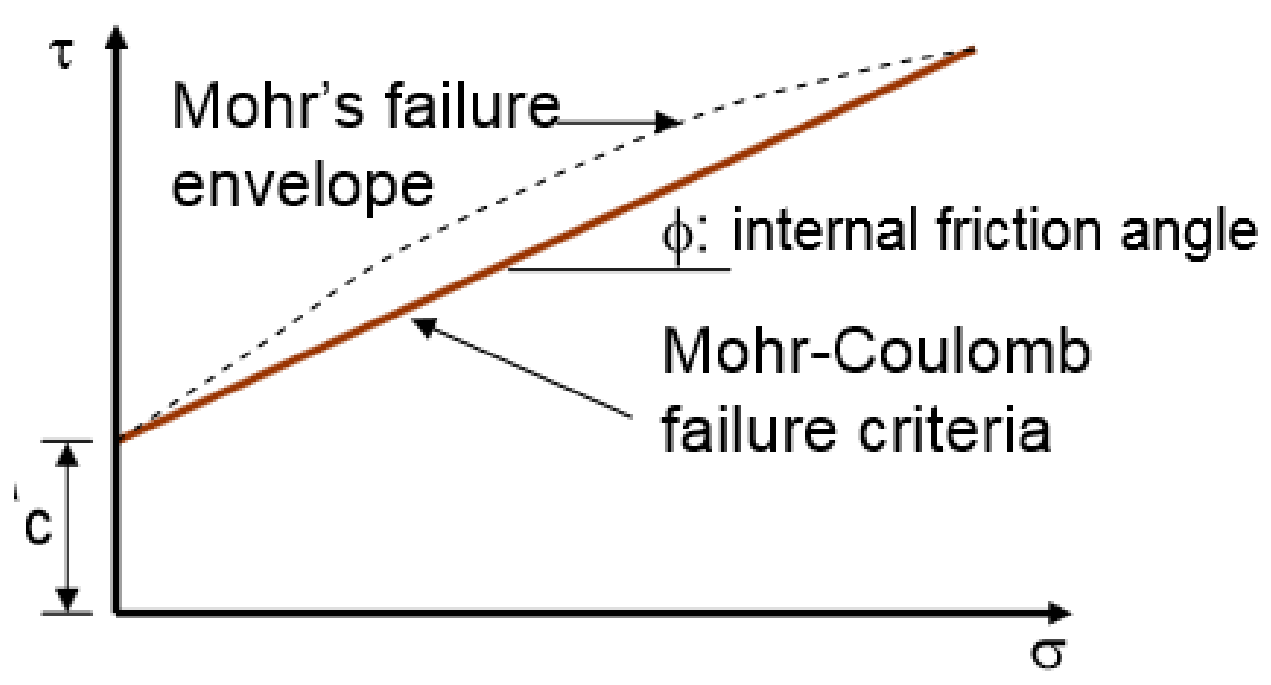

Figure 3-2 Mohr-Coulomb Failure Criterion (Pervizpour, 2004)

*MAT_PSEUDO_TENSOR is considered as a suitable material for modelling soil in LSDYNA (LS DYNA manual). This model requires basic soil information such as density, shear modulus and Poissons ratio. An EOS is also required for this material model. In the simplest form of the numerical model, a tabular pressure-dependent yield surface is used for the soil simulation. Figure 3-3 shows the failure criterion for the *MAT_PSEUDO_TENSOR. The failure characterized by the Tresca limit is also defined on Figure 3-3. 


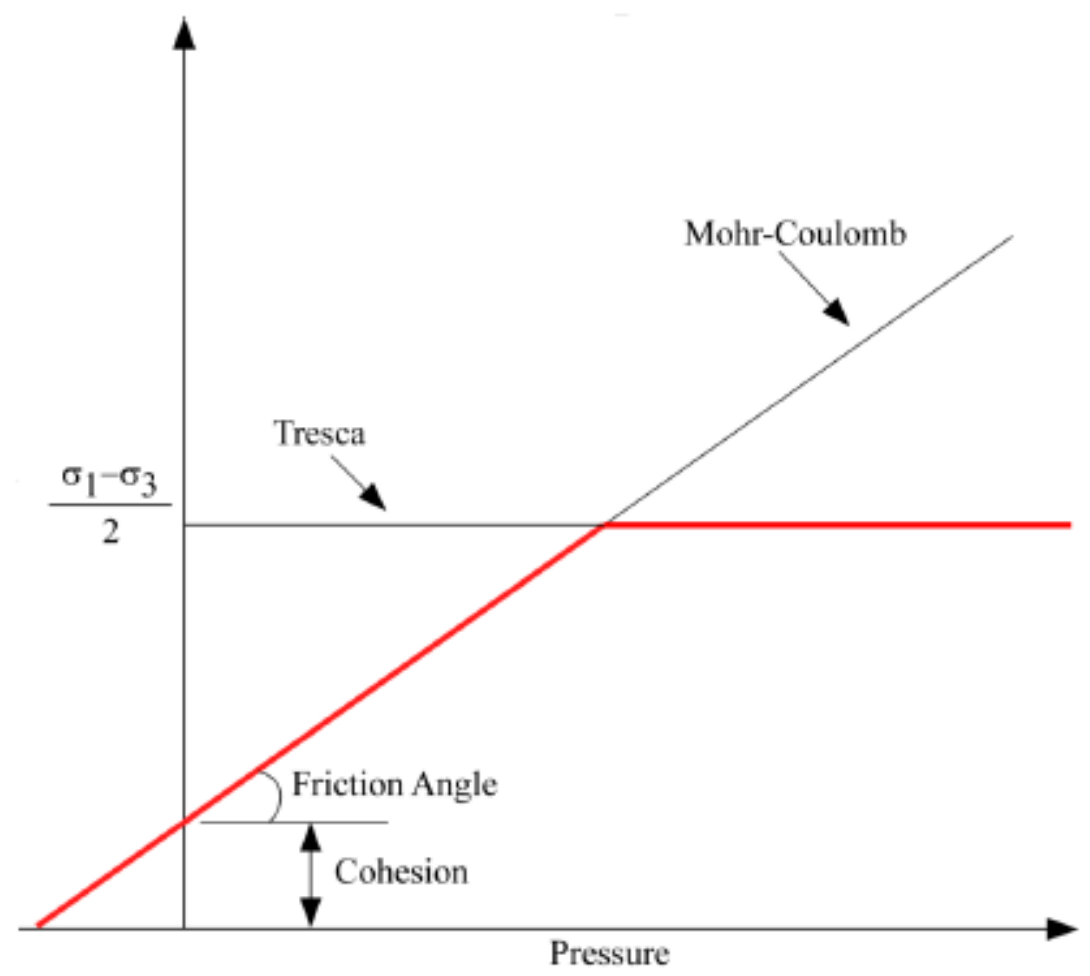

Figure 3-3 Failure Criterion Pseudo Tensor (LS-DYNA Material Manual 2011)

The Pseudo Tensor model has also been used with EOS type 9 in LS-DYNA to model ground shocks and soil structures up to $10 \mathrm{GPa}$ (LS-DYNAMaterial Manual, 2011). Details on input parameters of the material model as well as EOS are shown in the Appendix.

Figures 3-4, 3-5 and 3-6 show the comparison of the Pseudo Tensor and Mohr Coulomb for the parallel, and perpendicular diameters and depth respectively. Between the two materials, *MAT_MOHR_COULOMB provided better prediction of the crater dimensions in the experimental test. Hence Mohr Coulomb was selected as the material model for the embankment. 
Table 3-6: Crater Dimension for Suitable Material Models

\begin{tabular}{|l|c|c|c|}
\hline \multirow{2}{*}{ Material Model } & \multicolumn{3}{|c|}{ Crater Dimensions (mm) } \\
\cline { 2 - 4 } & $\begin{array}{c}\text { Parallel } \\
\text { Diameter }\end{array}$ & $\begin{array}{c}\text { Perpendicular } \\
\text { Diameter }\end{array}$ & Depth \\
\hline *MAT_PSEUDO_TENSOR & 1330 & 2150 & 90 \\
\hline *MAT_DRUCKER_PRAGER & $\mathrm{n} / \mathrm{a}$ & $\mathrm{n} / \mathrm{a}$ & $\mathrm{n} / \mathrm{a}$ \\
\hline *MAT_FHWA_SOIL & $\mathrm{n} / \mathrm{a}$ & $\mathrm{n} / \mathrm{a}$ & $\mathrm{n} / \mathrm{a}$ \\
\hline *MAT_MOHR_COULOMB & 2370 & 2940 & 360 \\
\hline Experimental Results & $\mathbf{2 2 6 0}$ & $\mathbf{3 3 9 0}$ & $\mathbf{3 7 0}$ \\
\hline
\end{tabular}

Table 3-7: Input Parameters for Soil

\begin{tabular}{|c|c|c|c|c|c|}
\hline MID & $\begin{array}{c}\text { Density } \\
\mathrm{kg} / \mathrm{m}^{3}\end{array}$ & $\begin{array}{c}\text { Shear Modulus } \\
\mathrm{Pa}\end{array}$ & Poisson's Ratio & $\begin{array}{c}\text { Friction Angle } \\
\mathrm{rad}\end{array}$ & $\begin{array}{c}\text { Cohesion } \\
\mathrm{Pa}\end{array}$ \\
\hline 1 & 1440 & $2.18 \mathrm{e}+5$ & 0.35 & 0.5236 & 0 \\
\hline
\end{tabular}

\section{Parallel to Dam Axis (1-1)}

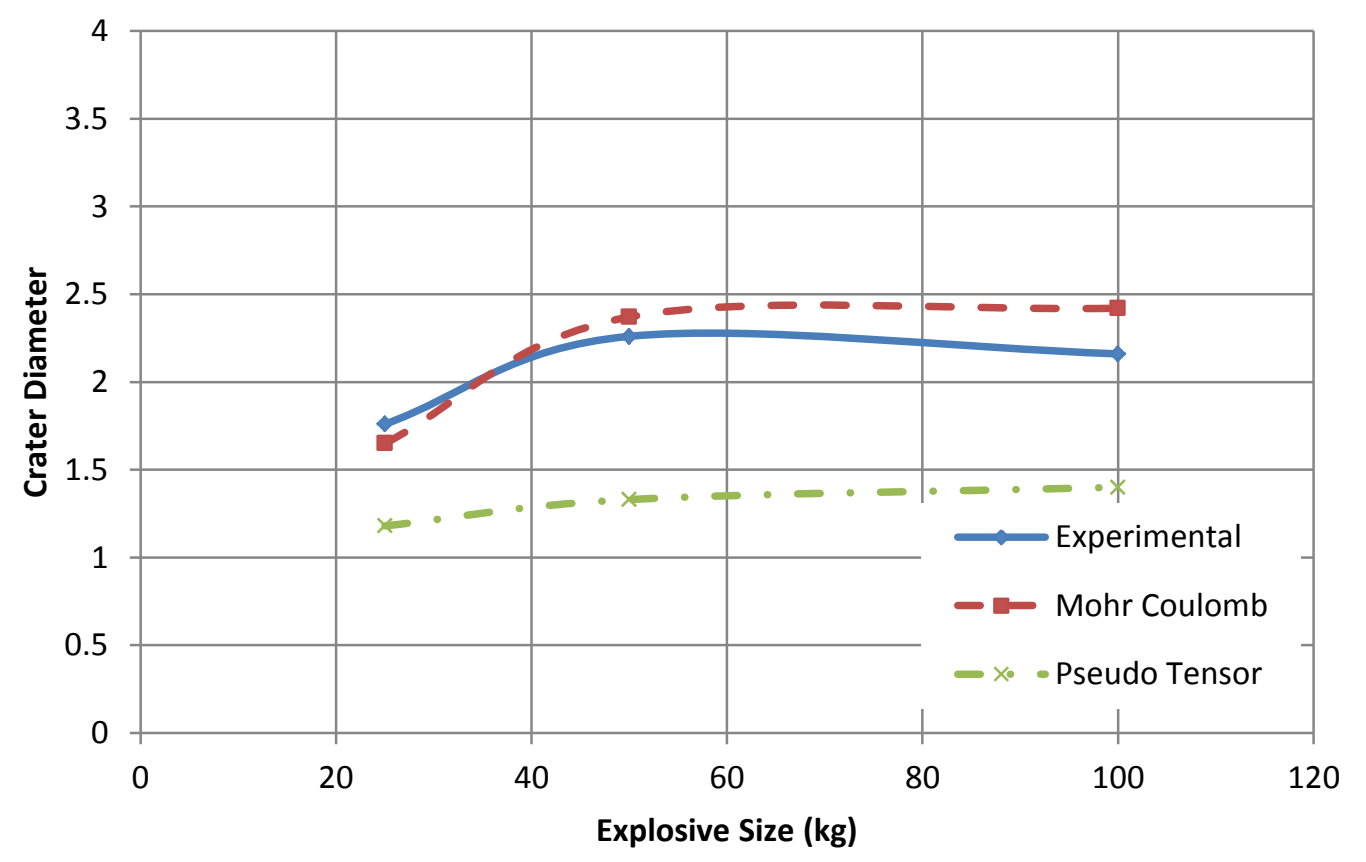

Figure 3-4 Comparison of Mohr Coulomb and Pseudo Tensor with Exnerimental Results 


\section{Perpendicular to Dam Axis (3-3)}

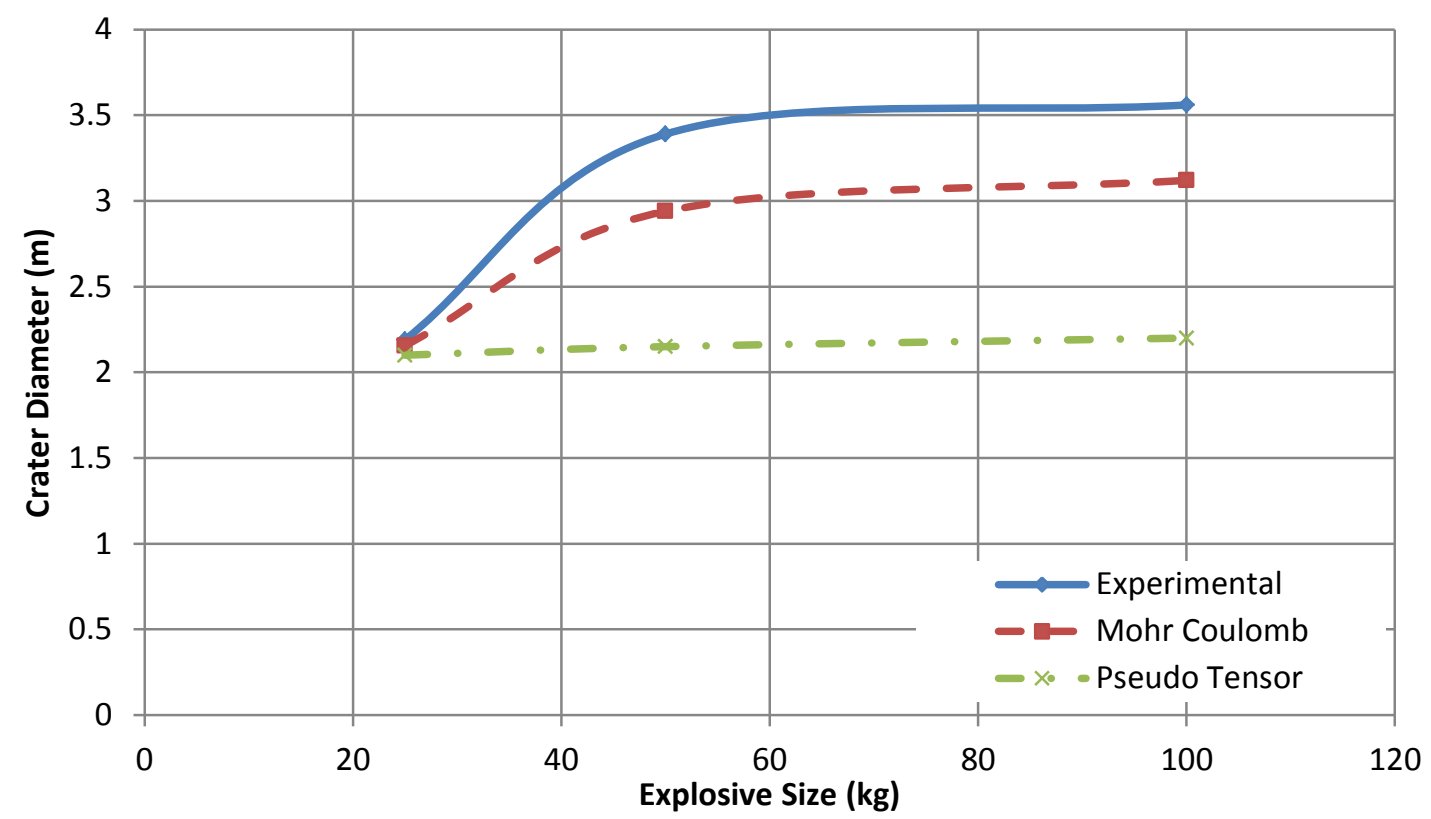

Figure 3-5 Comparison of Mohr Coulomb and Pseudo Tensor with Experimental Results

Crater Depth against Explosive Size

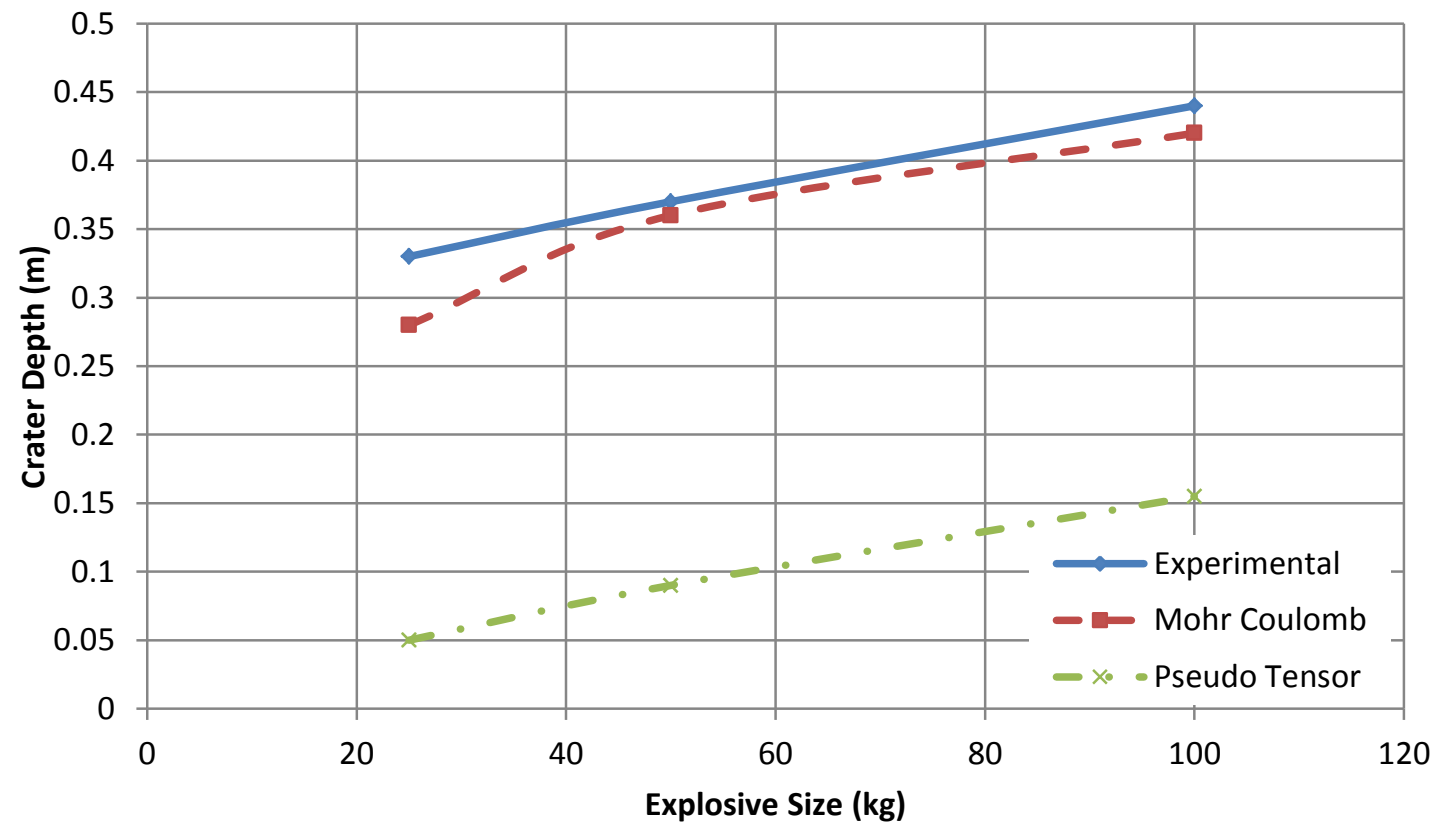

Figure 3-6 Comparison of Mohr Coulomb and Pseudo Tensor with Experimental Results 


\subsection{Contact Modelling}

In modelling contact surfaces in LS DYNA, there are over 50 listed contact choices available for use. Contact modelling is an integral part of finite element analysis as it defines how stresses or deformations are transferred from one body to the other. The contact list in LS-DYNA shows there are some which are applicable to specific scenarios (eg. Airbag analysis) and some for general use.

For this numerical investigation, the contact was defined for the explosive to embankment dam surfaces and explosive to air surfaces. To select the most appropriate contact type, three of these contacts were investigated including: *CONTACT_AUTOMATIC_NODES_TO_SURFACE, *CONTACT_CONTSRAINT_SURFACE_TO_SURFACE and *CONTACT_NODES_TO_SURFACE.

Among these three contacts used, *CONTACT_CONSTRAINT_NODES_TO_SUTFACE was selected and used for the numerical modelling. This was because this contact formulation was the only one among the three that showed the propagation of the blast waves from the explosive into the air and soil. Hence the use of the ${ }^{*}$ CONTACT_CONSTRAINT_NODES_TO_SUTFACE produced a crater, and the other two did not show any visible crater. Figure 3-7 shows the propagation of the shockwave through the embankment dam after detonation of the charge mass with the *CONTACT_CONSTRAINT_NODES_TO_SURFACE formulation. 


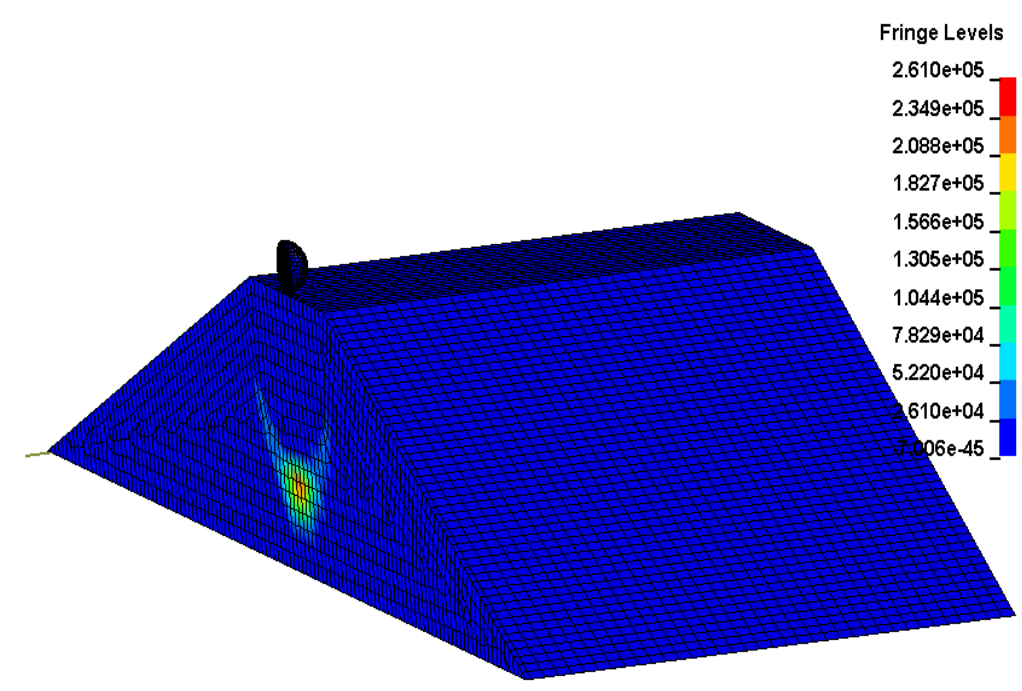

7

Figure 3-7: Propagation of Shockwave through the embankment dam

\subsection{Boundary Conditions}

To simulate the experimental work, appropriate boundary conditions were selected to represent the field condition. The selection of the boundary condition is imperative to ensure that the results for the numerical simulation are accurate. The boundary of the air and embankment models were restrained in the $\mathrm{X}, \mathrm{Y}$ and $\mathrm{Z}$ directions. This is because in the field test site the embankment was made up of infinite continuous soil which prevents the constructed embankment from undergoing translational movement, hence this was the rationale behind fixing the outer boundaries of the numerical model.

Blast waves reflect on surfaces and the resulting reflected pressure reduces the transmitted pressure that is applied to the soil. To curb this phenomenon, non-reflecting boundary conditions were applied to the external faces of the embankment dam and the 
air models to prevent the reflection of the blast waves at the outer boundaries of the numerical model.

\subsection{Model Verification}

To verify the model, a comparison was made with experimental program from $\mathrm{Li}$ et al. (2007) for the $25 \mathrm{~kg}, 50 \mathrm{~kg}$ and $100 \mathrm{~kg}$ ANFO charges. The propagation of the shockwave through the embankment leads to the formation of a crater. The dimension of the crater is measured by taking a cross-section through the dam at the crater location depending on the diameter required (perpendicular or parallel to the axis of the dam). Figure 3-8 shows a cross-section taken perpendicular to the axis of the dam to determine the crater dimensions.

Figures 3-9 and 3-10 present comparison of crater diameters in the parallel and perpendicular directions to the axis of the embankment dam respectively. The numerical modelling accurately determined the diameter of the crater for the three explosive charge masses considered; especially in the parallel direction where a difference of about $12 \%$ was observed at the higher charge masses. In the perpendicular direction the crater size was underestimated by the numerical model. The maximum difference in the crater diameter between the experimental and numerical was about $13 \%$. The numerical model also predicted the crater depth accurately. All the charge masses investigated showed a difference between the experimental and numerical of less than $10 \%$, with the exception of the $25 \mathrm{~kg}$ charge mass. The $25 \mathrm{~kg}$ charge mass showed a $24 \%$ difference between the experimental and the numerical. The difference in the prediction of the crater dimensions from the numerical model and those measured from the experimental can be attributed to 
the uncompacted nature of the soil used for the field testing which was just the native soil located at the test site.

Figures 3-11 and 3-12 indicate that the crater diameter increased as the detonation charge mass increased. This is consistent with previous findings reported by Ambrosini et al., (2004); Braimah et al., (2012); and De et al., (2013). Figure 3-13 shows that the crater depths from the numerical model also increased with increasing charge mass. This confirms the capability of LS-DYNA in simulating the behaviour of embankments subjected to explosion effects.

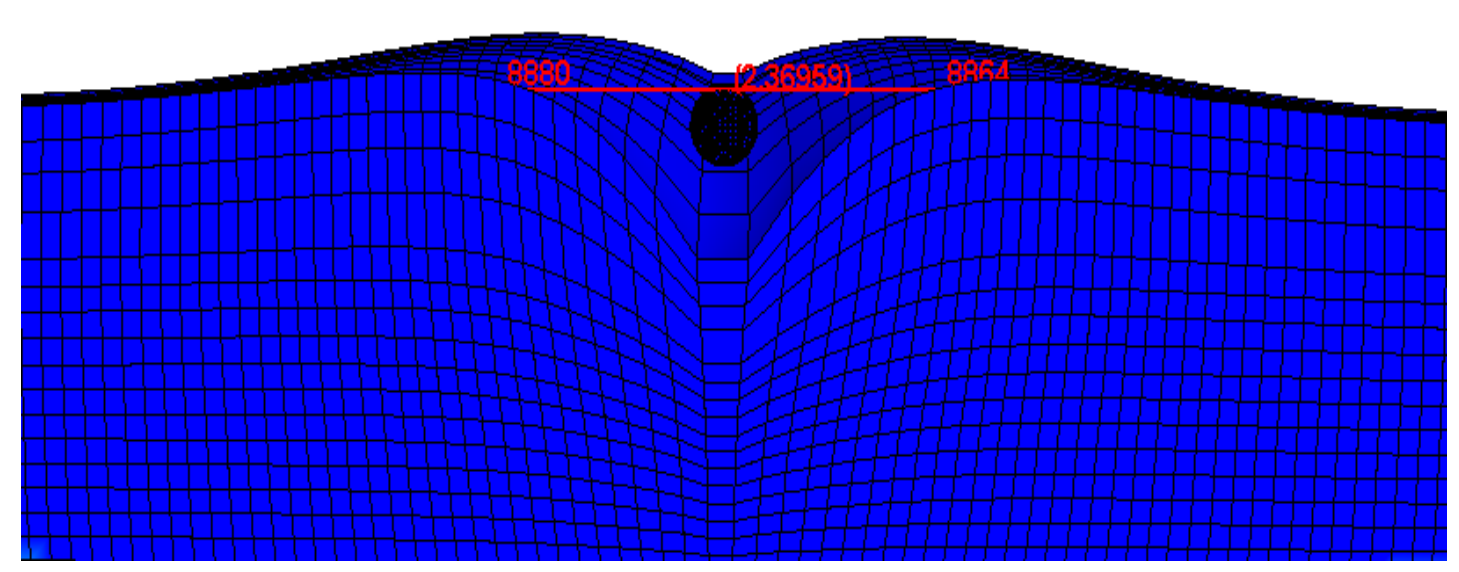

Figure 3-8: Cross-section of crater in numerical model for $50 \mathrm{~kg}$ charge mass 


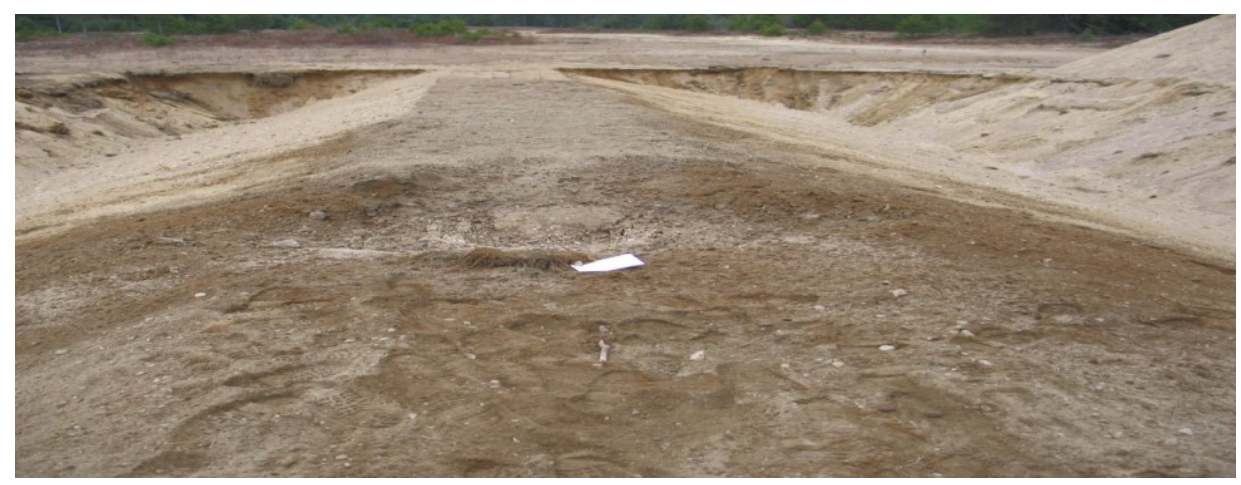

Figure 3-9: Crater formed for Field Experiment (Li et al., 2007)

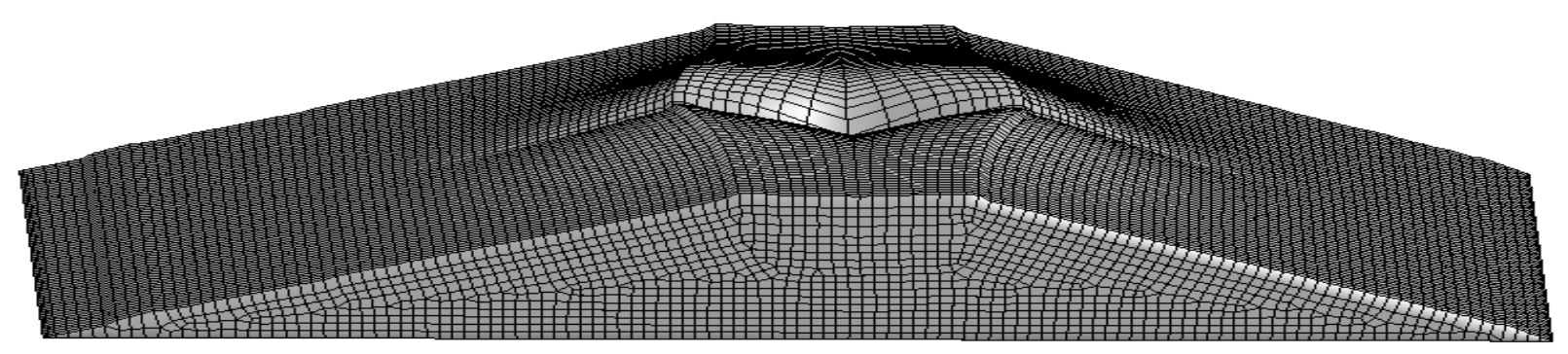

Figure 3-10: Crater formed for numerical modelling

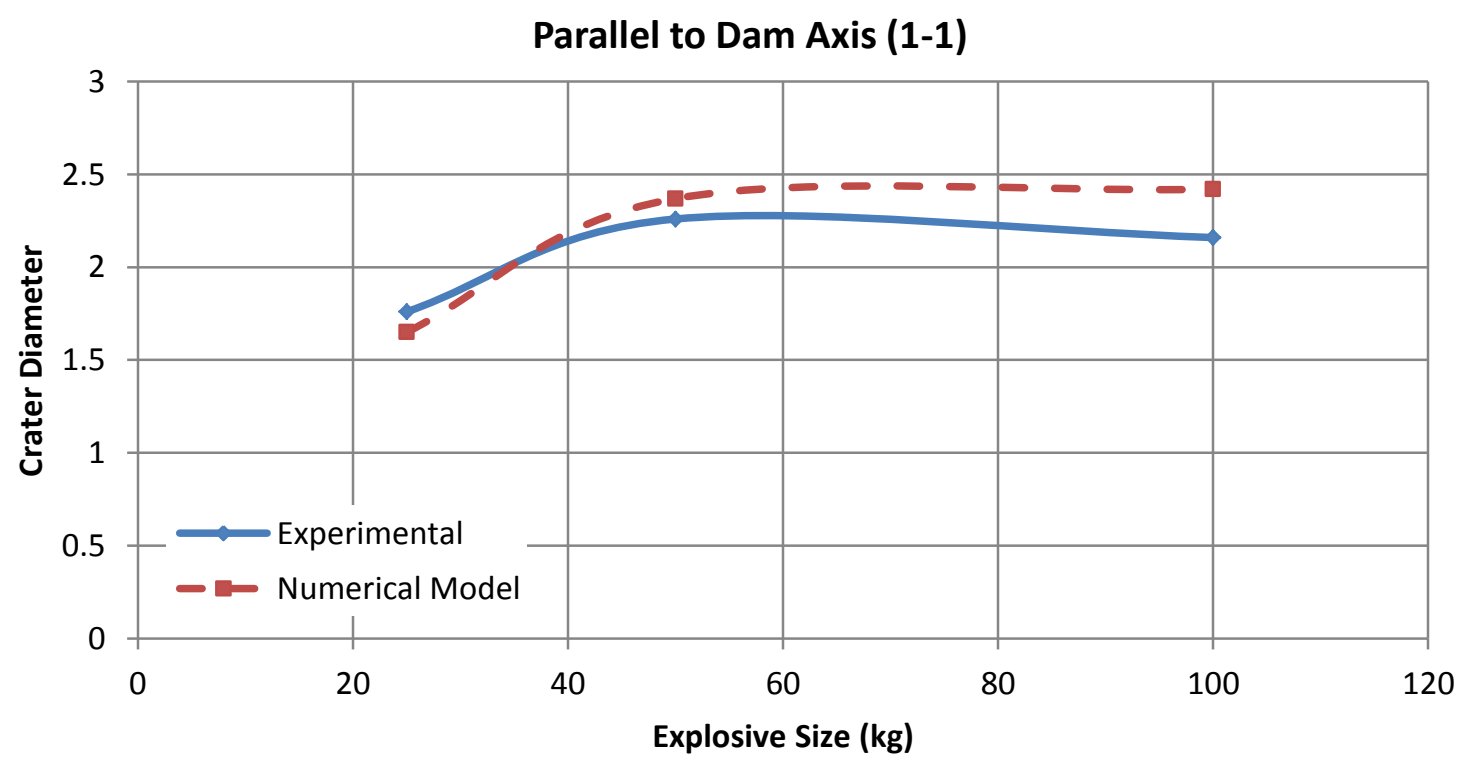

Figure 3-11: Verification of Crater Diameter Parallel to Dam Axis 


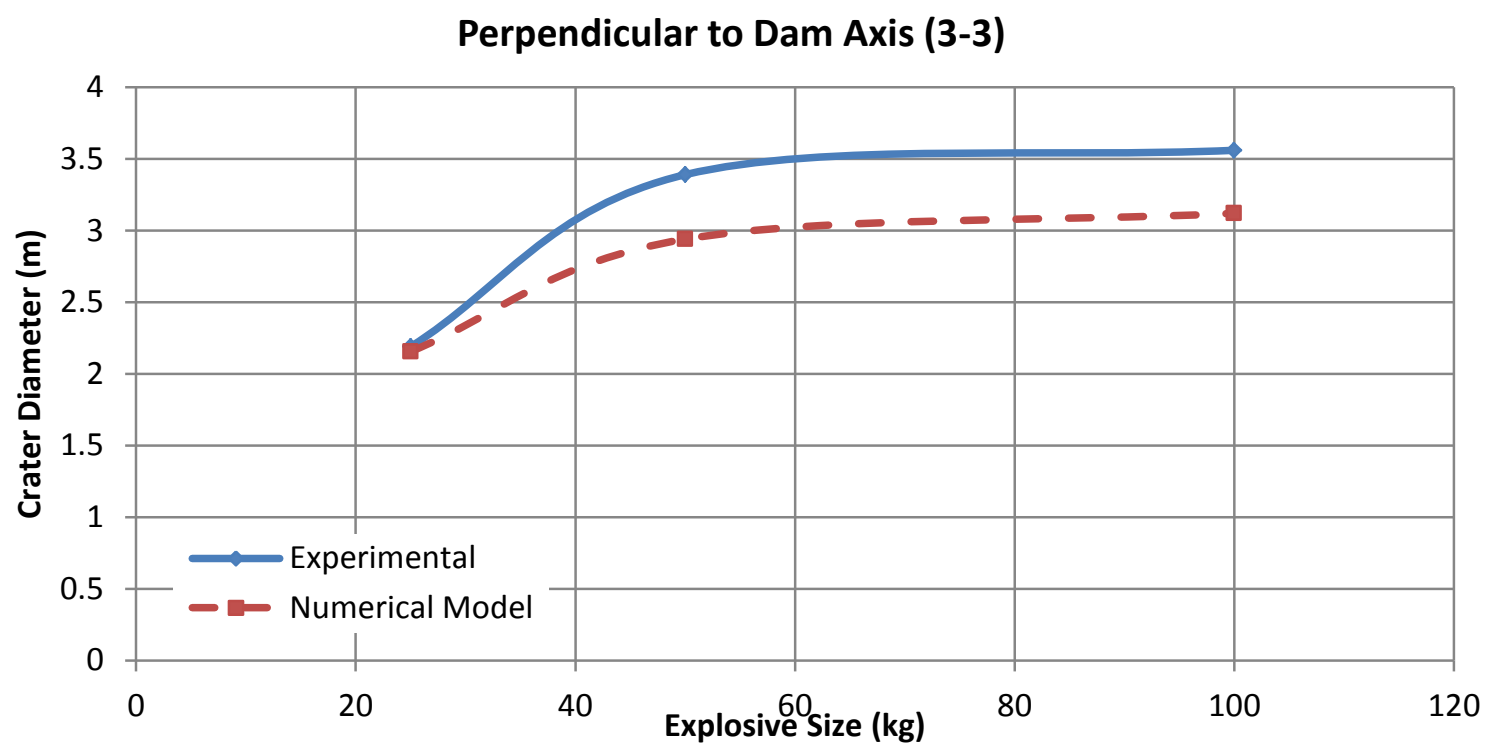

Figure 3-12: Verification of Crater Diameter Perpendicular to Dam Axis

Crater Depth against Explosive Size

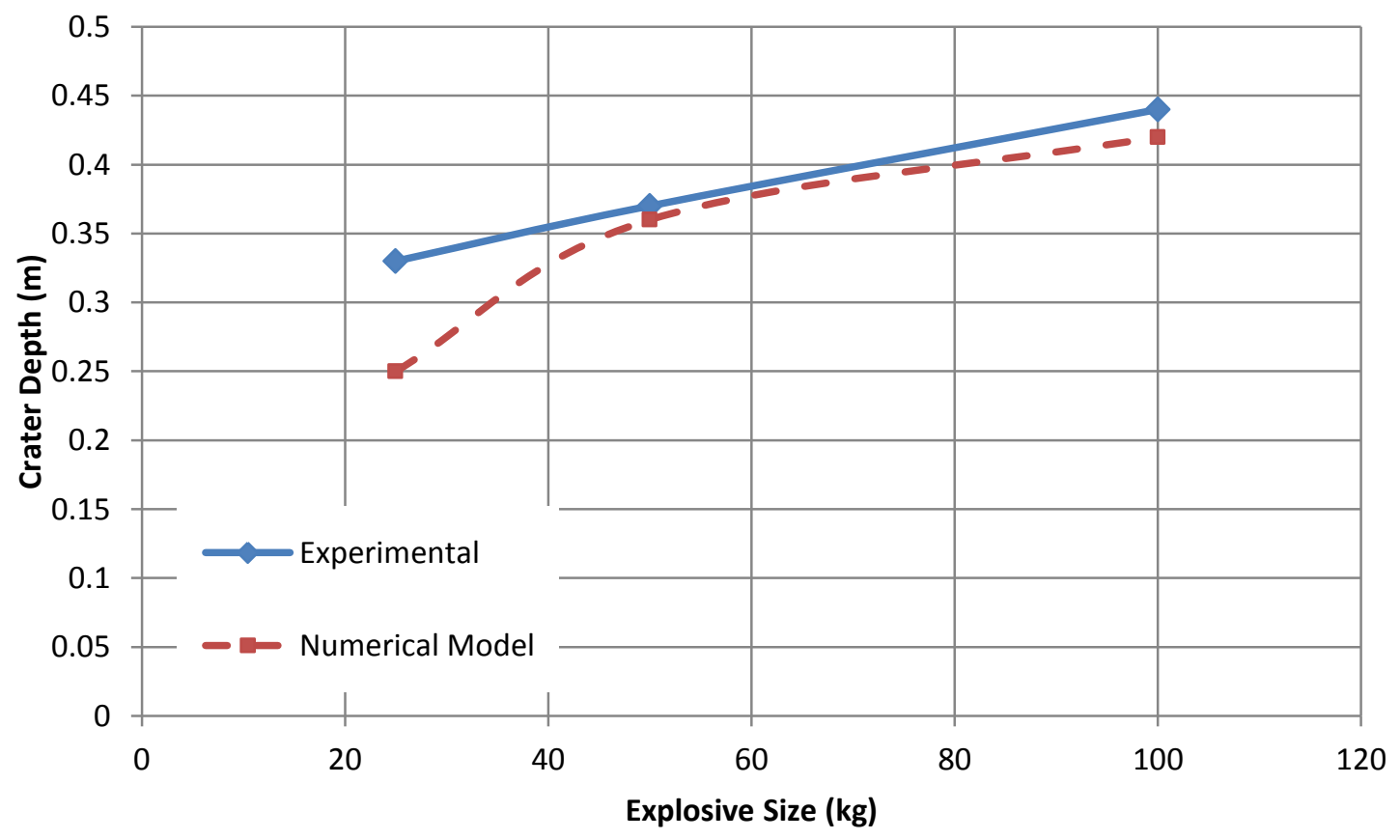

Figure 3-13: Verification of Crater Depth 


\subsection{LS-DYNA Model Comparison with ConWep}

The results of the numerical analysis were also compared with ConWep. ConWep is a computer programme which is a collection of conventional weapons effects calculation based on equations from TM 5-855-1. ConWep can be used in predicting the crater dimensions for 6 categories of soil, namely dry sand, dry sandy clay, wet sand, dry clay, wet sandy clay and wet clay.

Based on the particle size distribution of the soil used by Li et al. (2007), the soil was classified as mostly comprised of sand and gravel. Hence the best soil category which describes soil at the site is dry sand. Figure 3-14 shows the comparison of ConWep crater diameter with that predicted by LS-DYNA which shows that ConWep overestimates the crater diameters as compared to LS-DYNA at all the charge mass tested. In fact while the comparison of the experimental results with LS-DYNA simulation was about $12 \%$, the difference in ConWep and experimental results is significantly more at $71 \%$.

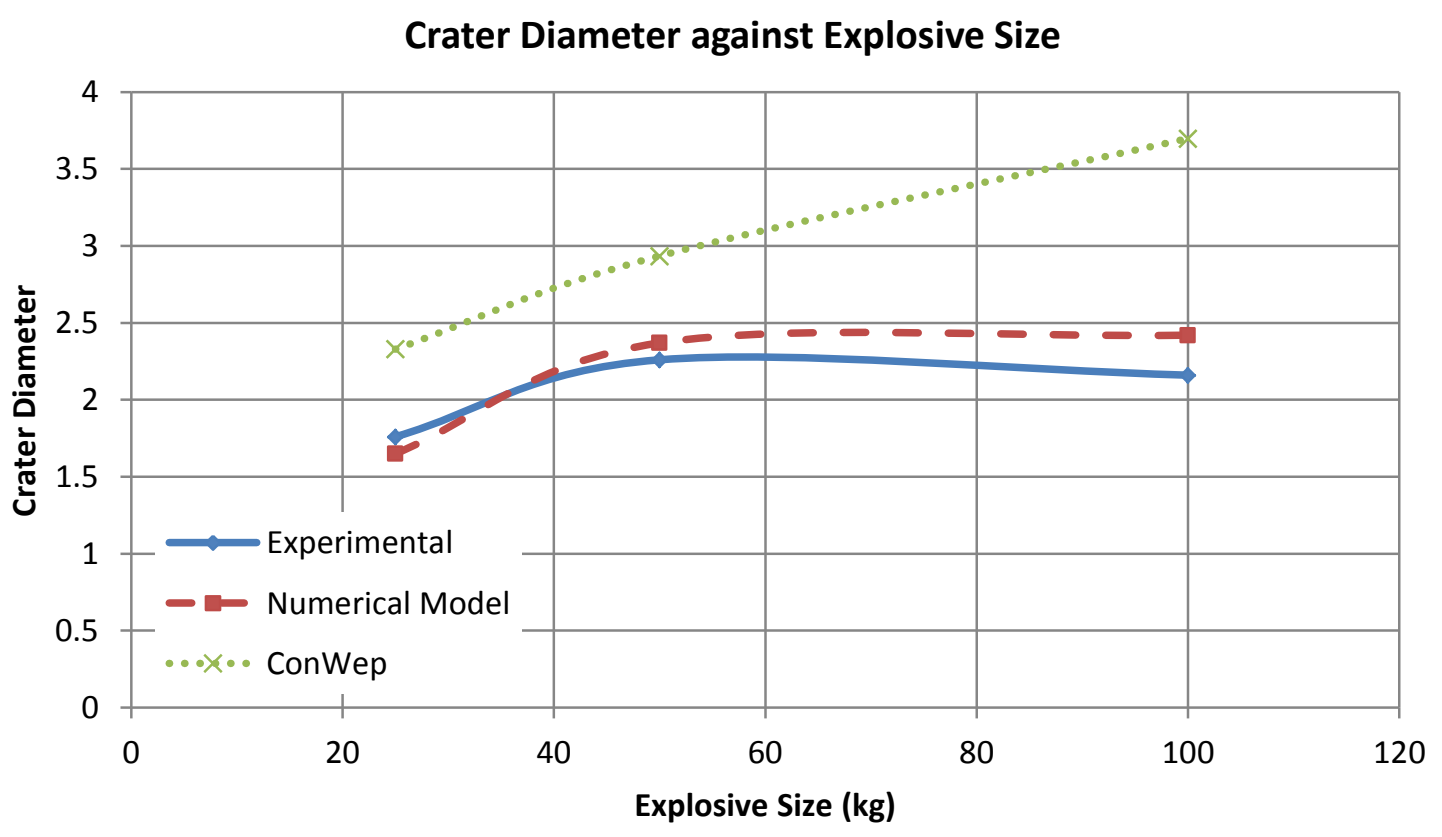

Figure 3-14: Comparison of ConWep and LS-DYNA Crater Diameters 
Figure 3-15 compares the crater depth of ConWep and LS-DYNA and also shows that the crater depth is overestimated by ConWep. The depth predicted by ConWep is almost twice the depth measured in the experimental programme. Although ConWep serves as a quick tool for assessing crater dimensions for various explosive types, it cannot be used in predicting crater sizes for comprehensive engineering works like design of dams.

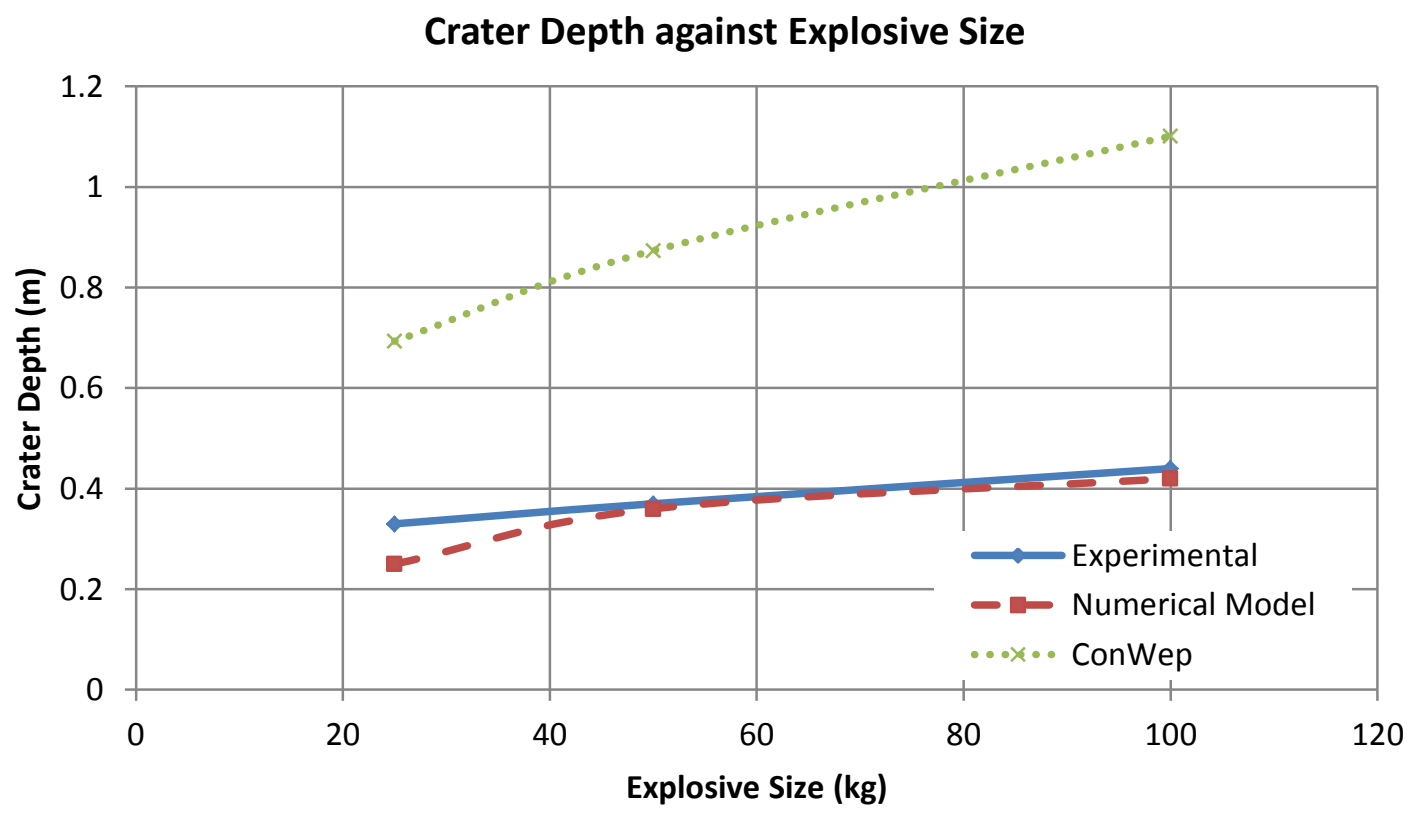

Figure 3-15: Comparison of ConWep and LS-DYNA Crater Depths

\subsection{Summary}

The numerical model that was used for the simulation of embankment dam consisted of the embankment material, explosive and air. All these material models were modelled using information from field testing. LS-DYNA was able to predict the crater dimensions accurately when compared with the field testing. The model accurately predicted the crater diameter to be larger in the direction perpendicular to the dam axis where there was less soil confinement as compared to the parallel direction. The numerical results together 
with field tests results were compared with ConWep. This showed that ConWep overestimates the crater dimensions. For the crater depth, ConWep predicted values that were twice as much as those predicted by the LS-DYNA model and the field test results. 


\subsection{Parametric Study of Explosion on Embankment Dams.}

\subsection{Introduction}

The numerical model was validated and serves as a tool to effectively predict the performance of embankments under explosive loading. The limitation of the experimental investigation is the fact that, there was no reservoir behind the dam and hence the dam structure was not under steady seepage conditions. The parametric study was therefore conducted to investigate the effects of the reservoir on the explosive crater dimensions on the embankment dam.

The steady seepage condition in the embankment dam was modelled by defining the water table (phreatic surface) and partitioning the soil mass into two parts. The part under water was modelled with saturated soil properties while the part above the phreatic surface was modelled with unsaturated soil properties. To incorporate the effects of steady seepage conditions within the embankment in LS-DYNA, the water within the embankment was applied as a boundary condition. In defining the pore water pressure distribution within the embankment, nodes within the embankment dam were selected to separate the saturated region from the unsaturated region after analysis with SEEP/W which is a component of GeoStudio. Figure 4-1 shows a typical GeoStudio simulation to show the position of the phreatic surface on the $2 \mathrm{~m}$ high dam at full reservoir level. This informed the selection of nodes for the phreatic surface for the LS-DYNA model. The analysis type for pore water pressure calculations was considered as undrained analysis. The reservoir upstream as well as water at the toe of the dam were not modelled in order to reduce the simulation time, however, the pressure by virtue of height of water was applied to the surfaces of the embankment in the upstream and downstream. The output 
data that can be retrieved from pore water analysis in LS-DYNA include total pore water pressure head, excess pore water pressure head, hydraulic pore water pressure head and volume change. The pore water pressure analysis in LS-DYNA is independent of the material model. The output that was required for the pore water pressure was specified as excess pore water pressure for the output of the simulation with pore water. In calculating the excess pore water pressure, LS-DYNA estimates the excess pore water pressure by taking into account the volume change that takes place at each node. The parametric study conducted considered the effect of a reservoir height, charge mass, slope angle, density of embankment material and suction (negative positive pressure).

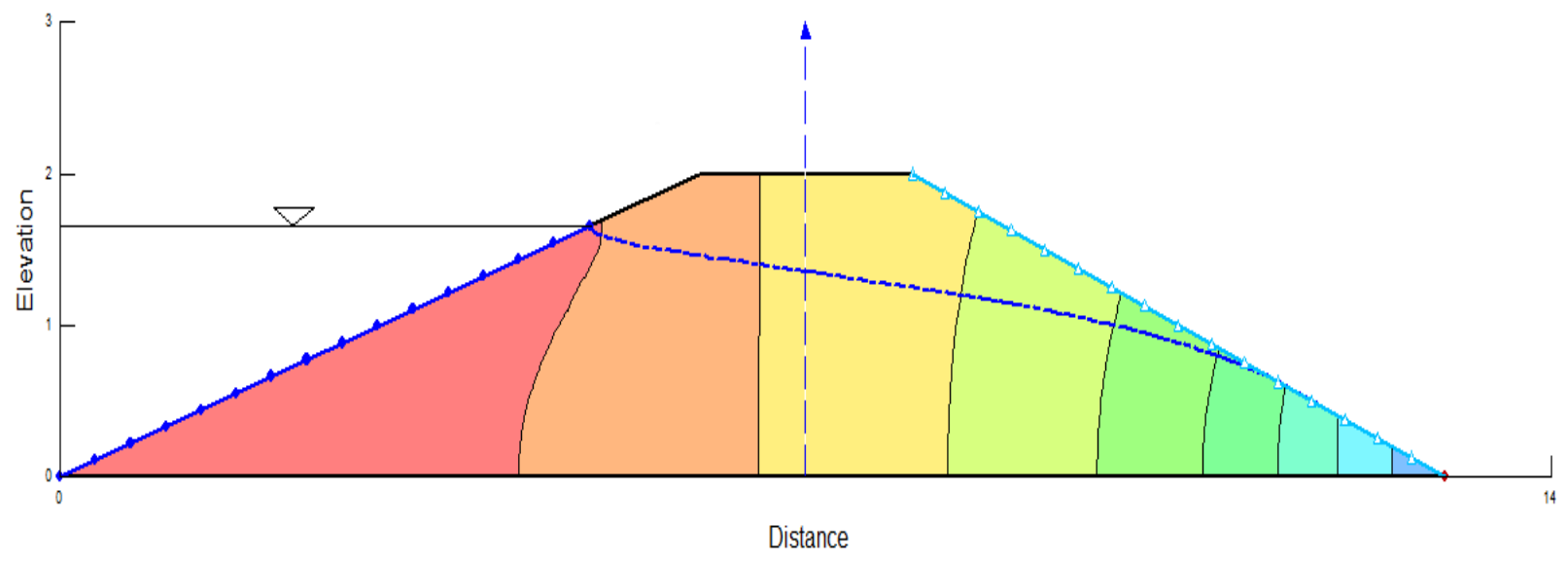

Figure 4-1: Typical GeoStudio Simulation showing Phreatic Surface

\subsection{Effects of Explosive Charge Mass}

The explosive in the dry embankment from Figures 3-9 and 3-10 showed that the crater diameter increased with increase in explosive size. These results were expected because the energy released from the explosive increases for the $25-\mathrm{kg}, 50-\mathrm{kg}$ and $100-\mathrm{kg}$ ANFO 
explosives. However, at $60-\mathrm{kg}$ for the parallel case and about $70-\mathrm{kg}$ for the perpendicular case the graphs have a constant crater diameter. This observation can be attributed to the fact that for the 100-kg charge, most of the blast pressures are reflected and goes into the air after detonation, hence the amount of pressure transmitted into the soil does not differ much from these charge masses, hence the crater diameter staying constant in both directions at $60-\mathrm{kg}$ for the parallel direction and $70-\mathrm{kg}$ for the perpendicular direction.

Figure 3-10 showed the verification of the crater depth. The graph also shows a trend that an increase in explosive size resulted in continual increase in the crater depth as opposed to the observation made for the diameter. The observation made is due to the initial amount of energy that is released when the explosive is detonated, this initial energy determines the amount of ejecta to be thrown out from the crater. At different charge masses, different energy is released, hence the crater depth increasing with increasing explosive mass.

The effect of explosive charge mass on the crater dimensions on an embankment with saturated embankment material was also investigated. With the embankment dam under steady state seepage, the observation made for the dry embankment in terms of crater dimensions was the same; an increase in explosive charge mass increased the crater dimensions. The observation that was made with LS-DYNA for the pore water pressure analysis was the bulging out of the elements downstream. This phenomenon that could not be explained is shown on the right (downstream) of Figure 4-2. 


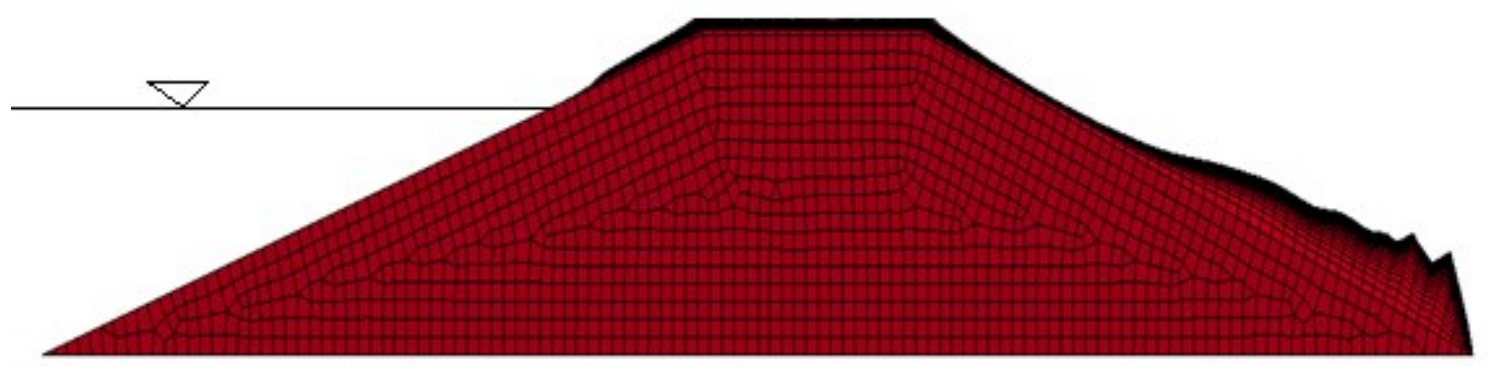

Figure 4-2: Bulging at Downstream of Embankment

\subsection{Effects of Slope Angle on Embankment Dam}

Dams have varying slopes for both the upstream and downstream. A series of analyses was conducted to examine the effects of altering the slopes on crater dimensions. In the first scenario, the slope angles for both the upstream and downstream faces were kept as $3 \mathrm{H}: 1 \mathrm{~V}$, while in the second scenario the dam had a downstream slope of $2 \mathrm{H}: 1 \mathrm{~V}$. Figure 4-3 shows the variation of the crater depth with slope angle.

For the crater depth, when the slope of $3 \mathrm{H}: 1 \mathrm{~V}$ was considered there was a decrease of up to about $7 \%$ from the original slopes of $3 \mathrm{H}: 1 \mathrm{~V}$ on the upstream and $2.5 \mathrm{H}: 1 \mathrm{~V}$ on the downstream side. This observation can be attributed to the soil confinement provided by the gentle slope of $3 \mathrm{H}: 1 \mathrm{~V}$ on the downstream slope hence the amount of ejecta thrown out as compared to the $2.5 \mathrm{H}: 1 \mathrm{~V}$ is reduced. Considering a downstream slope of $2 \mathrm{H}: 1 \mathrm{~V}$, there was an increase in crater depth of about $31 \%$ from the original downstream slope of $2.5 \mathrm{H}: 1 \mathrm{~V}$. The significant change in crater depth is due to the steeper slope of $2 \mathrm{H}: 1 \mathrm{~V}$ at the downstream slope, hence there is less confinement provided by the downstream slope and hence more ejecta is thrown from the crater downstream. 
Figures 4-4 and 4-5 show the variation of the crater diameter with slope angle for the parallel and perpendicular directions respectively. The variation of crater diameter with downstream slope angle showed a reduction of $3.1 \%$ and $3.8 \%$ in the perpendicular and parallel directions diameter respectively when the downstream slope angle changed from $3 \mathrm{H}: 2.5 \mathrm{~V}$ to $3 \mathrm{H}: 1 \mathrm{~V}$. This reduction is due to the presence of a gentle slope which provides more confinement and hence a decrease in crater diameter. For the downstream slope angle of $2 \mathrm{H}: 1 \mathrm{~V}$ there was an increase in crater diameter of $0.42 \%$ and $2.04 \%$ in the parallel and perpendicular directions. This observation from the initial slope angle of $2.5 \mathrm{H}: 1 \mathrm{~V}$ is also due to the presence of less confinement provided by $2 \mathrm{H}: 1 \mathrm{~V}$ slope angle.

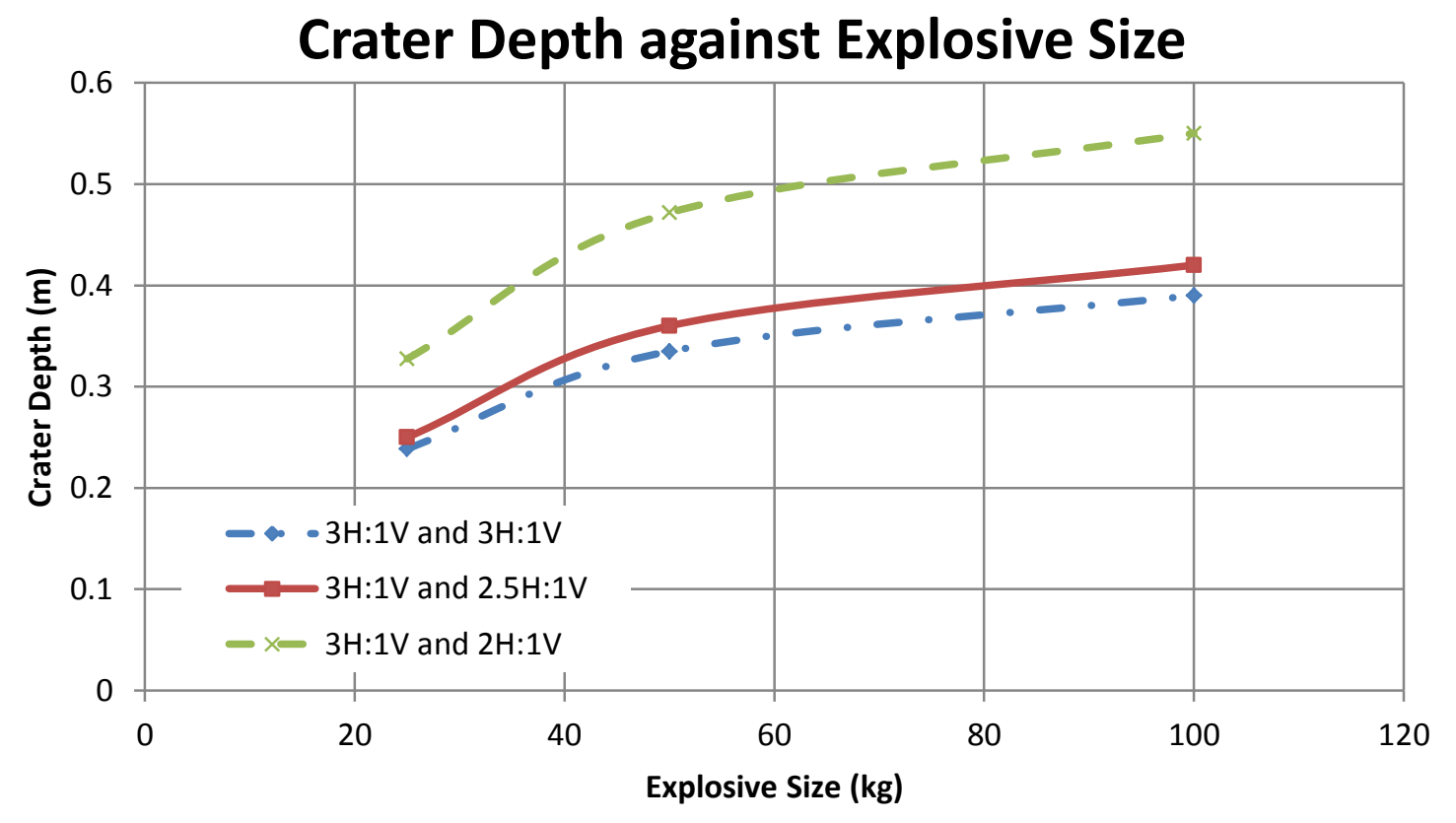

Figure 4-3 Effect of slope angle on crater depth 


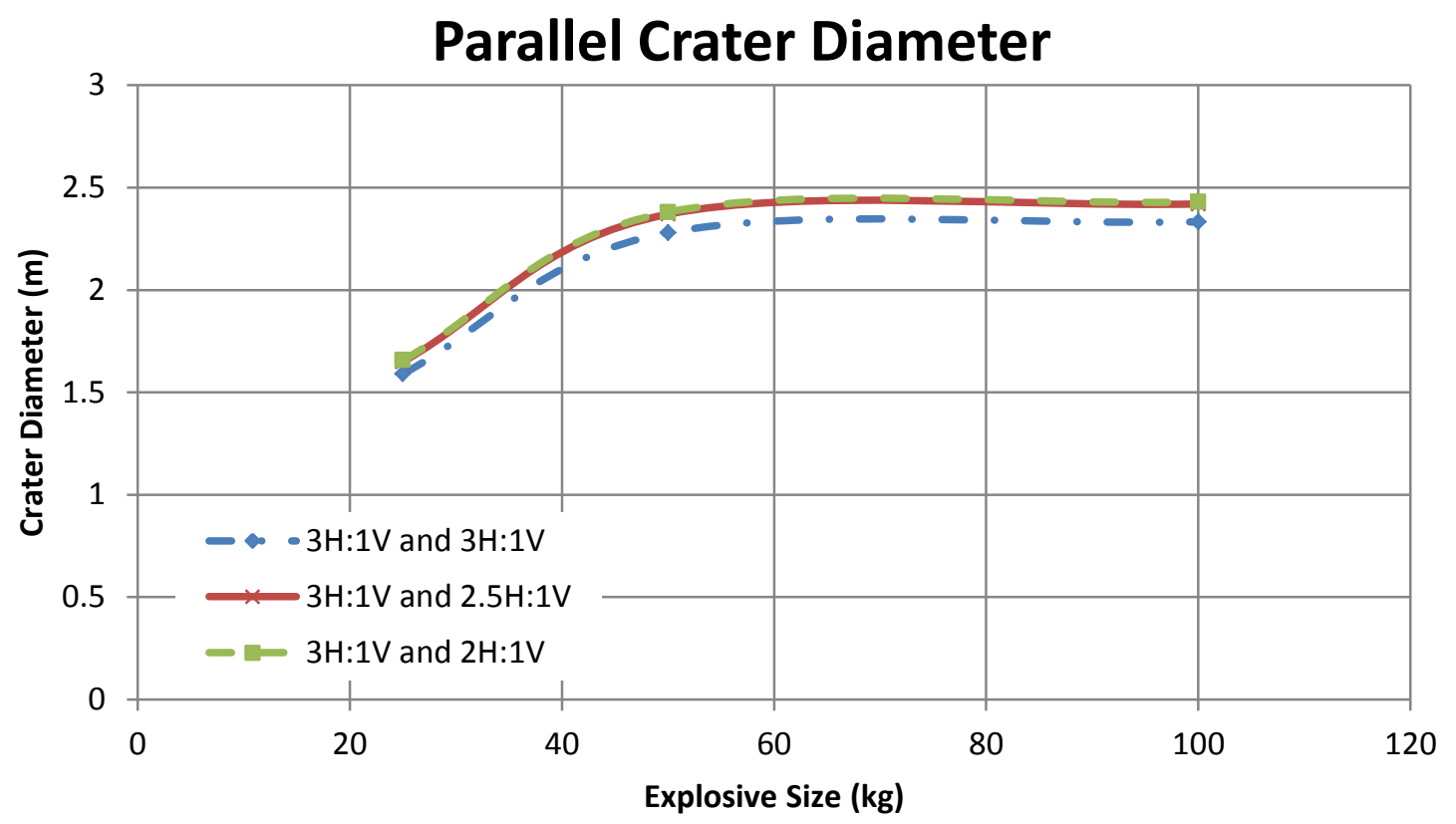

Figure 4-4 Comparison of Crater Diameter with Downstream Slope Angles

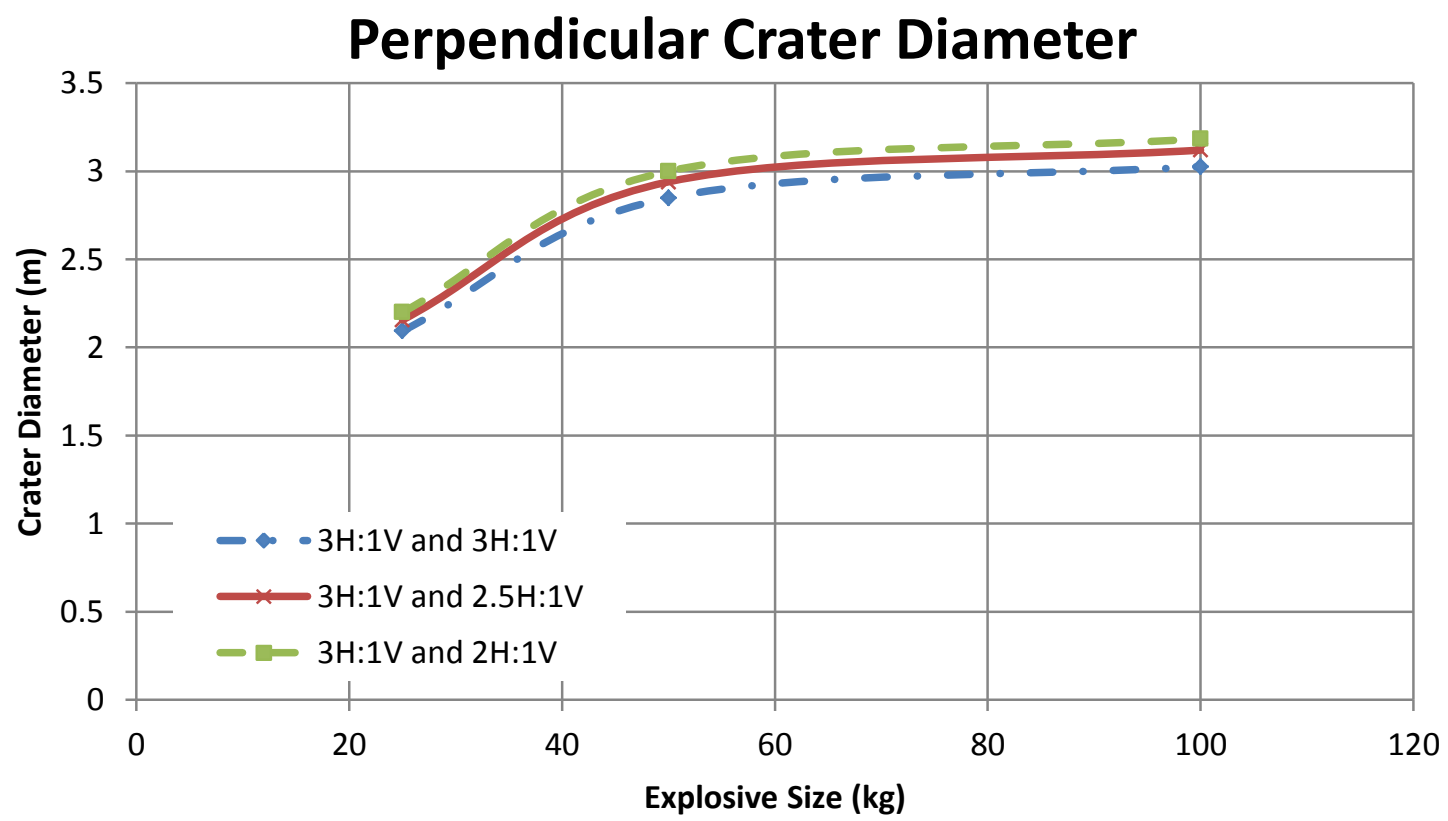

Figure 4-5 Comparison of Crater Diameter with Downstream Slope Angles 


\subsection{Effects of Reservoir Level on Crater Dimensions}

To simulate the effects of the reservoir on the embankment dam, two different scenarios were considered. In one scenario the dam was at a full reservoir level and in the second scenario the water level was at mid height of the embankment. The crater dimensions for these two scenarios were compared with the dry embankment crater dimensions from the validation of the numerical model.

\subsubsection{Reservoir at Maximum Level}

The maximum reservoir level was considered at $1.65 \mathrm{~m}$ above ground level, with a freeboard of $0.35 \mathrm{~m}$. A TNT charge was then detonated at the centre of the crest of the dam. Table 4-1 shows the comparison of the crater sizes for the dry embankment and embankment having pore water incorporated in the model. The simulation of the pore water within the embankment dam leads to the formation of larger crater dimensions as

compared to that of the dry embankment. For example, for a $100 \mathrm{~kg}$ ANFO (82 kg of TNT), the diameters measured in the direction perpendicular to the axis of the dam were $0.55 \mathrm{~m}$ and $2.47 \mathrm{~m}$ for the dry embankment and embankment with the reservoir level at $1.65 \mathrm{~m}$ respectively. In the direction parallel to the axis of the dam, the dry embankment recorded a crater diameter of $0.44 \mathrm{~m}$ whilst the embankment with the reservoir level at $1.65 \mathrm{~m}$ had a diameter of $2.29 \mathrm{~m}$. This represents a significant difference in crater diameters for these two aforementioned embankment dam conditions.

The depth of the crater for the dry and embankment with reservoir level at a height of $1.65 \mathrm{~m}$ were also compared in the simulation. The comparison of the depths for these two 
scenarios showed a depth variation of about $36 \%$ with the dry embankment having the lower depth. Figure 4-6 shows the variation of the crater depth with charge mass.

Table 4-1 Comparison of Crater Diameters for Dry and Reservoir backed Dam

\begin{tabular}{|c|c|c|c|c|c|c|}
\hline $\begin{array}{c}\text { Charge } \\
\text { Mass } \\
(\mathbf{k g})\end{array}$ & \multicolumn{2}{|c|}{ Dry Embankment } & \multicolumn{2}{|c|}{$\begin{array}{c}\text { Embankment Reservoir } \\
\text { Level at 1.65 m }\end{array}$} & $\begin{array}{c}\text { Embankment Reservoir } \\
\text { Level at 1 m }\end{array}$ \\
\cline { 2 - 7 } & $\begin{array}{c}\text { Parallel } \\
\text { Diameter } \\
(\mathrm{mm})\end{array}$ & $\begin{array}{c}\text { Perpendicular } \\
\text { Diameter } \\
(\mathrm{mm})\end{array}$ & $\begin{array}{c}\text { Parallel } \\
\text { Diameter } \\
(\mathrm{mm})\end{array}$ & $\begin{array}{c}\text { Perpendicular } \\
\text { Diameter } \\
(\mathrm{mm})\end{array}$ & $\begin{array}{c}\text { Parallel } \\
\text { Diameter } \\
(\mathrm{mm})\end{array}$ & $\begin{array}{c}\text { Perpendicular } \\
\text { Diameter } \\
(\mathrm{mm})\end{array}$ \\
\hline 25 & 120 & 238 & 652 & 1068 & 516 & 928 \\
\hline 50 & 340 & 450 & 1867 & 2002 & 1456 & 1711 \\
\hline 100 & 440 & 550 & 2390 & 2470 & 1816 & 2099 \\
\hline
\end{tabular}

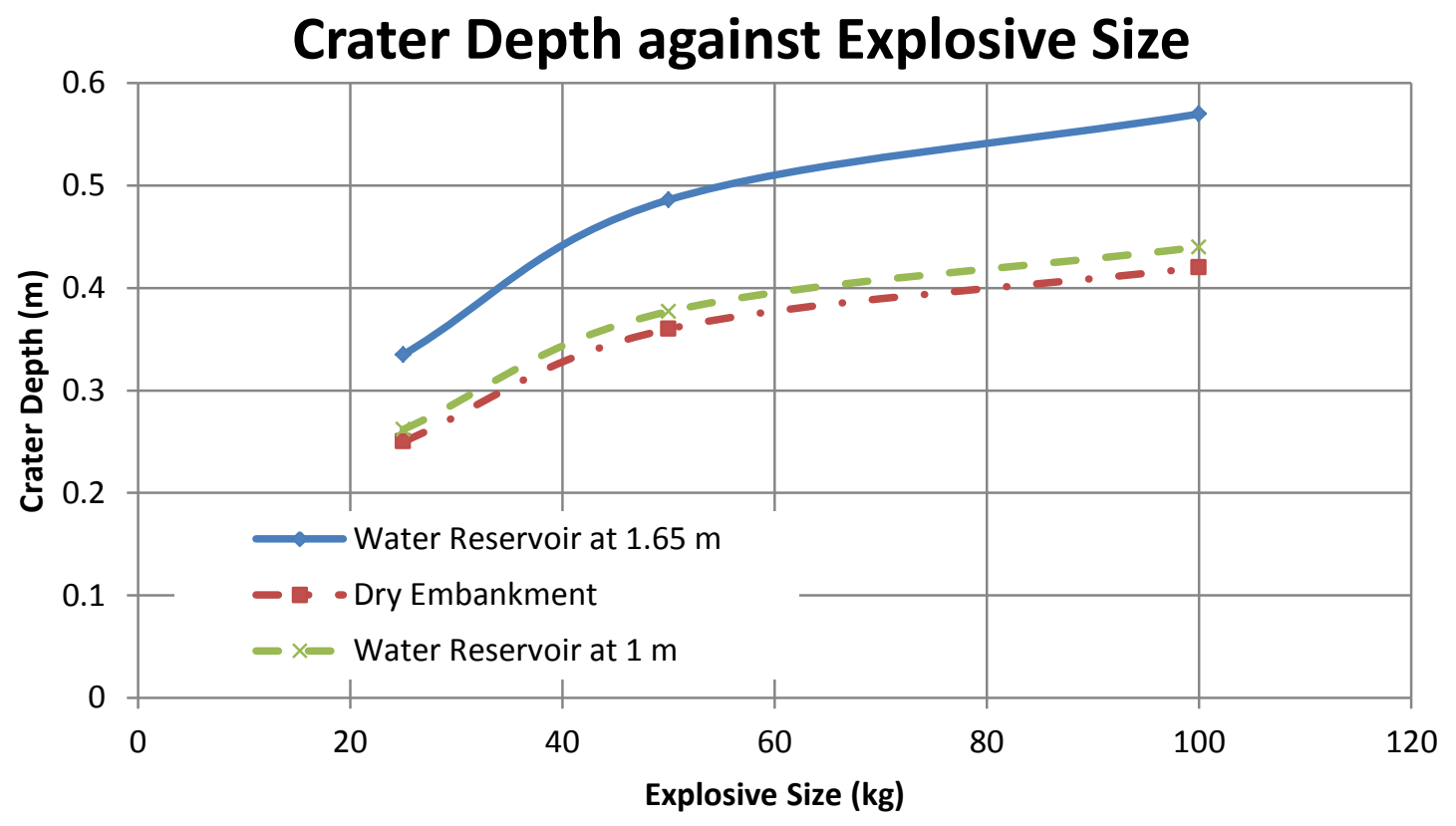

Figure 4-6: Comparison of True Crater Depth for Dry Embankment and Freeboards at $1.65 \mathrm{~m}$ and $1 \mathrm{~m}$ 
The increase in crater dimensions when the water reservoir is at $1.65 \mathrm{~m}$ can be attributed to the pore water pressure within the embankment. Positive pore water pressure tends to decrease soil strength and hence reduce the ability of the soil particles to withstand the high pressures from the shockwave, and hence more ejecta thrown out, leading to the deeper crater depth and larger diameters. In addition, the presence of the water reduces the air void within the soil as compared to that of the dry embankment, hence, the shockwave takes a longer time to attenuate within the embankment leading the soil particles experiencing a longer duration of loading of the blast load as compared to soil particles in the dry embankment (TM 5-855-1, 1986)

\subsubsection{Reservoir Level at $1 \mathrm{~m}$ above Ground Level}

The reservoir level was reduced to $1.0 \mathrm{~m}$ freeboard to consider the effect of reducing the water level on the crater dimensions. In reducing the water height, the observation made was similar to that of the freeboard at $0.35 \mathrm{~m}$. Table $4-1$ shows that the craters formed for the $1 \mathrm{~m}$ reservoir level which are smaller than those for the reservoir level with a $0.35 \mathrm{~m}$ freeboard but larger than that of the dry embankment. The crater diameter measured in the critical direction (axis 3-3) had about 15\% decrease in diameter from the case with the $0.35 \mathrm{~m}$ freeboard. Considering the crater diameter in the $1-1$ axis, up to a $24 \%$ reduction in crater size was predicted when compared to when the reservoir level is at $1.65 \mathrm{~m}$.

Similar to the previous analysis, the three different charge masses and their effects on crater depth was investigated. Figure 4-4 shows that crater depth variation considering the reservoir level at $1.65 \mathrm{~m}, 1 \mathrm{~m}$ and the dry embankment. 
The depth variation for the water level at $1.65 \mathrm{~m}$ and $1 \mathrm{~m}$ decreased up to $19 \%$ whereas that of the $1 \mathrm{~m}$ water level and dry embankment was up to $5 \%$ from the dry embankment. This observation for the reservoir level at $1 \mathrm{~m}$ can be attributed to a deeper phreatic surface implying a larger zone of unsaturation as compared to a reservoir level at $1.65 \mathrm{~m}$. There is no effect of positive pore water pressure on most part of the embankment below the explosive due to the deep phreatic surface. Hence this is the reason the depth variation is closely related to that of the dry embankment.

\subsection{Effect of Density on Crater Dimensions}

Fill materials required for construction of embankment dams maybe compacted to various densities. The density to which fill material is compacted is important as this determines the amount of water that can seep through the embankment dam. It also increases the overall weight of the dam and hence the stability. The effect of soil density on crater dimensions was also investigated in the numerical study. Ambrosini et al. (2004) investigated the effects density by increasing the initial density of $500 \mathrm{~kg} / \mathrm{m}^{3}$ and concluded that there is no significant effect on the crater diameter with or without the presence of a reservoir. Figures 4-7 and 4-8 show the variation of the crater diameter with explosive for density at 1440 and $1920 \mathrm{~kg} / \mathrm{m}^{3}$.

Results show that the density of the soil material has an effect on the depth of the crater. This simulation was conducted on a dry embankment and the embankment having a reservoir level of $1.65 \mathrm{~m}$. The dry embankment showed a crater depth increase of $8 \%$ with the increase in the density to $1920 \mathrm{~kg} / \mathrm{m}^{3}$. The same investigation was conducted on 
the embankment with the reservoir level at $1.65 \mathrm{~m}$. The density increase showed a reduction in the crater depth up to about 7\%. Figure 4-9 shows the crater depth variation for the aforementioned scenarios.

For the dry embankment, the observation of the increase in crater depth is due to the fact that granular soils with high density tend to attenuate the shockwave very slowly hence the effect of the shockwave on the crater dimensions is more pronounced, inducing deeper crater (TM 5-855-1). For the embankment with the reservoir level at $1.65 \mathrm{~m}$ the observation made on the crater depth can be attributed to the degree of saturation. The presence of water within soil leads to high peak stresses and acceleration within the soil. Thus granular soil with low density experience higher peak stresses and easily loses the grain to grain contact of the soil particles as compared to soil having high density (TM 5855-1). Therefore the LS-DYNA numerical model is consistent with reduction in crater depth when part of the embankment is saturated below the phreatic surface

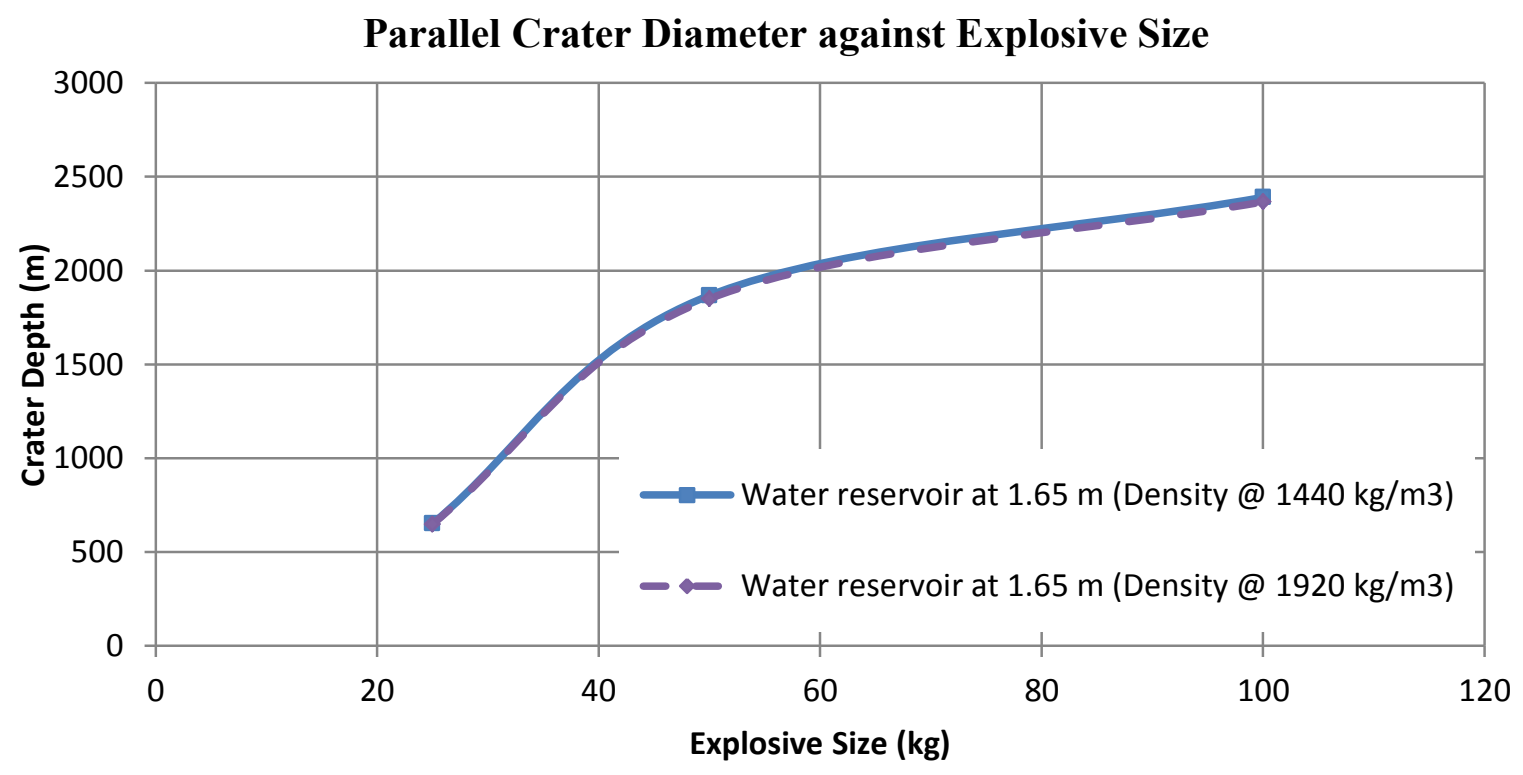

Figure 4-7 Effect of density on crater diameter parallel to dam axis 


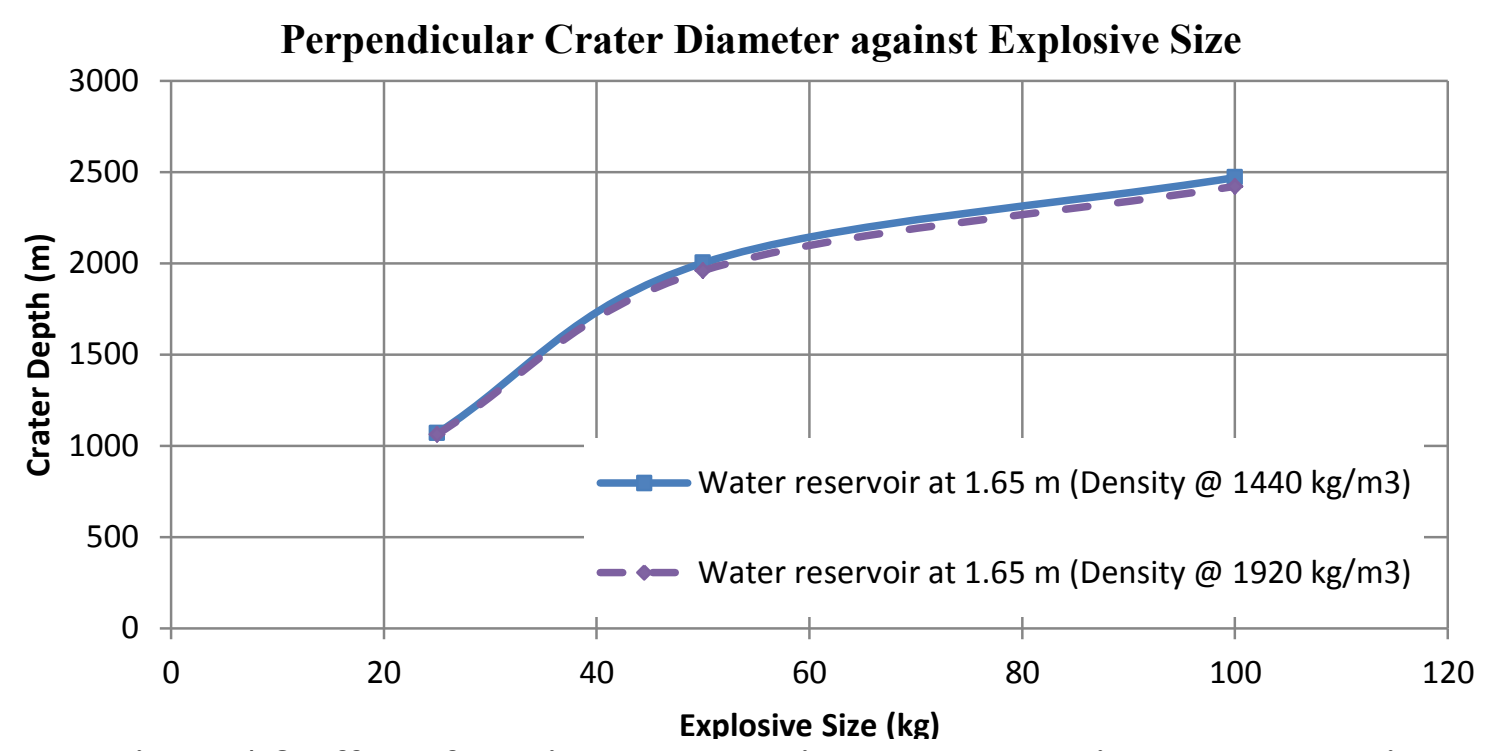

Figure 4-8 Effect of density on crater diameter perpendicular to dam axis

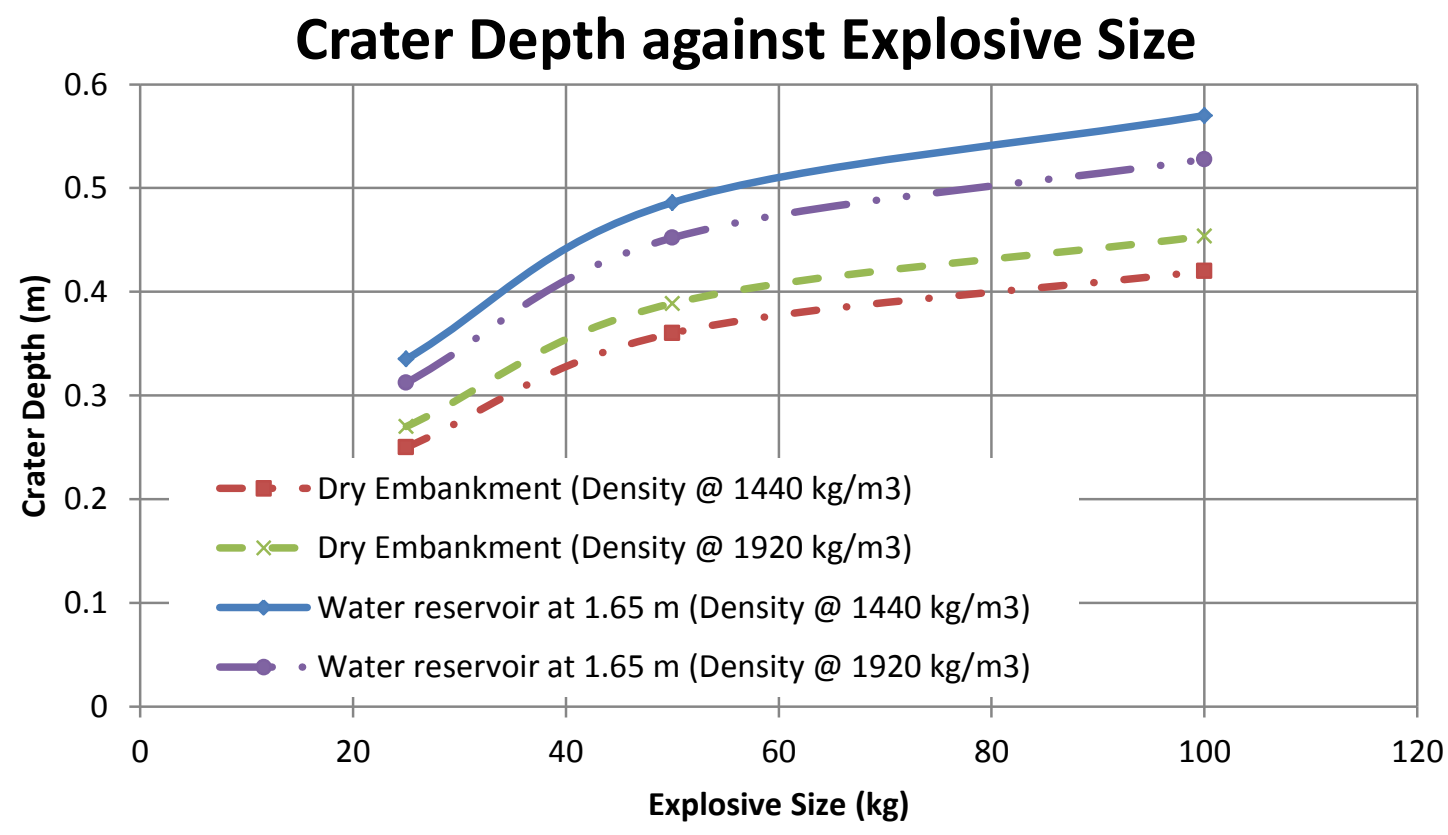

Figure 4-9: Effects of Density on Crater Depth for Dry Embankment and Embankment with Freeboard at $0.35 \mathrm{~m}$ 


\subsection{Effect of Suction on Crater Dimensions}

The pore water pressure analysis in LS-DYNA can consider the effects of suction on soil. The presence of suction contributes to the shear strength of the soil (Vanapalli, 2010; Zhang et al., 2010; Fredlund 1987). This was also investigated by setting the suction to a very large value within the embankment dam with the reservoir level at $1.65 \mathrm{~m}$ for the portion of the embankment above the phreatic surface. Table 4-2 compares the crater diameter of the embankment dam with and without suction. The crater diameter tends to reduce up to $35 \%$ from when there is no suction considered. Figure 4-10 illustrates the comparison of crater depth of the embankment dam with and without suction. This figure shows that the crater depth tends to decrease up to about $34 \%$ when suction is considered. This observation can be attributed to the negative pore water pressures due to suction, which tend to pull soil particles together and hence provide extra strength to the soil.

Table 4-2 Comparison of Effects of Suction on Crater Diameters for $1.65 \mathrm{~m}$ and $1 \mathrm{~m}$ Reservoir backed Dams

\begin{tabular}{|c|c|c|c|c|}
\hline \multirow{2}{*}{$\begin{array}{c}\text { Charge } \\
\text { Mass (kg) }\end{array}$} & \multicolumn{2}{|c|}{$\begin{array}{c}\text { Embankment with } 1.65 \mathrm{~m} \\
\text { Reservoir Level }\end{array}$} & \multicolumn{2}{c|}{$\begin{array}{c}\text { Embankment with } 1.65 \mathrm{~m} \\
\text { Reservoir Level with suction }\end{array}$} \\
\cline { 2 - 5 } & $\begin{array}{c}\text { Parallel } \\
\text { Diameter } \\
(\mathrm{mm})\end{array}$ & $\begin{array}{c}\text { Perpendicular } \\
\text { Diameter }(\mathrm{mm})\end{array}$ & $\begin{array}{c}\text { Parallel } \\
\text { Diameter } \\
(\mathrm{mm})\end{array}$ & $\begin{array}{c}\text { Perpendicular } \\
\text { Diameter } \\
(\mathrm{mm})\end{array}$ \\
\hline 25 & 652 & 1068 & 453 & 705 \\
\hline 50 & 1867 & 2002 & 1255 & 1301 \\
\hline 100 & 2390 & 2470 & 1270 & 1606 \\
\hline
\end{tabular}




\section{Crater Depth against Explosive Size}

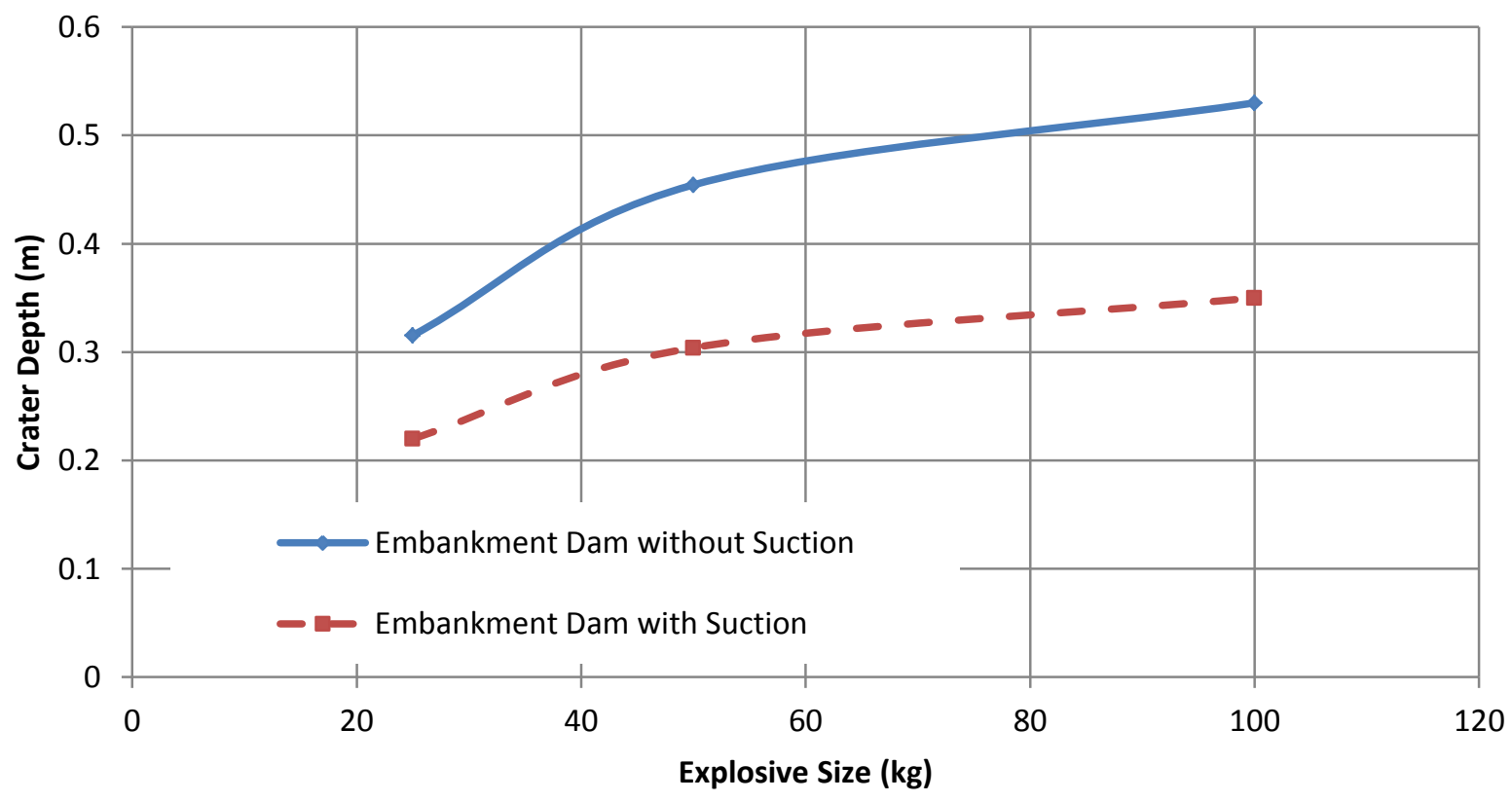

Figure 4-10 Effect of suction on crater depth

\subsection{Summary}

The numerical model that was developed in LS-DYNA can predict the performance of embankment dams under blast loads. The investigation on the charge mass showed that there was an increase in crater diameter and depth as the charge mass increased. The effects of slope angle on crater dimensions were investigated and it was realised that the steeper the slope the larger crater dimensions. The effects of the changes in reservoir level were investigated considering a $0.35 \mathrm{~m}$ freeboard, $1 \mathrm{~m}$ freeboard and when there is no freeboard (dry embankment). The crater dimensions predicted were highest when the reservoir level was maximum with a $0.35 \mathrm{~m}$ freeboard and lowest when the embankment is dry. Considering the effect of density of fill materials on the embankment, the 
investigation was conducted on the dry embankment as well as the embankment with a reservoir level at maximum with a 0.35 freeboard. The dry embankment showed an increment in crater dimensions whereas there was a significant decrease in crater dimensions for the embankment with the water reservoir when the soil density increased from 1440 to $1920 \mathrm{~kg} / \mathrm{m}^{3}$. Effects of negative pore water pressure (suction) above the phreatic surface was also investigated and the crater dimensions predicted showed a decrease in crater dimensions when compared to when suction is not incorporated into the model. 


\section{Chapter 5: Conclusion and Recommendation}

\subsection{Summary}

The effects of explosive on embankment dams were investigated. The unclassified literature shows that there is limited information on the effects of blast loads on embankment dams. Many researchers who have investigated the blast load effects on soil have mainly conducted the research on a flat ground. The few available researchers who investigated work on embankment dams either through field testing or numerical simulations failed to consider the effects of pore water within the embankment on crater dimensions. The investigation of crater dimensions that was investigated in this thesis considered the effects of pore water pressure within the embankment on crater dimensions. The numerical study used the high fidelity physics based finite element package, LS-DYNA. The validation of the numerical model was done using field testing conducted by Li et al. (2007). The LS-DYNA numerical model that was developed agreed well with the field testing results. Results from the numerical model was also compared with ConWep. Further parametric study was conducted on the LS-DYNA model.

\subsection{Conclusion}

The conclusions that were drawn from the numerical analysis presented in this work are as follows: 
- LS-DYNA as a numerical and analytical tool can adequately predict crater dimensions in soil.

- The level of reservoir of embankment dam affects the crater dimensions. The higher the reservoir level, the higher the pore water pressure distribution within the dam and hence the higher the crater dimensions.

- The density of fill materials has an effect on crater dimensions. When part of the dam is saturated, an increase in the density reduces the crater dimensions on the dam.

- The incorporation of suction in the numerical model led to a decrease in crater dimensions.

- Explosive detonated at a height of burst does not lead to significant crater dimensions.

- ConWep overestimates crater dimensions as compared to LS-DYNA.

- Based on current practices in Ontario, the minimum freeboard required for dams are not adequate to prevent overtopping for the $50 \mathrm{~kg}$ and $100 \mathrm{~kg}$.

\subsubsection{Application of Research Work}

The findings of this thesis are beneficial in practice for dam owners and stakeholders as well as the mining industry. Table 2-1 shows the current practice for minimum freeboard that is provided for the various fetch length of dams. Copariason of the research results with these freeboard requirements show that the current freeboards used in the dam design would not be enough to withstand an explosive attack. Hence based on this research there is a need for these minimum freeboard allowances to be increased for future dam constructions. For existing dams whose minimum freeboard requirements are 
not satisfactory, it is important that dam owners and stakeholders always adjust water levels to ensure that the freeboard that is available can withstand a dam attack using explosive devices.

The research outcome can also be used in mining industry. As it was discussed earlier, the crater diameter has not increased significantly as the mass charge increased from

$60 \mathrm{~kg}$ to $100 \mathrm{~kg}$. In mining, where explosives are used in excavation for their mining process, the use of these findings aids in selecting the most economical charge masses in order to achieve desirable crater sizes.

\subsubsection{Limitations of LS-DYNA}

The LS-DYNA model had limitations associated with it. These limitations included;

- The restriction of the element formulation of the Mohr Coulomb material model as only solid elements. This prevents the comparison of the performance of the material model with other techniques such as the $\mathrm{SPH}$.

- The introduction of pore water pressure into the embankment dam resulted in bulging of the elements.

\subsection{Recommendations}

Listed below are recommendations for future work:

- There is a need for field testing to be undertaken with the presence of a water reservoir to further verify the behaviour of the embankment dam under explosion. 
- This research concentrated its findings on the behaviour of homogenous embankment dam. Further investigations should be considered on the effect of zoned embankment dams on crater dimensions.

- In undertaking the parametric study, an infinite suction value was defined. Further studies should be considered in selecting suction values representative of the soil forming the embankment fill materials. 


\section{References}

Abaqus User Manual 6.12. 2012. Dassault Systems Simulia Corp.

http:/www.maths.cam.ac.uk/computing/software/abaqus_docs/docs/v6.12/pdf_books/CAE.pdf

Ambrosini R.D, Luccioni B. M., Danesi R.F., Reira J.D. and Rocha M.M. 2002. "Size of craters produced by explosive charges on or above the ground surface." Springer-Verlag, Shock Waves 12: 69-78.

Ambrosini D, Luccioni B, Danesi R. 2004. "Craters produced by explosions on the soil surface." Computer Mechanics $22: 678-92$.

An J., Tuan C. Y., Cheeseman B. A. and Gazonas G. A. 2011. "Simulation of Soil Behavior under Blast Loading." Int. J. Geomechanics, 11: 323-334.

Aquastat Programme. 2007. "Dams and Agriculture in Africa." FAO Aquastat Dams in Africa 070524. http://www.fao.org/nr/water/aquastat/damsafrica/aquastat_dams_africa 070524.pdf $14 / 25 / 04$

Association of State Dam Safety Officials. "Dam Failures and Incidents." http://www.damsafety.org/news/?p=412f29c8-3fd8-4529-b5c9-8d47364c1f3e 14/25/04

ANSYS AUTODYN User Manual 12.0. 2009. ANSYS Inc. http://orange.engr.ucdavis.edu/Documentation12.0/120/AUTODYN/cusrm120.pdf

Braimah A., Contestabile E., (2007). "Bombings of Dams - A Historical Review." Canadian Dam Association 2007 Annual Conference, Canada.

Braimah A., Rosen von B., Li Y., Rayhani M. 2012. "Explosive Cratering on Embankment Dams." Canadian Dam Association 2012 Annual Conference, Canada.

Braimah, A. and Rayhani, M. 2012. "How Explosives Affect Embankment Dams" http://www.hydroworld.com/articles/print/volume-20/issue-2/articles/dam-safety/howexplosives-affect.html 14/07/22

Bretz T.E. 1990. "Soil liquefaction resulting from blast-induced spherical stress waves." $\mathrm{PhD}$ Thesis, Colorado State University..

British Broadcasting Corporation (BBC). 2008. In Pictures: Islamabad aftermath. http://news.bbc.co.uk/2/hi/in pictures/7627729.stm, 13/11/12, 14:22. 
Canadian Dam Association (CDA), 2003. Dams in Canada, Canadian Dam Association, Edmonton, Alberta.

Charlie, W. A., Lewis, W. A., and Doehring, D.O. 2001. "Explosive Induced Pore Pressure in a Sandfill Dam." Geotechnical Testing Journal. 24:4 pp. 391-400.

Charles, J. A. 2004. "Internal erosion in European embankment dams." Progress Report, ICOLD $\begin{array}{llll}\text { European Club } \quad \text { [online]. } & \text { Available } & \text { from }\end{array}$ http://cnpgb.inag.pt/IcoldClub/documents/Internal_erosionProgressRep.pdf

Dahms S.H. 2004. "Damage Caused to Earth Embankment Dams by Earthquakes in United States." http://academic.emporia.edu/aberjame/student/dahms3/web1.htm 14/16/04

Darina Fiserova, 2006." Numerical Analysis of Buried Mine Explosions with Emphasis on Effect of Soil Properties on Loading." PhD Thesis, Cranfield University, United Kingdom.

De Alba P.A., Seed B., Retamal E. and Seed R.B. 1988. "Analyses of Dam Failures in 1985 Chilean Earthquake.” J. Geotech. Eng. 1988.114:1414-1434.

De A., Butler S., Zimmie T.F., (2013). "Effects of Surface Explosions on top of Earth Embankment Dams.” Geo-congress 2013; ASCE 2013.

Defence R\&D Canada. 2009. "Numerical Study of Soil Modelling Approaches using LS-DYNA: Part 2.” Defence R\&D Contract Report DRDC Valcartier CR 2009-164.

Dobry, R., Ladd, R.S., Yokel, F.Y., Chung, R.M. and Powell, D. 1982. "Prediction of Porewater Pressure Buildup and Liquefaction of Sands during Earthquakes by Cycle Strain Method." National Bureau of Standards Building Science Series 138, 150 pp.

Drake, J. L., and Ingram L. F. 1981. "Predictions of the Airblast and Ground Motions Resulting from Explosive Removal of Bird's Point -New Madrid Fuze Plug Lever.” Misc. Paper SL-81-30, U.S. Army Engineer WES, Vicksburg, MS, 1981

Dupont, Blasters Handbook, 16th edition. 1980 E. I. Dupont de Nemours and Company. Explosive Products Division, Wilmington, DE.

Fan Y., Chen Z., Liang X., Zhang X., Huang X. 2012. “Geotechnical Centrifuge Model Test for Explosion Cratering and Propagation Laws of Blast Waves in Sand". Applied phys \& Eng, 13(5):335-343.

FEMA. (2003). Risk Management Series: Reference Manual to Mitigate Potential Terrorist Attack Against Buildings. Federal Emergency Management Agency.

Fast Lagrangian Analysis of Continua (FLAC) Version 5. 2002. Itasca Consulting Group. http://www.civil.utah.edu/ bartlett/CVEEN6920/FLAC\%20manual.pdf 
Foundation, Concrete and Earthquake Engineering. Failure of Dam. http://civil-enggworld.blogspot.ca/2009/03/failure-of-dam.html 14/25/03

Fredlund, D. G. (1987). Slope stability analysis incorporating the effect of soil suction. John and Wiley and Sons Ltd.

http://www.soilvision.com/subdomains/unsaturatedsoil.com/Docs/Research\%20Papers/1987/Co nference $\% 20$ Papers/Slope $\% 20$ stability $\% 20$ analysis $\% 20$ incorporating $\% 20$ the $\% 20$ effect $\% 20$ of $\% 2$ 0soil $\% 20$ suction.pdf $14 / 03 / 23$

Fredlund, D.G. \& Rahardjo H. 1993. “Soil Mechanics for Unsaturated Soils.” New York: A Wiley-Interscience Publication. ISBN: 978-0-471-85008-3

Graham W.J. 2009. "Major U.S. Dam Failures: Their Cause, Resultant Losses, and Impact on Dam Safety Programs and Engineering Practice." World Environmental and Water Resources Congress : Great Rivers History Great Rivers History. ASCE.

Johnson W.F. 1889. History of the Johnstown flood first edition. Edgewood Publications ISBN 10-1125954558.

Hydroworld. 2012. "How Explosives Affect Embankment Dams." http://www.hydroworld.com/articles/print/volume-20/issue-2/articles/dam-safety/howexplosives-affect.html 14/25/06 18:00

Jayasinghe, L.B., Thambiratnam, D.P., Perera, N., Jayasooriya, J.H.A.R. 2013. "Computer Simulation of Underground Blast Response of Pile in Saturated Soil." Computers and Structures, 120, pp. 86-95. http://eprints.qut.edu.au/59919/

Kennard M.F. and Bromhead E.N. 2000. "Carsington Dam-The Near-Miss which became a Bulls-Eye.” Forensic Engineering. ASCE.

Kinney GF, Graham K.J. 1985. Explosive shocks in air. $2^{\text {nd }}$ Edition, Springer Verlag, Berlin.

Kirschner, O. 1949., "Destruction and Protection of Dams and Levees." Military Hydrology, Research and Development Branch, U.S. Corps of Engineers, Department of the Army, Washington District. From Schweizerische Bauzeitung, March 14, 1949. Translated by H.E. Schwarz, Washington, D.C.

Leong E.C., Anand S., Cheong H.K. and Lim C.H. 2007. "Re-examination of peak stress and scaled distance due to ground shock." International Journal of Impact Engineering, ScienceDirect ,34:1487-1499. 
Li, Y., Contestabile, E., Braimah, A. and Wilson, D., 2007. "Preliminary Vulnerability of an Embankment Dam due to Explosions." CERL Report 2007-01 (CF).

Long, J. H., E. R. Ries, and Michalopoulos A. P. 1981. "Potential for Liquefaction Due to Construction Blasting." Proceedings lnternational Conference on Recent Advances in Geotechnical Engineering and Soil Dynamics University of Missouri-Rolla, St. Louis, MO.

Luccioni, B.M. and Ambrosini D. 2008. "Evaluating the effect of underground explosions on structures." Mecánica Computacional, 27, 1999-2019.

Luccioni B., Ambrosini D., Nurick G, Snyman I. 2009. "Craters produced by underground explosions." Computers and Structures, ScienceDirect, 87:1366-1373.

LS-DYNA Forum. 2011. "Review of Solid Elements Formulation in LS-DYNA". http://www.dynamore.de/de/download/papers/forum11/entwicklerforum-2011/erhart.pdf

MacDonald C.T. and Langridge-Monopolis J. 1984. "Breaching Characteristics of Dam Failures.” J. Hydraul. Eng. 1984.110:567-586.

Muhunthan B. and Schofield A.N. 2000. "Liquefaction and dam Failures." Slope Stability. ASCE.

Nonveiller, E., Rupcic, J., and Sever, Z., 1999. "War damages and reconstruction of Peruca Dam." J. of Geotechnical and Geoenvironmental Eng., 125 (4): 280 -288.

Ontario Ministry of Natural Resources, 2011. Spillways and Flood Control Structures Technical Bulletin. $\quad$ http://www.creditvalleyca.ca/wp-content/uploads/2011/02/stdprod_069405.pdf $14 / 02 / 22$

Roman DH. 1986. "Study of physical and chemical aspects of blast densification." PhD thesis, Northwestern University.

Sausville, M. J. 2005. "Explosive cratering using a geotechnical centrifuge on dry, saturated, and partially saturated earth embankments and dams." MS thesis, Rensselaer Polytechnic Institute.

Shepherd R. 2003. “The St. Francis Dam Failure. Forensic Engineering.” ASCE, Virginia, USA.

St-Arnaud, G. 1995. "The high pore pressures within embankment dams; an unsaturated soil approach." Canadian Geotechnical. Journal 32: 892-898

TM 5-855-1. 1986. "Fundamentals of protective design for conventional weapons." Department of the army, Washington, DC, USA. 
United States Bureau of Reclamation (USBR), 1998. "Earth Manual." Earth Sciences and Research Laboratory, Denver, Colorado.

United States Society on Dams (USSD). 2011. "Materials for embankment dams." http://ussdams.org/materials.PDF

United States Homeland Security, 2011. "Estimating the Economic Consequences for Dam Failure Scenarios.

"http://www.damsafety.org/media/documents/owner\%20documents/Dam\%20Security/Dams\%2 0Sector\%20-\%20Consequence $\% 20$ Estimation $\% 20-\% 20$ Economic\%20Consequences.pdf

United States Homeland Security, 2012. A Worldwide Attacks against Dams. http://www.cowarn.org/uploads/news/Worldwide\%20Attacks\%20against\%20Dams\%20\%202012.pdf

United States Department of Interior. 1985. "Review of Present Practices Used in Predicting the Effects of Blasting on Pore Pressure." Bureau of Reclamation, Division of Research and Laboratory Services, Geotechnical Branch, GR-85-9.

Vajic, N., 1994. "Protection of Dams in Armed Conflicts: The Peruca Case." Journal of Chemists and Chemical Engineers, 43 (3), 108-114.

Vanpalli S.K. 2010. "Shear strength of unsaturated soils and its application in geotechnical engineering practice." Taylor and Francis Group, London.

Wang Z., Lu Y. and Bai C. 2011. "Numerical simulation of explosive-induced soil liquefaction and its effects on surface structures." Finite Elements in Analysis and Design 47: 1079-1090, Elsevier.

Wiss J.F. 1981. "Construction vibration: state of the art." J Constr Div, 100(GT2):167-82.

Zhang Z., Cui, W. and Guo, R. 2010. "Effect of Environmental Conditions on Stanility of an Unsaturated Soil Slope.” Experimental and Applied Modelling of Unsaturated Soil, ASCE. 


\section{Appendix A}

\section{SEEP/W Analysis}

Report generated using GeoStudio 2007, version 7.10. Copyright (C) 1991-2008 GEO-SLOPE International Ltd.

\section{File Information}

Revision Number: 5

Date: 09/08/2014

Time: 8:24:44 PM

File Name: seep.gsz

Directory: C: $\backslash$ Users $\backslash$ George $\backslash$ Desktop $\backslash$

Last Solved Date: 09/08/2014

Last Solved Time: 8:24:52 PM

\section{Project Settings}

Length(L) Units: meters

Time(t) Units: Seconds

Force(F) Units: kN

Pressure(p) Units: kPa

Mass(M) Units: g 
Mass Flux Units: g/sec

Unit Weight of Water: $9.807 \mathrm{kN} / \mathrm{m}^{3}$

View: 2D

\section{Analysis Settings}

SEEP/W Analysis

Kind: SEEP/W

Method: Steady-State

Settings

Include Air Flow: No

Control

Apply Runoff: Yes

Convergence

Maximum Number of Iterations: 50

Tolerance: 0.1

Maximum Change in $\mathrm{K}: 1$

Rate of Change in K: 1.1

Minimum Change in K: 0.0001

Equation Solver: Direct

Potential Seepage Max \# of Reviews: 10

\section{Time}

Starting Time: $0 \mathrm{sec}$

Duration: $0 \mathrm{sec}$

Ending Time: $0 \mathrm{sec}$

Materials 
sand

Model: Saturated Only

Hydraulic

K-Sat: $0.001 \mathrm{~m} / \mathrm{sec}$

Volumetric Water Content: $1 \mathrm{~m}^{3} / \mathrm{m}^{3}$

Mv: $0 / \mathrm{kPa}$

K-Ratio: 1

K-Direction: $0^{\circ}$

Boundary Conditions

Zero Pressure

Type: Pressure Head $=0$

Potential Seepage Face

Review: true

Type: Total Flux (Q) 0

\section{Reservoir Level}

Type: Head (H) 1.6491

\section{Flux Sections}

Flux Section 1

Coordinates

Coordinate: $(7,0) \mathrm{m}$

Coordinate: $(7,3) \mathrm{m}$

Regions

\begin{tabular}{|l|l|l|l|}
\hline & Material & Points & Area $\left(\mathrm{m}^{2}\right)$ \\
\hline Region 1 & sand & $1,8,7,3,4,2$ & 15 \\
\hline
\end{tabular}


Lines

\begin{tabular}{|l|l|l|l|}
\hline & Start Point & End Point & Hydraulic Boundary \\
\hline Line 1 & 1 & 2 & \\
\hline Line 2 & 3 & 4 & \\
\hline Line 3 & 4 & 2 & Potential Seepage Face \\
\hline Line 4 & 5 & 6 & \\
\hline Line 5 & 7 & 3 & \\
\hline Line 6 & 1 & 8 & reservoir level \\
\hline Line 7 & 8 & 7 & \\
\hline
\end{tabular}

\section{Points}

\begin{tabular}{|l|l|l|l|}
\hline & $\mathrm{X}(\mathrm{m})$ & $\mathrm{Y}(\mathrm{m})$ & Hydraulic Boundary \\
\hline Point 1 & 0 & 0 & \\
\hline Point 2 & 13 & 0 & Zero Pressure \\
\hline Point 3 & 6 & 2 & \\
\hline Point 4 & 8 & 2 & \\
\hline Point 5 & 0 & 1.6491 & \\
\hline Point 6 & 4.9487 & 1.6491 & \\
\hline Point 7 & 5 & 1.6666667 & \\
\hline Point 8 & 4.9733333 & 1.6577778 & \\
\hline
\end{tabular}




\section{Appendix B}

Units: mass (kg), distance (m), time (s)

PARTS OF MODEL

*Parts

\begin{tabular}{|c|c|c|c|c|c|c|c|}
\hline TITLE & & & & & & & \\
\hline Air & & & & & & & \\
\hline PID & SECID & MID & EOSID & HGID & GRAV & ADOPT & TMID \\
\hline 3 & 1 & 3 & 2 & 0 & 0 & 0 & 0 \\
\hline
\end{tabular}

\begin{tabular}{|c|c|c|c|c|c|c|c|}
\hline TITLE & & & & & & & \\
\hline Emban & t Dam & & & & & & \\
\hline PID & SECID & MID & EOSID & HGID & GRAV & ADOPT & TMID \\
\hline 1 & 2 & 2 & 0 & 0 & 0 & 0 & 0 \\
\hline
\end{tabular}

\begin{tabular}{|c|c|c|c|c|c|c|c|}
\hline TITLE & & & & & & & \\
\hline TNT E & & & & & & & \\
\hline PID & SECID & MID & EOSID & HGID & GRAV & ADOPT & TMID \\
\hline 2 & 1 & 1 & 1 & 0 & 0 & 0 & 0 \\
\hline
\end{tabular}

SECTIONS

*SECTION_SOLID

\begin{tabular}{|c|c|c|}
\hline \multicolumn{3}{|l|}{ TITLE } \\
\hline \multicolumn{3}{|c|}{ TNT Explosive, Air } \\
\hline SECID & ELFORM & AET \\
\hline 1 & 11 & 0 \\
\hline
\end{tabular}

\begin{tabular}{|c|c|c|}
\hline \multicolumn{3}{|c|}{ TITLE } \\
\hline \multicolumn{3}{|c|}{ TNT Explosive, Air } \\
\hline SECID & ELFORM & AET \\
\hline 2 & 1 & 0 \\
\hline
\end{tabular}


Material Constitutive Model

*MAT_HIGH_EXPLOSIVE_BURN

TITLE
\begin{tabular}{|c|c|c|c|c|c|c|c|}
\hline TNT Explosive \\
\hline MID & RO & D & PCJ & BETA & K & G & SIGY \\
\hline 1 & 1630 & 6930 & $2.1 \mathrm{e}+10$ & 0 & 0 & 0 & 0 \\
\hline
\end{tabular}

*MAT_NULL

\begin{tabular}{|c|c|c|c|c|c|c|}
\hline TITLE & & & & & & \\
\hline Air & & & & & & \\
\hline MID & $\mathrm{RO}$ & MU & TEROD & CEROD & YM & PR \\
\hline 3 & 1 & 3 & 2 & 0 & 0 & 0 \\
\hline
\end{tabular}

*MAT_MOHR_COULOMB

\begin{tabular}{|l|l|c|c|c|c|c|c|}
\hline \multicolumn{7}{|l|}{ TITLE } \\
\hline Soil \\
\hline MID & RO & GMOD & RNU & PHI & CVAL & 'PSI & \\
\hline 2 & 1440 & $2.18 \mathrm{e}+8$ & 0.35 & 0.5236 & 0 & 0 & \\
\hline- & NPLANES & - & LCCPDR & LCCPT & LCCJDR & LCJT & LCSFAC \\
\hline 0 & 1 & 0 & 0 & 0 & 0 & 0 & 0 \\
\hline GMODDP & GMODGR & LCGMEP & LCPHIEP & LCPSIEP & LCGMST & LCGMST & ANISO \\
\hline 0 & 0 & 0 & 0 & 0 & 0 & 0 & 1 \\
\hline DIP & DIPANG & CPLANE & FRPLANE & TPLANE & SHRMAX & LOCAL & \\
\hline 0 & 0 & 0 & 0 & 0 & $1 \mathrm{e}+20$ & 0 & \\
\hline
\end{tabular}

*MAT_PSEUDO_TENSOR

\begin{tabular}{|c|c|c|c|c|c|c|c|}
\hline TITLE & & & & & & & \\
\hline Soil & & & & & & & \\
\hline MID & RO & G & PR & & & & \\
\hline 2 & 1440 & $2.18 \mathrm{E}+08$ & 0.35 & & & & \\
\hline $\mathrm{X} 1$ & $\mathrm{X} 2$ & $\mathrm{X} 3$ & $\mathrm{X} 4$ & $\mathrm{X} 5$ & X6 & $\mathrm{X} 7$ & $\mathrm{X} 8$ \\
\hline 0 & 4444 & 5277 & 5872 & $1.25 \mathrm{e}+4$ & $1.333 \mathrm{e}+4$ & $1.639 \mathrm{e}+4$ & $1.689 \mathrm{e}+4$ \\
\hline $\mathrm{X9}$ & $\mathrm{X} 10$ & X11 & $\mathrm{X} 12$ & $\mathrm{X} 13$ & X14 & $\mathrm{X} 15$ & X16 \\
\hline $1.721 \mathrm{e}+4$ & $1.722 \mathrm{e}+4$ & $1.744 \mathrm{e}+4$ & $1.757 \mathrm{e}+4$ & $1.759 \mathrm{e}+4$ & $1.778 \mathrm{e}+4$ & $1.781 \mathrm{e}+4$ & $1.788 \mathrm{e}+4$ \\
\hline Y1 & $\mathrm{Y} 2$ & Y3 & $\mathrm{Y} 4$ & Y5 & Y6 & $\mathrm{Y7}$ & Y8 \\
\hline 0 & 5333 & 6333 & 7047 & $1.5 \mathrm{e}+4$ & $1.6 \mathrm{e}+4$ & $1.967 \mathrm{e}+4$ & $2.027 \mathrm{e}+4$ \\
\hline Y9 & Y10 & Y11 & Y12 & Y13 & Y14 & Y15 & Y16 \\
\hline $2.065 \mathrm{e}+4$ & $2.067 \mathrm{e}+4$ & $2.093 \mathrm{e}+4$ & $2.108 \mathrm{e}+4$ & $2.11 \mathrm{e}+4$ & $2.133 \mathrm{e}+4$ & $2.134 \mathrm{e}+4$ & $2.146 \mathrm{e}+4$ \\
\hline
\end{tabular}




\section{*EOS_TABULATED_COMPACTION FOR *MAT_PSEUDO_TENSOR}

\begin{tabular}{|c|c|c|c|c|c|c|c|c|c|}
\hline \multicolumn{10}{|l|}{ TITLE } \\
\hline \multicolumn{10}{|l|}{ Soil } \\
\hline EOSID & GAMA & E0 & V0 & & & & & & \\
\hline 2 & 0 & 0 & 1 & & & & & & \\
\hline EV1 & EV2 & EV3 & EV4 & EV5 & EV6 & EV7 & EV8 & EV9 & EV10 \\
\hline 0 & $-2.5 e-5$ & $-5.0 e-5$ & -0.0033 & -0.0029 & -0.0042 & -0.0043 & -0.0044 & -0.005 & -0054 \\
\hline $\mathrm{C} 1$ & $\mathrm{C} 2$ & C3 & $\mathrm{C} 4$ & $\mathrm{C} 5$ & C6 & $\mathrm{C} 7$ & $\mathrm{C} 8$ & C9 & $\mathrm{C} 10$ \\
\hline 0 & 4444 & $1.33 \mathrm{e}+4$ & $1.64 \mathrm{e}+4$ & $1.69 \mathrm{e}+4$ & $1.72 \mathrm{e}+4$ & $1.73 \mathrm{e}+4$ & $1.74 \mathrm{e}+4$ & $1.76 \mathrm{e}+4$ & $1.79 \mathrm{e}+4$ \\
\hline $\mathrm{K} 1$ & $\mathrm{~K} 2$ & K3 & K4 & K5 & K6 & K7 & $\mathrm{K} 8$ & K9 & K10 \\
\hline $5.0 \mathrm{e}+7$ & $5.0 \mathrm{e}+7$ & $5.0 \mathrm{e}+7$ & $5.0 \mathrm{e}+7$ & $5.0 \mathrm{e}+7$ & $5.0 \mathrm{e}+7$ & $5.0 \mathrm{e}+7$ & $5.0 \mathrm{e}+7$ & $5.0 \mathrm{e}+7$ & $5.0 \mathrm{e}+7$ \\
\hline
\end{tabular}

BOUNDARY CONDITIONS

*BOUNDARY_NON_REFLECTING

\begin{tabular}{|c|c|c|}
\hline SSID & AD & AS \\
\hline 1 & 0 & 0 \\
\hline
\end{tabular}

*Boundary_Pore_Fluid_Part

\begin{tabular}{|c|c|c|c|c|c|c|c|}
\hline PID & WTABLE & PF RHO & ATYPE & PF BULK & ACURVE & WTCUR & SUCLIM \\
\hline 1 & 1.65 & 1000 & 0 & $2.2 \mathrm{e}+9$ & 0 & 0 & 0 \\
\hline
\end{tabular}

*BOUNDARY_PWP_SET

\begin{tabular}{|c|c|c|c|c|c|}
\hline SID & LC & CMULT & LCDR & TBIRTH & TDEATH \\
\hline 2 & 0 & 1.65 & 0 & 0 & $1 \mathrm{e}+20$ \\
\hline IPHRE & ITOTEX & IDRFLAG & TABLE & & \\
\hline 0 & 4 & 0 & 0 & & \\
\hline
\end{tabular}


CONTROL KEYCARD

*CONTROL_ENERGY

\begin{tabular}{|c|c|c|c|}
\hline HGEN & RWEN & SLNTEN & RYLEN \\
\hline 2 & 2 & 2 & 1 \\
\hline
\end{tabular}

*CONTROL_PORE_FLUID

\begin{tabular}{|c|c|c|c|c|c|c|}
\hline ATYPE & WTABLE & PF RHO & GRAV & PF BULK & OUTPUT & TMF \\
\hline 1 & 1.65 & 1000 & 9.81 & $2.2 \mathrm{e}+9$ & 0 & 1 \\
\hline TARG & FMIN & FMAX & - & CONV & CONMAX & ETERM \\
\hline 0 & 0 & 0 & 1 & $1 \mathrm{e}-4$ & $1 \mathrm{e}+20$ & 0 \\
\hline
\end{tabular}

*CONTROL_TERMINATION

\begin{tabular}{|c|c|c|c|c|}
\hline ENDTIM & ENDCYC & DTMIN & ENDENG & ENDMAS \\
\hline 7 & 0 & 0.5 & 0 & 0 \\
\hline
\end{tabular}

\section{DATABASE KEYCARD}

*DATABASE_BINARY_D3PLOT

\begin{tabular}{|c|c|c|c|c|}
\hline DT & LCDT & BEAM & NPLTC & PSETID \\
\hline $7 \mathrm{e}-4$ & 0 & 0 & 0 & 0 \\
\hline IOOPT & & & & \\
\hline 0 & & & & \\
\hline
\end{tabular}

*DATABASE_PWP_OUTPUT

\begin{tabular}{|c|c|c|c|c|}
\hline IVEL & IACCX & IACCY & IACCZ & NCYOUT \\
\hline 1 & 2 & 2 & 2 & 10 \\
\hline
\end{tabular}




\section{DEFINE KEYWORD}

*DEFINE_CURVE

\begin{tabular}{|c|c|c|c|c|c|c|c|}
\hline \multicolumn{8}{|c|}{$\begin{array}{l}\text { TITLE } \\
\text { Water Pressure Upstream }\end{array}$} \\
\hline LCID & SIDR & SFA & SFO & OFFA & OFFO & DATTYP & - \\
\hline \multirow[t]{2}{*}{1} & 0 & 1 & 1 & 0 & 0 & 0 & 0 \\
\hline & A1 & O1 & & & & & \\
\hline 1 & 0 & 16177 & & & & & \\
\hline 2 & $3.45 \mathrm{e}-2$ & 15833 & & & & & \\
\hline 3 & $6.9 \mathrm{e}-002$ & 15489 & & & & & \\
\hline 4 & 0.1047 & 15144 & & & & & \\
\hline 5 & 0.1398 & 14800 & & & & & \\
\hline 6 & 0.1749 & 14456 & & & & & \\
\hline 7 & 0.21 & 14111 & & & & & \\
\hline 8 & 0.2451 & 13767 & & & & & \\
\hline 9 & 0.2802 & 13423 & & & & & \\
\hline 10 & 0.3153 & 13078 & & & & & \\
\hline 11 & 0.3504 & 12734 & & & & & \\
\hline 12 & 0.3855 & 12390 & & & & & \\
\hline 13 & 0.4206 & 12045 & & & & & \\
\hline 14 & 0.4557 & 11701 & & & & & \\
\hline
\end{tabular}

\section{LOAD KEYWORD}

*SEGMENT_SET

\begin{tabular}{|c|l|l|l|l|}
\hline ID & \multicolumn{4}{l|}{ Heading } \\
\hline 1 & \multicolumn{4}{l|}{} \\
\hline LSID & LCad for upstream hydrostatic pressure & DT \\
\hline 12 & 2 & SF & AT & 0 \\
\hline
\end{tabular}

\section{ALE KEYWORD}

*ALE_MULTI-MATERIAL_GROUP

\begin{tabular}{|c|c|c|}
\hline SID & IDTYPE & GPNAME \\
\hline 2 & 1 & - \\
\hline
\end{tabular}

